\title{
A Parameterized Design Optimization Framework for Worker-Friendly Workplaces in Modular Construction
}

\author{
Ahmed Zaalouk \\ A Thesis \\ In the Department \\ of \\ Building, Civil, and Environmental Engineering \\ Presented in Partial Fulfillment of the Requirements \\ For the Degree of \\ Master of Applied Science in (Building Engineering) at \\ Concordia University \\ Montreal, Quebec, Canada
}

April 2020

(C) Ahmed Zaalouk, 2020 


\section{Concordia University}

\section{School of Graduate Studies}

This is to certify that the thesis prepared

By: Ahmed Zaalouk

Entitled: A Parameterized Design Optimization Framework for Worker-Friendly Workplaces in Modular Construction

and submitted in partial fulfillment of the requirements for the degree of

Master of Applied Science (Building Engineering)

Signed by the final Examining Committee:

Chair

Dr. M. Nik-Bakht

Examiner

Dr. F. Mafakheri

Examiner

Dr. J. Lee

Supervisor

Dr. S. H. Han

Approved by

Dr. Michelle Nokken, Graduate Program Director

April 16, 2020

Dr. Amir Asif, Dean, Gina Cody School of Engineering and Computer Science 


\title{
Abstract \\ A Parameterized Design Optimization Framework for Worker-Friendly Workplaces in Modular Construction
}

\begin{abstract}
Ahmed Zaalouk
Workers in modular construction suffer frequent exposure to ergonomic risks that lead to work-related musculoskeletal disorders (WMSDs). Addressing ergonomic risk factors is thus critical to enhance the productivity of production lines and reduce social expenses for workers' recovery. Towards this goal, an ergonomic-driven workplace design approach is essential to not only prevent risks through design changes proactively but also accommodate medical restrictions for workers getting back on the job during the health recovery period. However, a lack of methods to identify root causes of ergonomic risks among various workplace design parameters (WDPs) and design optimal workplace settings for complex and multiple tasks leads to difficulties in adopting this twofold design approach. To address this limitation, this thesis proposes a parameterized workplace design optimization framework that involves four procedures: (i) performing design initiation to identify WDPs and accordingly create design alternatives using the definitive screening design (DSD) method; (ii) building interactive worker-workplace simulation models to acquire workers' body posture data and assess ergonomic risks among the different design alternatives; (iii) developing predictive surrogate models of the tasks using DSD statistical analysis; and (iv) optimizing workplace settings using the genetic algorithm to minimize ergonomic risk scores. The proposed framework is demonstrated through a case study to design a drywall preparation workplace in a real modular construction plant.
\end{abstract}


To my family; Marwa Eltony, Alia and Zeina 


\section{Acknowledgements}

First and foremost, I would like to express my deepest appreciation and gratitude to my supervisor Dr. SangHyeok Han for his continuous support, patient guidance, and encouragement. I am grateful for his substantial amount of effort and guidance over the past two years.

I would like to thank Dr. Lan Lin, Dr. Shahin Karimidorabati, and Dr. Bruno Lee from the BCEE department for their continuous support, encouragement, and inspiration.

Especially, my deepest gratitude is given to my mother, Ms. Shadya Zaalouk, for her unconditional love, prayers, sacrifices, and support at every stage of my life.

I would also like to thank my beloved wife, Marwa Eltony, for her patience and love. I could never achieve this goal without her endless encouragement, energy, and support.

Last but not least, I must also acknowledge my dear friends Dr. Ahmed Eweda, Mr. Lyamine Benkhadra, and Eng. Mohamed Labib, for being such a great source of support and motivation. 


\section{Table of Contents}

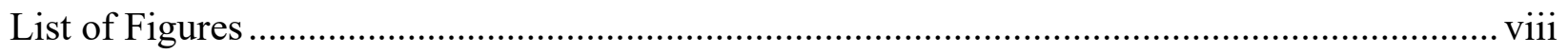

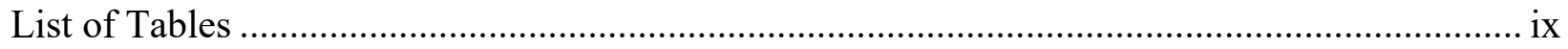

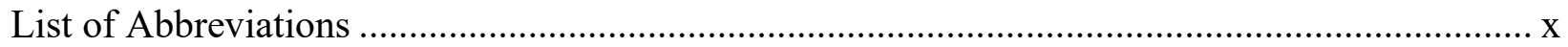

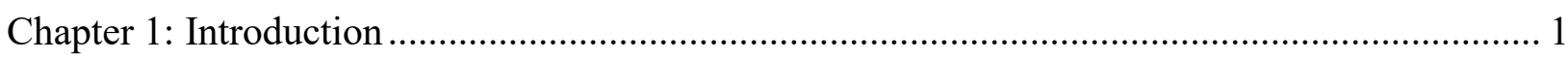

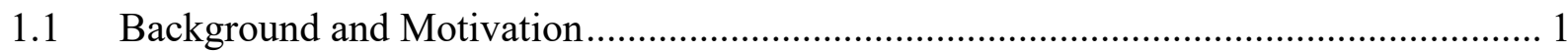

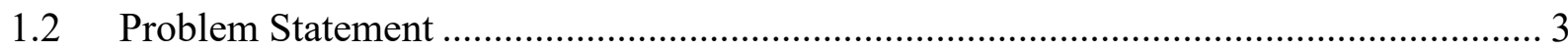

1.3 Objective and Scope

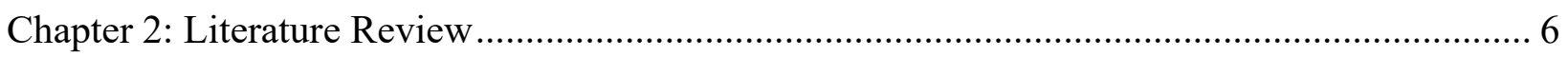

2.1 Worker-friendly workplace design in modular construction ........................................ 6

2.2 Three-dimensional (3D) visualization for ergonomic posture assessment ..................... 8

2.3 Six Sigma tools for parameterized workplace design ................................................ 10

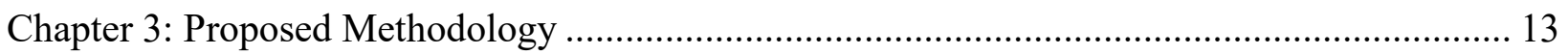

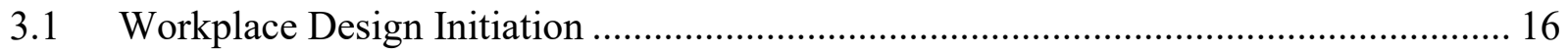

3.1.1 Working Pattern Analysis ............................................................................ 16

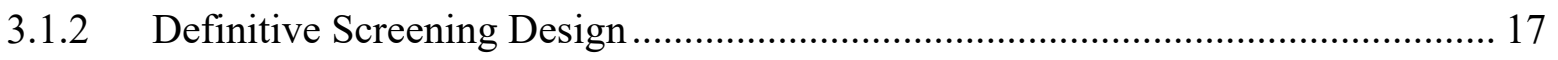

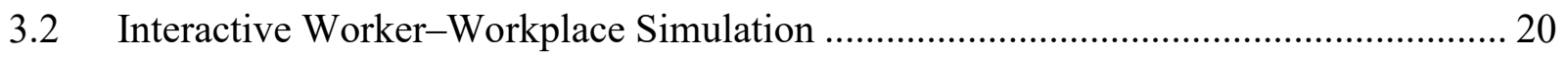

3.3 Development of predictive surrogate models ................................................................ 26

3.3.1 Statistical Regression Analysis ........................................................................... 26

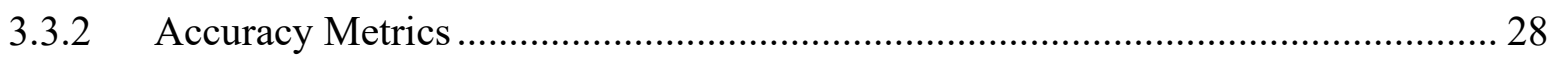

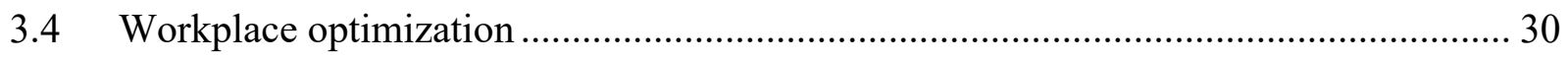

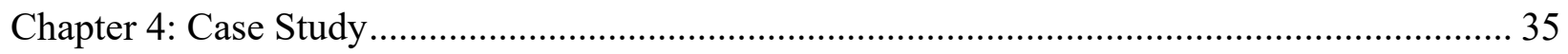

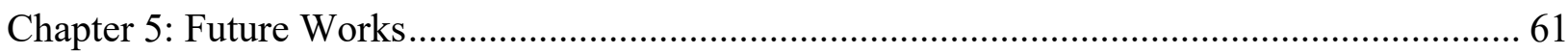




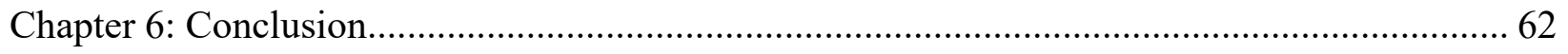

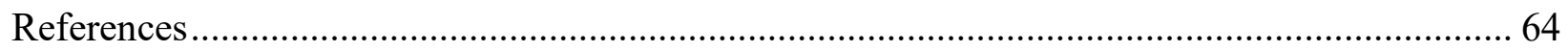

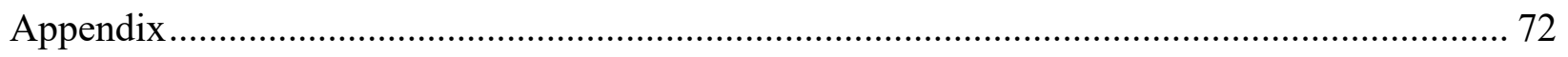

Appendix 1: Statistical analysis of CT - REBA surrogate models ........................................... 72

Appendix 2: Statistical analysis of CT - RULA surrogate models ............................................ 73

Appendix 3: Statistical analysis of ST - REBA surrogate models........................................... 74

Appendix 4: Statistical analysis of ST - RULA surrogate models .......................................... 75

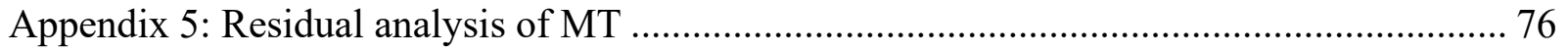

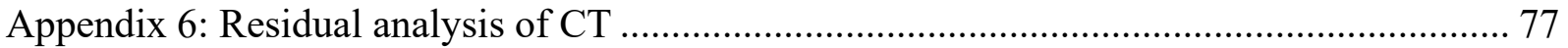

Appendix 7: Standardized effects of significant WDPs - CT .................................................... 78

Appendix 8: Standardized effects of significant WDPs - ST ............................................... 79 


\section{List of Figures}

Fig. 1. 2017 Lost Time Claims in Canada, by industry [5] ................................................ 2

Fig. 2. The proposed workplace design framework....................................................... 13

Fig. 3. An example of workplace design parameters ................................................... 17

Fig. 4. The general design structure of DSD for $(m)$ WDPs ................................................ 18

Fig. 5. Dynamic movements with the structure of full-body IK solver.................................... 21

Fig. 6. Process flow of the interactive worker-workplace simulation ..................................... 22

Fig. 7. A concept for the development of the animation keyframes ..................................... 25

Fig. 8. An example of calculating coded values of WDPs ............................................... 28

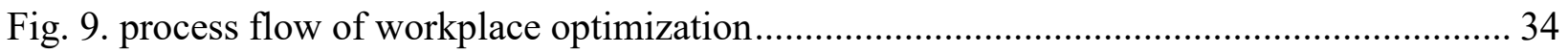

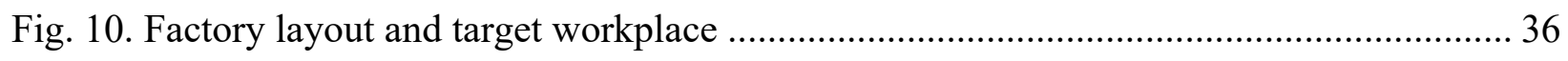

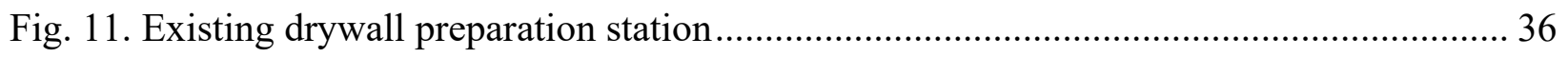

Fig. 12. An example of a CT data collection sheet .......................................................... 38

Fig. 13. The WDPs and their values for the three tasks.................................................... 39

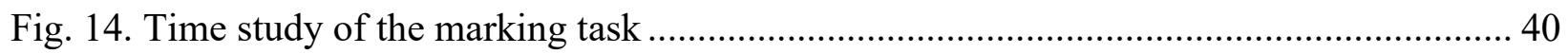

Fig. 15. Time study of the cutting task .......................................................................... 41

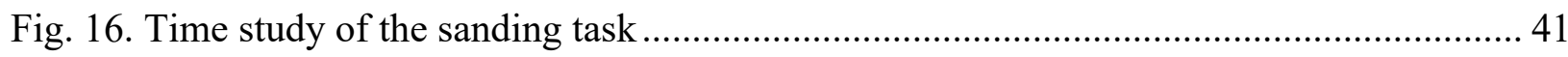

Fig. 17. Work methods and 3D Visualization of the marking task...................................... 42

Fig. 18. Work methods and 3D Visualization of the cutting task ....................................... 42

Fig. 19. Work methods and 3D Visualization of the sanding task ..................................... 43

Fig. 20. Interactive simulation model for alternative 6 - MT ............................................ 44

Fig. 21. Significant WDPs using REBA in MT .............................................................. 49

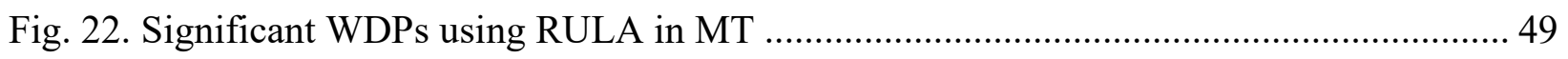


Fig. 23. An example of the of the residual analysis - ST.

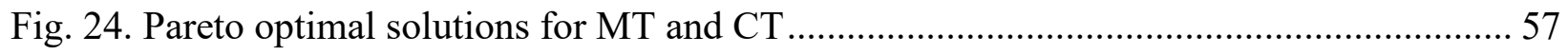

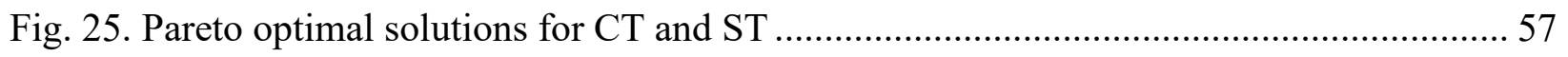

Fig. 26. Pareto optimal solutions for MT, CT, and ST ….............................................. 58

Fig. 27. Validation results of the solution 14 for MT, CT, and ST ......................................... 59

\section{List of Tables}

Table 1. Overall REBA/RULA scores of all alternatives for the marking task....................... 45

Table 2. Overall REBA/RULA scores of all alternatives for the cutting task ........................ 46

Table 3. Overall REBA/RULA scores of all alternatives for the sanding task....................... 47

Table 4. Statistical analysis of MT - REBA surrogate models ........................................... 50

Table 5. Statistical analysis of MT - RULA surrogate models .......................................... 51

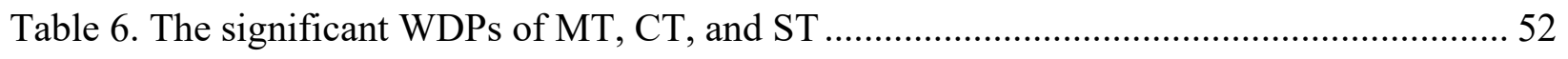

Table 7. The developed surrogate models of MT, CT, and ST ......................................... 52

Table 8. Verification results of the surrogate models for MT, CT, and ST ............................ 53

Table 9. Optimal solutions and tradeoff weights of three tasks for workplace settings ............. 56 


\section{List of Abbreviations}

\begin{tabular}{|c|c|}
\hline WMSDs & Work-related musculoskeletal disorders \\
\hline WDPs & Workplace design parameters \\
\hline DSD & Definitive screening design \\
\hline WCB & Workers' compensation boards \\
\hline MWP & Modified work program \\
\hline $3 \mathrm{D}$ & Three-dimensional \\
\hline REBA & Rapid entire body assessment \\
\hline RULA & Rapid upper limb assessment \\
\hline DOE & Design of experiments \\
\hline RSM & Response surface methodology \\
\hline SOPs & Standard operating procedures \\
\hline$N O D_{\text {alternatives }}$ & Number of design alternatives \\
\hline FK & Forward kinematics \\
\hline Full-body IK & Full-body inverse kinematics \\
\hline ANOVA & Analysis of variance \\
\hline RMSE & Root mean square error \\
\hline$R^{2}$ & R-squared \\
\hline$R_{a d j}^{2}$ & Adjusted R-squared \\
\hline $\mathrm{R}_{\text {pred }}^{2}$ & Predicted R-squared \\
\hline
\end{tabular}


GA

NSGA-II

NSGA-III

SBX

LGS

MT

CT

ST

WP
Genetic algorithm

Non-dominated sorting GA

Many-objective NSGA-II

Simulated binary crossover

Light gauge steels

Marking task

Cutting task

Sanding task

Workpiece 


\section{Chapter 1: Introduction}

\subsection{Background and Motivation}

Modular construction has increasingly gained attention as an efficient approach that provides cost and time reduction along with high quality and low environmental impact [1]. By moving activities from conventional (onsite) construction to an indoor environment, modular construction produces modules and/or panels (e.g., walls, floors, and roofs) in a factory-controlled environment, then transport them to sites for installation. However, despite advanced technologies and the potentials of modular construction strategies to improve safe practices during the factory operation, workers still perform labor-intensive and hazardous manual tasks with frequent exposure to ergonomic risks [2]. As a result, the repetitive nature of these tasks leads to increase the risk of work-related musculoskeletal disorders (WMSDs) that not only reduces the productivity of production lines but also increases social expenses for workers' recovery [[3], [4]].

As shown in Fig. 1, the Canadian manufacturing and construction industries had the second and fourth highest number of lost-time claims, which were 33,893 and 26,510 cases, respectively, due to numerous injuries in 2017 [5]. Moreover, statistics reveal that WMSDs account for approximately $47 \%$ of disabling injury claims in the construction industry in Canada [2]. In the United States, the rate of WMSDs in the construction was $16 \%$ higher than the rate for all industries, which made 20,510 cases in 2015, resulting in days away from work, inability to perform job tasks, and temporary or permanent disability [[6], [7]]. Thus, in order to gain full benefits from using the modular construction method (e.g., less time and lower cost), ergonomic precautions should be fully considered to ensure a safe and productive workplace that prevents ergonomic risks and decrease the rate of WMSDs injuries. 


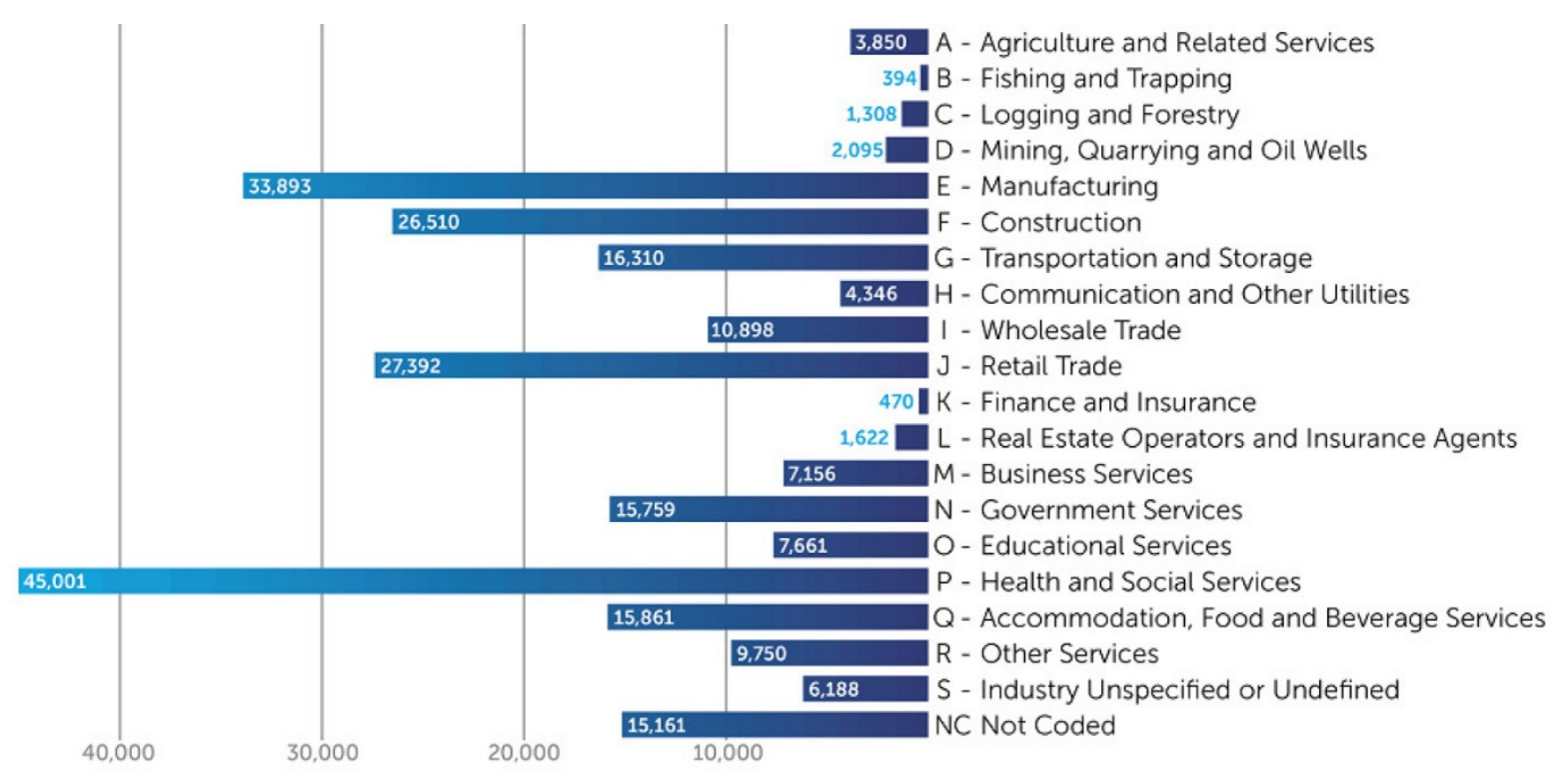

Fig. 1. 2017 Lost Time Claims in Canada, by industry [5]

The WMSDs are a group of painful disorders of muscles, tendons, and nerves in which workplace design and associated ergonomic risk factors (e.g., awkward postures, repetitive motions, and high force) significantly contribute to developing injuries over time [8]. However, it becomes more critical in modular construction where the primary focus of workplace design is on productivity improvement rather than addressing ergonomic risk issues to mitigate WMSDs [9]. As an effort to reduce enormous human and economic costs of WMSDs (e.g., the risk of disability, increased premium rates and prolonged absence of workers), employers are encouraged by workers' compensation boards (WCB) to prevent WMSDs and/or reduce their consequences by simultaneously adopting two strategies [10]:

i. Designing worker-friendly workplaces that boost injury prevention.

ii. Establishing a modified work program (MWP) to help injured workers return to work while recovering. 
The integration of these strategies can be highly advantageous for both employers and employees due to the following benefits [[10], [11]]:

i. Permitting employers to lower their premium rates determined by the number of accidents and injuries that occurred in the company.

ii. Enabling employers to reduce worker's time away from work, which can reduce overall (medical and re-employment services) claim costs.

iii. Providing a healthy option for workers' rehabilitation that yields promising results, physically and psychologically.

iv. Boosting workers' morale and loyalty while having a better recovery.

In this respect, ergonomic-driven workplace design/modification becomes highly effective in determining appropriate work conditions, which can be built by adjusting workplace design parameters (e.g., work methods and workplace dimensions) in order to prevent workers' exposure to ergonomic risks and accommodate any medical restrictions (e.g., restricted lifting, bending or standing) [[10]-[12]]. Accordingly, there is a need for a comprehensive ergonomic-driven workplace design framework to not only prevent risks through design changes proactively but also count for accommodating the situation after an accident occurs and assist injured workers getting back on the job safely at the earliest opportunity [10].

\subsection{Problem Statement}

Implementation of this twofold approach is not fully established yet in the construction industry, especially modular construction, due to the lack of effective workplace design methods that take into consideration the following workplace design requirements: 
i. A parameterized design process that allows manipulating several workplace design parameters (WDPs) in order to investigate the root causes of ergonomic risks.

ii. Multiform of WDPs (i.e., categorical, and/or continuous types) in order to count for dynamic interactions between different types of WDPs and ergonomic risks.

iii. Optimal workplace settings to minimize ergonomic risk levels for safety and productivity improvement.

\subsection{Objective and Scope}

The main objective of this research is to propose a workplace design method for safety enhancement in modular construction facilities in order to ultimately help companies to reduce their direct costs for ergonomic injuries.

The scope of this study is limited to the following aspects:

i. The evaluation of workplace designs is based on ergonomic posture assessment.

ii. Quantified ergonomic risk scores are based on REBA and RULA ergonomic posture assessment tools.

iii. The considered ergonomic risk factors in the workplace are awkward postures, repetitive motions, and handled force/load.

Accordingly, to accomplish the research objective, this study satisfies the workplace design requirements by proposing a parameterized workplace design framework that involves a comprehensive ergonomic-driven workplace design process integrating a skeletal simulation for workers' body motions and ergonomic posture assessment with six sigma analysis. This approach determines significant WDPs, which mostly contribute to increasing the overall ergonomic risks, 
in order to support in making better-informed design decisions for safe work methods and optimum workplace configurations (e.g., width, height, and length of a table). In this respect, the proposed framework consists of mainly four core components:

i. Workplace design initiation.

ii. Interactive worker-workplace simulation.

iii. Development of predictive surrogate models.

iv. Workplace optimization.

To implement the proposed framework and validate its effectiveness, a drywall preparation workplace, which requires performing three consecutive operational tasks in a real modular construction plant, is designed as a case study. 


\section{Chapter 2: Literature Review}

\subsection{Worker-friendly workplace design in modular construction}

In modular construction, ergonomic design principles (e.g., working within neutral reach zones at a proper height) are not fully considered while applying workplace changes and/or designs that are frequently required to correspond to Lean implementation (i.e., waste reduction process of production lines) for continuous productivity improvement [[3], [9]]. Due to this trend, workers may perform tasks with high physical demands at poorly-designed and/or unsuitable workplaces leading to awkward postures (e.g., bending and kneeling) repetitively in order to fit into given workplaces and carry out assigned tasks. These postures cause not only risk increases for WMSDs but also subsequent productivity losses due to inadequate performance of workers that is commonly associated with longer cycle times of tasks. In this respect, the reduction of poor postures using workplace design changes is essential to avoid ergonomic risks that conflict with the fundamental goal of Lean for boosting workplace productivity [3]. In order to support this direction, Wang et al. [13] have proposed two steps: (i) conducting an ergonomic risk assessment to detect risk factors in the workplace and their severity levels; and (ii) redesigning the workplace based on the results of step (i).

In this respect, numerous studies have been conducted to design worker-friendly workplaces that mitigate and/or eliminate awkward postures and other ergonomic risk factors (e.g., force exertion) for productivity improvement. For instance, Golabchi et al. [9] introduced an automated biomechanical simulation approach to evaluate ergonomics considerations early in the design stage of workplaces before workers experience any unsafe conditions. Furthermore, in order to effectively model manual tasks, an integrated ergonomics framework was proposed to count for 
durations of activities by combining posture-based ergonomic assessments with discrete event simulation. The main goal of this study was to concurrently incorporate safety and labor efficiency analysis in workplace design [[14], [15]]. Li et al. [16] considered the assessment of the physical demand for modular construction tasks and related ergonomic risk using three-dimensional (3D) skeletal modeling to provide a modified workplace or to analyze proposed workstations during the design phase. Afterward, the proposed framework was expanded to develop an automated posturebased ergonomic risk assessment system for rapid workplace design in modular construction. This system was successfully implemented in a real modular construction task to determine the suitable work surface tilt angle that reduces the overall ergonomic risk [3].

However, these methods do not satisfy the workplace design requirements described above fully due to the following limitations:

i. The lack of scientific methods to manipulate numerous WDPs concurrently in order to identify the main roots of ergonomic risks.

ii. The lack of a systematic approach to identify the most significant WDPs and their effects on ergonomic risks based on the investigation of the correlation between overall ergonomic risk scores and WDPs.

iii. Perception-based workplace design depending on the users instead of optimizing the workplace design considering the WDPs and the ergonomic risks.

iv. Overlooking the nature of construction works in which multiple tasks are performed at one single workplace, which may require different values of the same WDPs. 


\subsection{Three-dimensional (3D) visualization for ergonomic posture assessment}

Ergonomic posture assessment is mainly conducted during the workplace design and/or modification to assess the ergonomic risks based on workers' motions corresponding to operational tasks in the workplace. To implement this assessment, various models and tools, such as rapid entire body assessment (REBA) [17] and rapid upper limb assessment (RULA) [18], are widely used based on body joint angles, muscle use, and handled force/load. In REBA and RULA, body segments (e.g., trunk, legs) are divided into different posture categories, which represent a particular portion of the range of motion, based on the angles between body joints [16]. Therefore, acquiring precise body posture data is significant for reliable assessment and accurate evaluation of workplaces. In this respect, utilizing 3D visualization to simulate human body motions in the proposed workplace has received attention recently due to the following benefits [[3], [9], [14], [16]]:

i. Less time-consuming with a high level of accuracy in comparison to traditional manual observation methods.

ii. A practical method to assess multiple design alternatives without the need for physical experiments.

iii. A cost-effective option that eliminates the need for onsite devices (e.g., body motion sensors) to track workers' motions.

iv. Facilitating accurate perception and communication of the design.

To obtain these benefits, many researchers have adopted 3D visualization for ergonomic posture assessment and workplace design in modular construction. For instance, Han et al. [19] 
proposed a 3D-based physical demand assessment technique to assist the proactive detection of WMSDs. Golabchi et al. [9] introduced a motion-driven framework to ergonomic job analysis using animated 3D models of workers that imitate actual operational tasks. Based on these efforts, Li et al. [3] applied 3D visualization to enable ergonomic risk assessment of workers' continuous movements instead of conventional approaches that analyze the risks for only a few of the static postures selected by ergonomic analysts. These studies have adopted Autodesk 3ds Max [20] as a handy $3 \mathrm{D}$ visualization and simulation platform due to the following features:

i. Compatibility with various CAD systems widely used in the construction industry, which facilitates the acquisition of required design inputs data (e.g., workplace layouts).

ii. Effective modeling and visualization capabilities supported by a massive 3D objects archive in an existing library for work-related typical components (e.g., workstations, tools, and equipment).

iii. Creation of animated biped characters (i.e., human hierarchical bone structures) to simulate workers' body motions in the virtual work environment.

To take these benefits fully, the reliability of using $3 \mathrm{ds}$ Max for human body motion data acquisition has been validated by Li et al. [16]. However, previous studies to design the expected human motions in the proposed workplaces using 3D skeleton models have two challenges:

i. Manual and time-consuming tasks are required to adjust the biped skeletons in accordance with the proposed design alternatives.

ii. The manual adjustment of the biped skeletons may lead to variances in the body joint angles with low accuracy depending on the users when examining several design alternatives. 


\subsection{Six Sigma tools for parameterized workplace design}

Establishing a parameterized design that successfully achieves the workplace design requisites should be backed by a data-driven analysis to efficiently examine correlations between variables in the workplace design and ergonomic risk scores using REBA and RULA. Six Sigma is a robust data-driven industrial engineering technique that counts on a broad set of different tools (e.g., Pareto chart, 5 Whys, and Design of Experiments) to identify the root causes of inefficient work processes and eliminate them for better task performance. These tools could be applied during different phases of the workplace design to not only identify the causes leading to WMSDs but also improve the quality of workplaces [21]. One of the key tools in six sigma used widely in parameterized design studies is the design of experiments (DOE) which uses statistics to achieve the following objectives [[22]-[24]]:

i. Manipulating several input factors to identify their effects on outputs of a process.

ii. Developing surrogate models which are mathematical-based predictive models to represent the relation between inputs and outputs of a process.

iii. Enabling process optimization during the improvement phases of projects.

Due to these benefits, DOE is vastly utilized to design parameterized-based worker-friendly workplaces in the manufacturing industry. For instance, Rio Vilas et al. [25] presented a general framework for the manufacturing workstation design emphasizing the role of DOE as a methodical technique to achieve a parameterized optimization-based design using digital human modeling. Also, Cimino et al. [26] adopted DOE for proposing a practical ergonomic design of the workstations in a real industrial plant based on multiple design parameters. To apply this design methodology, Modeling \& Simulation in a three-dimensional virtual environment were used. 
Another framework for ergonomically friendly workstations design that used DOE was proposed by Ben-Gal and Bukchin [27] to decrease the number of design alternatives, then, determine optimal workplace settings using response surface methodology (RSM).

However, these DOE-based design methods may not be fitted for workplace design in the modular construction sector due to the following challenges:

i. Categorical WDPs (e.g., the quality level of products) are not considered, whereas modular production lines have complicated and dynamic operational tasks (e.g., alternately adopting different work methods to handle massive workpieces) that necessitate considering multiform of WDPs (i.e., categorical and/or continuous types) during the design process.

ii. The design options are evaluated in industrial-oriented commercial software (e.g., Tecnomatix-Siemens [28]), which is suitable for the level of simplicity of the analyzed motions in the manufacturing industry. Furthermore, these tools rarely allow users to simulate customized motions that are required to develop 3D visualization of dynamic task procedures in modular construction.

iii. A time-consuming process is required to implement two-levels DOE considering multiple tasks at one single workplace with a large number of WDPs in modular construction manufacturing. At this junction, it should be noted that the two-levels DOE involves a screening design to identify the significant WDPs among a large number of WDPs and response surface design that only use the significant WDPs in order to achieve workplace design optimization with less number of simulation runs [[29], [30]].

In order to overcome the limitations mentioned above, designing worker-friendly workplaces in modular construction requires a compatible method satisfying the following features: 
i. Customized, dynamic, and interactive 3D body motions in accordance with different design alternatives (e.g., heights, lengths, and widths).

ii. An efficient method to implement DOE technique (i.e., one-level approach with less number of simulation runs) corresponding to the features of modular construction.

iii. A multi-criteria design optimization strategy for not only single-task workplaces but also multiple-tasks workplaces in order to enable the tradeoff between design requirements of all operational tasks at the workplace. 


\section{Chapter 3: Proposed Methodology}

The proposed methodology for a parameterized workplace design optimization framework is illustrated in Fig. 2.

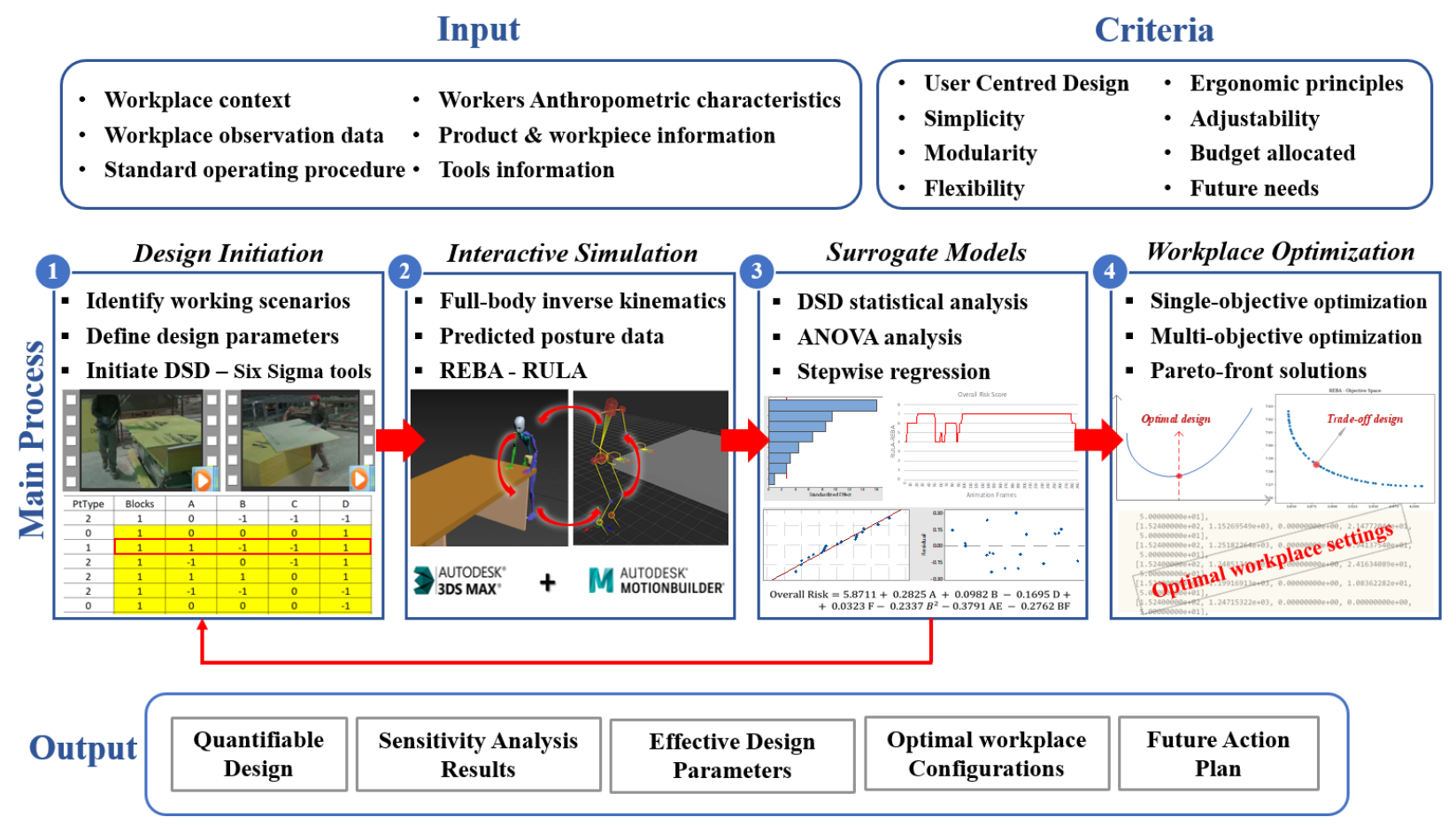

Fig. 2. The proposed workplace design framework

The required input data, which includes information about both operations and work environment, consists of:

i. Workplace observation data (e.g., video recordings for workers' motions).

ii. Workplace context details (e.g., blueprints for adjacent workplaces).

iii. Standard operating procedures (SOPs) that describe the sequences of repetitive manual tasks in workplaces.

iv. Workers anthropometric data (e.g., height and sex). 
v. Handled tools information (e.g., weight, and function).

vi. Workpiece technical specification (e.g., material dimensions and types).

In order to implement the proposed framework successfully, specific design criteria should be considered to ensure the practicality of the proposed workplace solutions:

i. Ergonomic design principles (e.g., working within neutral reach zones at a proper height).

ii. User-centered design in which the workplace design process should also focus on workers and their needs (e.g., the usability of designed workplaces) instead of focusing only on the task requirements.

iii. Modularity and simplicity of the proposed designs.

iv. Achievement of client objectives in terms of allocated budget and future requirements of the modular construction plant.

Based on the input and criteria, the proposed methodology to design virtual prototypes of concerned workplaces in modular construction facilities before implementing physical models in practice involves mainly four sequential procedures:

i. Performing workplace design initiation to create all possible workplace alternatives using the definitive screening design (DSD) method, which is one of the design of experiments techniques, based on workplace design parameters (WDPs) and their values.

ii. Developing an interactive worker-workplace simulation that utilizes full-body inverse kinematics-based 3D visualization using a biped skeleton to produce workers' motion data changed based on the different design alternatives.

iii. Developing predictive surrogate models that mimic the behavior of the simulation using 
the regression analysis of the DSD in order to identify the mathematical relationships between significant design parameters and REBA/RULA risk scores so that the ergonomic risks associated with any newly proposed design options can be predicted.

iv. Performing design optimization in order to reach optimal workplace settings that achieve minimal ergonomic risks.

Finally, the outputs of this framework are:

i. Optimal workplace design that minimizes ergonomic risks and consequently enhances safety and productivity in modular construction tasks.

ii. Significant workplace design parameters and their relation to the root causes of injuries in the workplace, wherefrom future action plan can be initiated to ensure safe work practices for injured workers returning to work.

At this junction, it should be noted that the proposed methodology uses the DSD twice to not only produce the design alternatives based on the number of WDPs but also determine significant WDPs leading to expose workers to ergonomic risks significantly. In addition, the proposed framework contains two repeated process flows:

i. Design initiation, interactive simulation, and development of the surrogate models are repeatedly implemented in accordance with the number of tasks assigned to the workplace since each operational task may involve different types and number of WDPs.

ii. The interactive simulation is repetitively implemented to not only acquire the body motion data but also assess the ergonomic risk scores of design alternatives. 


\subsection{Workplace Design Initiation}

WMSDs mostly occur in workplaces as a result of interactions between various factors (e.g., available equipment) and human behavior (e.g., postures required to complete tasks) [14]. To prevent WMSDs, the workplace must be designed based on considering the task information and anthropometric characteristics of the workers [31]. In this respect, the proposed workplace design initiation has the following procedures:

i. Collection of current working scenarios, such as different working methods (e.g., side cutting and front cutting), and the number of operational tasks assigned to the target workplace.

ii. Identification of the WDPs, including low and high values (i.e., minimum and maximum values), which may lead to exposing workers to ergonomic risks.

iii. Implementation of the initial DSD to generate the potential design alternatives based on the result of step (ii).

\subsubsection{Working Pattern Analysis}

To identify the working scenarios and WDPs associated with their values successfully, data collection sheets, which can be adopted to gather useful input data in a structured format, and/or the fishbone diagram, which can yield a deep understanding of workplace design concerns and its relation with ergonomic risk factors in the place, can be used [21]. In addition, the brainstorming can be implemented with the concerned project team (i.e., production engineers and manager) in order to ensure the identification of working scenarios and WDPs from a practical perspective. In this respect, the WDPs encompass not only the continuous numerical factors (e.g., workpiece position/orientation and working surface inclination angle) but also categorical parameters, such 
as working method and types of the modules (e.g., interior or exterior). Moreover, the required design space of each WDP should be defined by an acceptable range of values representing the minimum and maximum values, which allows workers to perform the tasks in more comfortable and natural postures. In practice, these values are commonly defined based on design standards (e.g., ISO 14738 [31]) or assumptions. As an example, illustrated in Fig. 3, a number of workplace design parameters with their minimum and maximum values are represented.
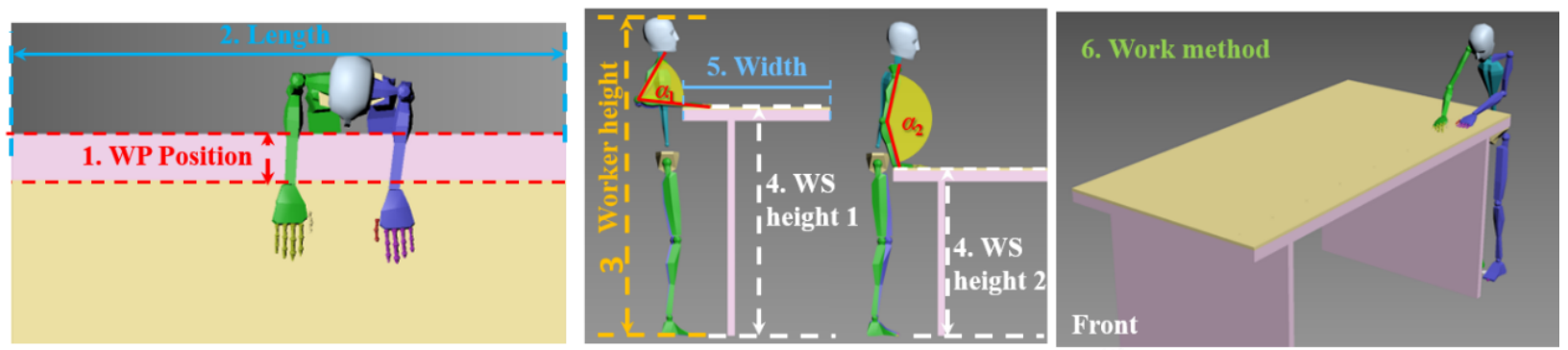

\begin{tabular}{lccc}
\hline Workplace design parameters & \multicolumn{3}{c}{ Levels } \\
\cline { 2 - 4 } & Low (-1) & Center (0) & High (1) \\
\hline 1: WP position & 0 & $162.5 \mathrm{~mm}$ & $325 \mathrm{~mm}$ \\
2: Workstation length & $1000 \mathrm{~mm}$ & $1250 \mathrm{~mm}$ & $1500 \mathrm{~mm}$ \\
3: Worker height & $1640 \mathrm{~mm}$ & $1705 \mathrm{~mm}$ & $1770 \mathrm{~mm}$ \\
4: Workstation height & $800 \mathrm{~mm}$ & $950 \mathrm{~mm}$ & $1100 \mathrm{~mm}$ \\
5: Workstation width & $900 \mathrm{~mm}$ & $1150 \mathrm{~mm}$ & $1400 \mathrm{~mm}$ \\
6: Work method & Front & - & Side \\
\hline
\end{tabular}

Fig. 3. An example of workplace design parameters

\subsubsection{Definitive Screening Design}

Once the required information is acquired, the initial DSD is implemented by the following procedures: (i) calculate the number of design alternatives (NOD alternatives) determined by Eq. (1) based on the number of WDPs $(m)$, which involves only the continuous values; and (ii) transform 
the numerical and categorical values of the WDPs into the coded units used mainly to develop the surrogate models using the DSD. It is worth to be noted that $N O D_{\text {alternatives }}$ has one additional design alternative when some of the WDPs are categorical values.

Once $N O D_{\text {alternatives }}$ is determined, the DSD transforms the numerical values of the WDPs into the three levels of the coded units, which are -1 for the lowest value, 0 for the average value, and +1 for the maximum value. The categorical values of the WDPs are converted into two levels, which are -1 and +1 . At this junction, it should be noted that this transformation not only efficiently determines the significant WDPs, which have the most substantial impact on the measure response (i.e., ergonomic posture risk scores), but also allows the estimate of quadratic effects in addition to main and interaction effects (i.e., second-order surrogate model) in a single step (i.e., one-level DOE) [[32]-[34]]. Fig. 4 represents the general design structure of the DSD implementation for (m) continuous numerical WDPs.

\begin{tabular}{|c|c|c|c|c|c|}
\hline \multicolumn{7}{|c|}{$W=m$} \\
\hline Run & $\boldsymbol{P}_{\boldsymbol{I}}$ & $\boldsymbol{P}_{2}$ & $\boldsymbol{P}_{3}$ & $\ldots$ & $\boldsymbol{P}_{\boldsymbol{m}}$ \\
\hline 1 & 0 & \pm 1 & \pm 1 & $\cdots$ & \pm 1 \\
\hline 2 & 0 & $\mp 1$ & $\mp 1$ & $\ldots$ & $\mp 1$ \\
\hline 3 & \pm 1 & 0 & \pm 1 & $\cdots$ & \pm 1 \\
\hline 4 & $\mp 1$ & 0 & $\mp 1$ & $\ldots$ & $\mp 1$ \\
\hline 5 & \pm 1 & \pm 1 & 0 & $\cdots$ & \pm 1 \\
\hline 6 & $\mp 1$ & $\mp 1$ & 0 & $\cdots$ & $\mp 1$ \\
\hline$\vdots$ & $\vdots$ & $\vdots$ & $\vdots$ & $\ddots$ & $\vdots$ \\
\hline$\left[2(\mathrm{~m}+1)+(-1)^{\mathrm{m}+1}\right]-2$ & \pm 1 & \pm 1 & \pm 1 & \pm 1 & 0 \\
\hline$\left[2(\mathrm{~m}+1)+(-1)^{\mathrm{m}+1}\right]-1$ & $\mp 1$ & $\mp 1$ & $\mp 1$ & $\mp 1$ & 0 \\
\hline $2(\mathrm{~m}+1)+(-1)^{\mathrm{m}+1}$ & 0 & 0 & 0 & $\cdots$ & 0 \\
\hline
\end{tabular}

Fig. 4. The general design structure of DSD for $(m)$ WDPs 
Accordingly, a certain number of feasible design alternatives is created by alternating design parameters along with their low-center-high values using the DSD method. These design alternatives are used as input in the worker-workplace interactive simulation procedure, which simulates workers' body motions at each design alternative and calculates REBA and RULA scores of the design alternatives. Several statistical packages (e.g., JMP, and Minitab) support the creation and analysis of the DSD method. To implement the DSD method successfully, this research work uses Minitab18 [35].

$$
N O D_{\text {alternatives }}=2(m+1)+(-1)^{m+1}
$$

Where:

- $\boldsymbol{N O D}_{\text {alternatives }}$ is the number of design alternatives.

- $\boldsymbol{m}$ is the number of continuous numerical WDPs. 


\subsection{Interactive Worker-Workplace Simulation}

Human body animation is a particular area of the 3D visualization process that involves creating 3D human skeletons (e.g., biped characters) and animates them using two different techniques: (i) forward kinematics (FK), which is the process of obtaining the position of biped's end effector (e.g., wrist/fist) given joint angles and length of the related manipulator (e.g., shoulder and elbow); and (ii) inverse kinematics, which is the opposite to FK for obtaining joint angles from known coordinates of an end effector [36]. Traditionally, these techniques are applied using kinematics solvers in order to create human body motions based on hierarchical bone structures of the biped characters [16]. However, these solvers have the difficulty of making bone movements realistically since they allow for only single-joint movements instead of entire body movements interacting with the surrounding environment [37]. Due to this feature, manual adjustment of the character is usually required at each keyframe (i.e., animation time unit) of the produced animations, which is a time-consuming and error-prone process.

To overcome these limitations and develop reliable character animations in games and animation movies, full-body inverse kinematics (Full-body IK) solvers [38], which uses a biomechanical model of the human body, are introduced to allow biped characters to interact dynamically and more realistically with the changes of the surrounding environment in 3D visualization. At this junction, it should be noted that $3 \mathrm{D}$ visualization of surrounding environment changes is essential to develop the full-body IK successfully. In other words, the full-body IK is not established without 3D visualization of the workplace changes (i.e., animation of WDPs). Once the animation of WDPs is built, as shown in Fig. 5, parent-child constraints between biped's end effectors and animated workplace components (e.g., workpiece, and work surface) are established 
so that the joint angles (e.g., $\alpha, \beta$, and $\theta$ ) are changed interactively and dynamically in accordance with different positions of the biped's end effectors, which are animated corresponding to the changes of WDPs in 3D visualization.
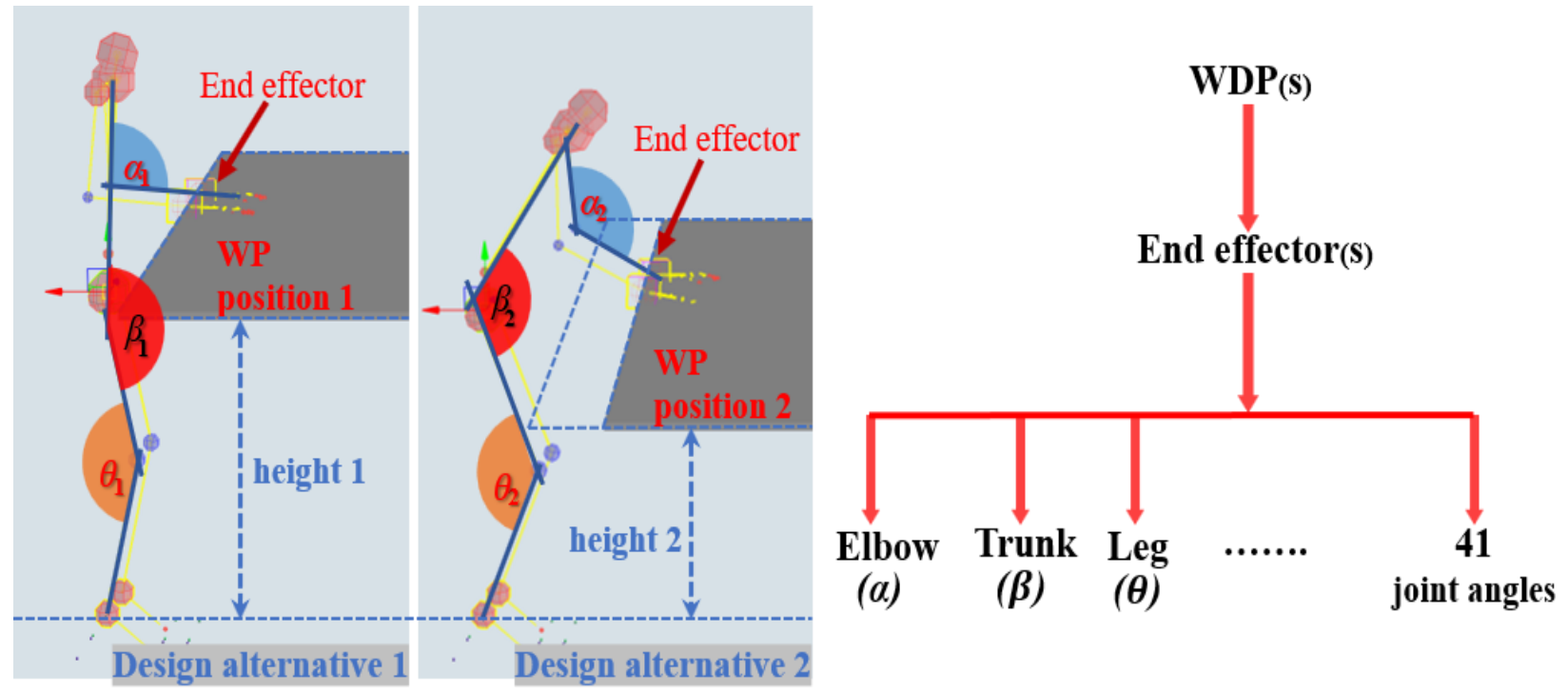

Fig. 5. Dynamic movements with the structure of full-body IK solver

Based on the benefits of the full-body IK solver given in Autodesk MotionBuilder [39], the proposed interactive worker-workplace simulation is implemented to acquire the body posture data, compute the body joint angles, and assess the ergonomic risks using REBA and RULA among all workplace design alternatives resulted in initial DSD implementation. As shown in Fig. 6, the proposed interactive worker-workplace simulation has mainly six procedures:

i. Develop a preliminary 3D workplace model and a 3D worker represented as a bipedal skeleton in 3ds Max based on the values of WDPs in one of the design alternatives selected randomly.

ii. Build a 3D visualization of the worker's motions at the preliminary 3D workplace model. 
iii. Assess REBA and RULA risk scores using the body joint angles.

iv. Animate the 3D workplace model by changing the values of WDPs in another selected workplace design alternative.

v. Establish the full-body IK, which is activated by linking the biped skeleton to the animated workplace to simulate worker's motions in the investigated design alternative.

vi. Repeat steps (iii) to (v) until all the design alternatives are simulated.

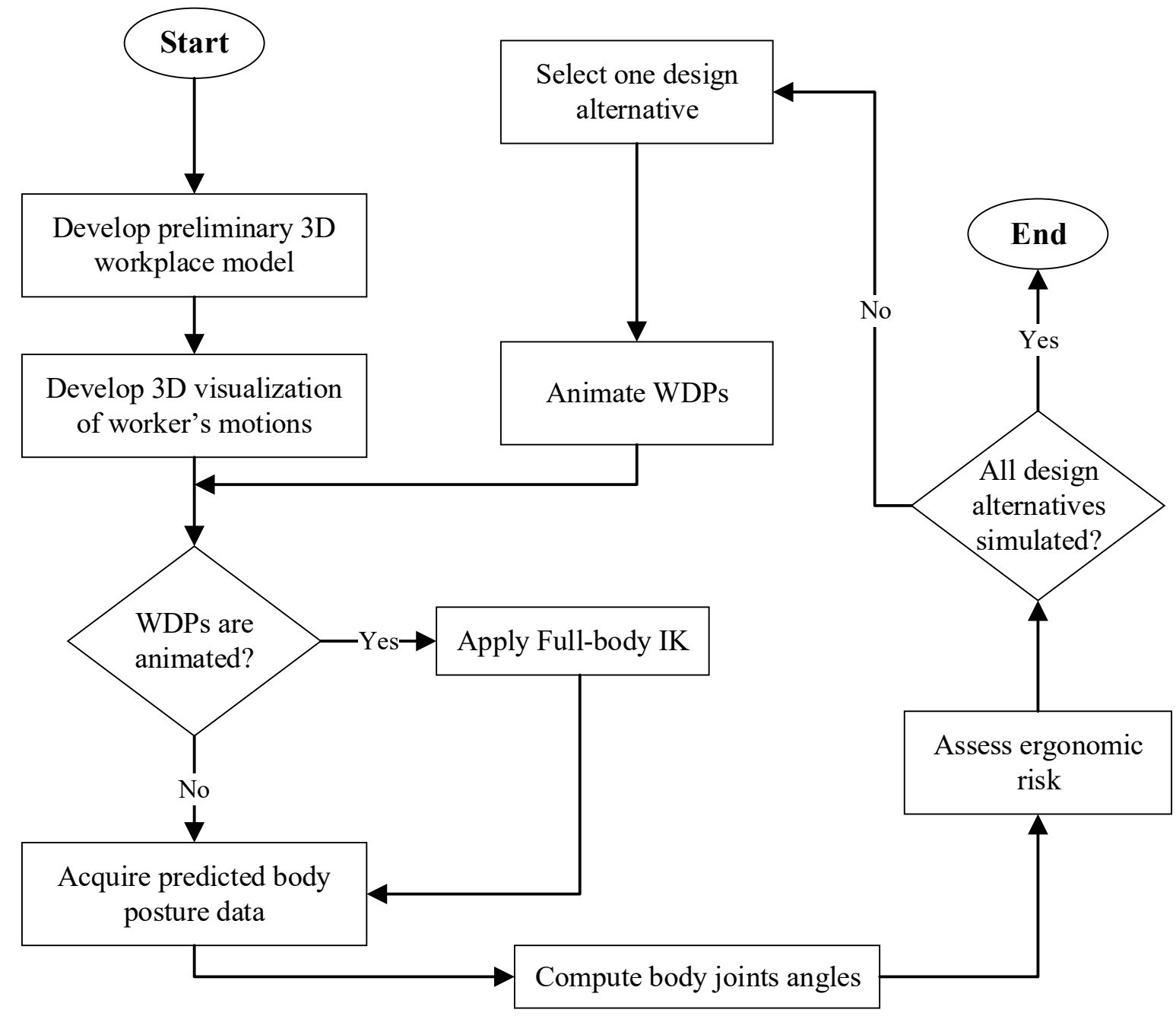

Fig. 6. Process flow of the interactive worker-workplace simulation 
To produce reliable and realistic 3D body posture data, the preliminary workplace model should satisfy the following requirements:

i. 3D geometric models of the workplace should be built in the real scale to reflect actual dimensions of the WDPs and other items, including workpieces and tools.

ii. Basic ergonomic principles, such as the provision of sufficient clearance for legs, should be considered to ensure more realistic postures and avoid any undesirable contact between the worker's body and workplace parts during the simulation.

iii. The 3D workers should reflect workers' main characteristics such as height and sex, which can be easily adjusted using biped creation settings in 3ds Max.

Based on these requirements, the 3D preliminary workplace model and a 3D worker are built in 3ds max and exported to MotionBuilder to develop the worker's motions. In MotionBuilder, the first step is defining the bone structure of the biped character to imitate the hierarchical movements of human body structures. Following that, based on the video recordings of the workplace and the process suggested by Li et al. [16], 3D visualization of the worker's motions during the operational task is developed based on the following information:

i. The prime body postures adopted by the worker with the standard operating procedures (SOPs).

ii. Corresponding keyframes of each prime body posture based on a time study of the motions and the speed of movement. To calculate the keyframes, this research study uses 30 frames per second, which is a common scale to convert the real-time to animation time (frame) in games and animation movies. 
As illustrated in Fig. 7, the preliminary workplace model and the worker's motions are built on the same animation time frame. To establish full-body IK solver into the 3D worker, WDPs in the preliminary workplace model are visualized by changing the values of the WDPs in another workplace design alternative selected by the user. The animation time frames for the $3 \mathrm{D}$ visualization of the WDPs are defined by the user before animating the worker's motions. However, some of WDPs can be associated with force utilization, which is a critical factor to increase the REBA and RULA risk scores. These WDPs should be animated corresponding to the worker's motions so that the worker's motions using full-body IK solver are dynamically animated. At this junction, it should be noted that the duration of force exposure, which is the duration of animating the force-related WDPs, should be calculated based on the consideration of the animation time scale since this study assesses the ergonomic risks based on the continuous motions of the workers in $3 \mathrm{D}$ visualization instead of a few static body postures.

For example, workpiece positions should be changed using force in accordance with the values (e.g., from $0 \mathrm{~cm}$ to $100 \mathrm{~cm}$ ) in design alternatives. To represent the change of the workpiece positions in 3D visualization, the animation time frames should be calculated by Eq. (2). That is, the workpiece position from $0 \mathrm{~cm}$ to $50 \mathrm{~cm}$ is animated from 70 to 100 frames, which is 1 second estimated from the time study in the videos. To examine another design alternative that moves the workpiece from $0 \mathrm{~cm}$ to $100 \mathrm{~cm}$, the total number of required animation time frames is 60 frames, which are duration to visualize not only the workpiece positions but also relevant worker's motions. Once each design alternative is visualized, the system [[3], [16]] used in this research study computes 41 body joint angles and assesses REBA and RULA risk scores, which are used as response values to develop surrogate models in the DSD analysis. 


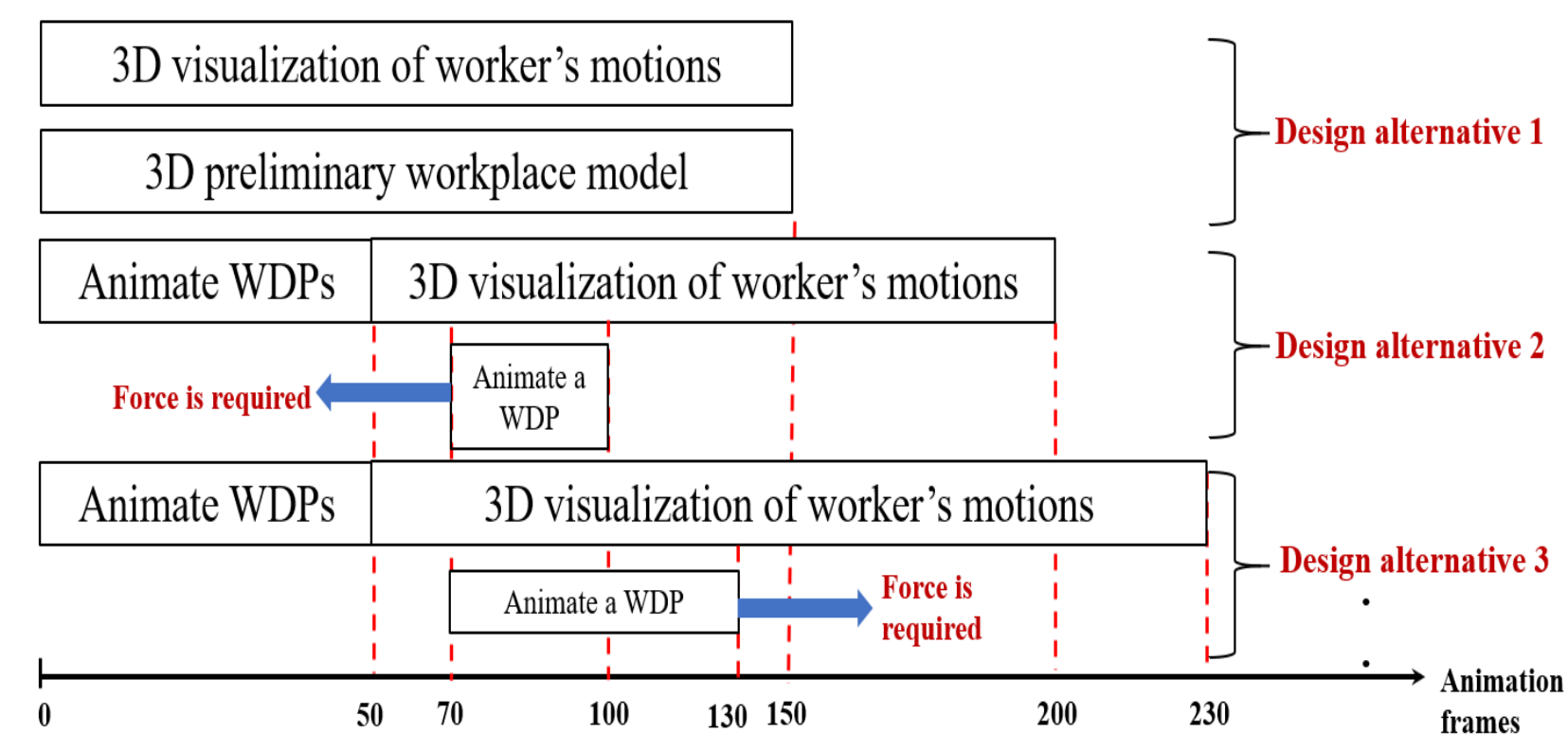

Fig. 7. A concept for the development of the animation keyframes

$$
F_{\text {alter }}=\frac{F_{\text {pre }} \times P V_{\text {alter }}}{P V_{\text {pre }}}
$$

Where:

- $\boldsymbol{F}_{\text {alter }}$ is the number of required keyframes.

- $\boldsymbol{F}_{\text {pre }}$ is the number of keyframes for the WDP in the previous alternative.

- $\boldsymbol{P} \boldsymbol{V}_{p r e}$ is the parameter value in the previous alternative.

- $\boldsymbol{P} \boldsymbol{V}_{\text {alter }}$ is the parameter value in the examined design alternative. 


\subsection{Development of predictive surrogate models}

\subsubsection{Statistical Regression Analysis}

To develop the predictive surrogate models, statistical regression analysis of the definitive screening design (DSD) method is conducted to:

i. Identify significant WDPs, which mostly contribute to increasing overall REBA or RULA risk scores using analysis of variance (ANOVA).

ii. Quantify interactive relations between overall REBA or RULA scores and the significant WDPs by fitting a full quadratic model using the stepwise regression method.

The DSD uses the stepwise regression technique [32] to not only identify the significant WDPs but also develop the mathematical predictive models, also called as the surrogate models in this thesis. The significant WDPs, which are used as parameters in the models, are determined in this study when the p-value computed by analysis of variance (ANOVA) is less than 0.05 . At this junction, it should be noted that the DSD considers not only one single WDP itself but also the combination of the WDPs (i.e., interaction effects) as one parameter in the surrogate models. Following the normal theory linear model, the proposed surrogate model generated by the DSD is shown in Eq. (3).

$$
E R=\beta_{0}+\beta_{1} \mathrm{P}_{1}+\beta_{2} \mathrm{P}_{2}+\cdots+\beta_{i} \mathrm{P}_{\mathrm{i}}+\sum \beta_{i k} \mathrm{P}_{\mathrm{i}} \mathrm{P}_{\mathrm{k}}+\sum \beta_{i i} \mathrm{P}^{2}
$$

Where:

- $\quad \boldsymbol{E} \boldsymbol{R}$ denotes the ergonomic risk score (i.e., REBA, or RULA overall score).

- $\boldsymbol{\beta}_{0}$ is a constant. 
- $\boldsymbol{\beta}_{\boldsymbol{i}}$ is the corresponding regression coefficients that describe main effects of each significant design parameter.

- $\boldsymbol{\beta}_{\boldsymbol{i} \boldsymbol{k}}$ is the coefficients for active interaction effects between different WDPs.

- $\boldsymbol{\beta}_{i i}$ is the coefficients for any estimated quadratic effects.

- $\boldsymbol{P}_{\boldsymbol{i}}$ is a design parameter notation.

- $\boldsymbol{P}_{i} \boldsymbol{P}_{\boldsymbol{k}}$ and $\boldsymbol{P}^{2}{ }_{i}$ are the interaction and quadratic terms, respectively.

Since the surrogate model is developed based on the three levels of the coded units $(-1,0$, and +1 ), the actual values of the WDPs between the minimum and maximum values of the WDPs should be transformed to the coded values between -1 and +1 to predict the risk scores efficiently and effectively using the surrogate model. In this respect, the coded values of the numerical WDPs $\left(p_{i}\right)$ are computed by Eq. (4). However, the coded values of the categorical values of the WDPs are determined by users as -1 or +1 . Fig. 8 illustrates an example to calculate the coded value of a table height based on Eq. (4).

$$
p_{i}=\frac{\left(P_{i}-P_{i, 0}\right)}{\Delta P_{i}}
$$

Where:

- $\quad \boldsymbol{P}_{i}$ is the actual value of the $i^{t h}$ design parameter to predict the ergonomic risk score.

- $\boldsymbol{P}_{i, 0}$ is the average value of the $i^{\text {th }}$ design parameter.

- $\Delta \boldsymbol{P}_{\boldsymbol{i}}$ is the step change value for that parameter. 


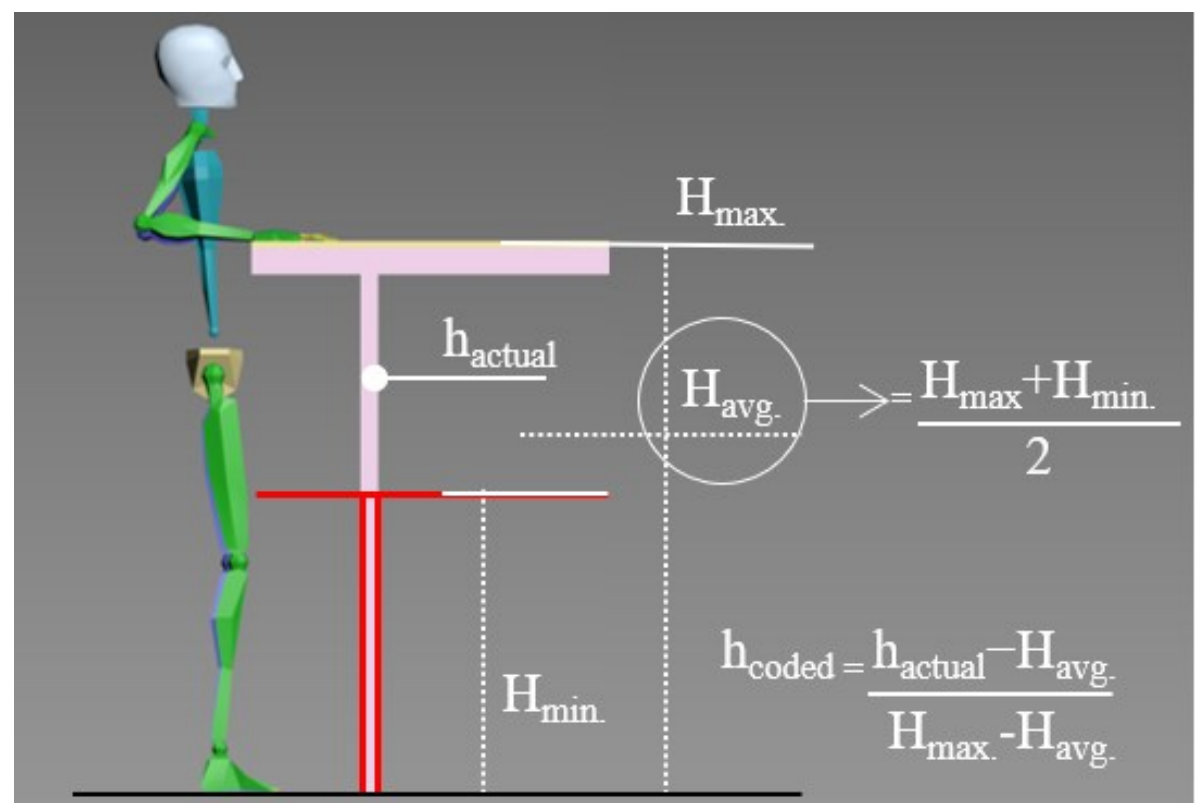

Fig. 8. An example of calculating coded values of WDPs

\subsubsection{Accuracy Metrics}

To use the developed surrogate models as objective functions in the optimization model, the proposed models are evaluated to determine how well they fit the response values (i.e., REBA or RULA scores corresponding to each examined design alternative). The goodness of models' fit and the prediction ability is determined using the following accuracy metrics:

i. Root mean square error (RMSE) [33], which represents how far the actual response values fall from the predicted values.

ii. R-squared $\left(R^{2}\right)$ [30], which indicates how close the predicted response values to the fitted regression curve or line.

iii. Adjusted R-squared $\left(R^{2}{ }_{a d j}\right)$ [30], which compares different models involving a various number of WDPs. 
iv. Predicted R-squared $\left(\mathrm{R}^{2}\right.$ pred $)$ [33], which is a cross-validation method used to determine how well the surrogate model predicts risk scores for new design alternatives. The $\mathrm{R}^{2}$ pred is mainly used to determine whether or not the surrogate model is overfitted. The detailed information and calculation are described by Frost [40].

In addition to these metrics, the ability of the model to predict risk scores for new design alternatives, which are not included in developing the proposed surrogate models, is verified by the percentage of the prediction error satisfying Eq. (5). Furthermore, a residual analysis is conducted to determine whether the model meets the assumptions of the analysis (e.g., residuals are normally distributed).

$$
\text { Percentage of prediction error }=\frac{|E R-\widehat{E R}|}{E R} \%
$$

Where:

- $\boldsymbol{E} \boldsymbol{R}$ is the actual response value (i.e., risk score value) in the 3D simulation.

- $\widehat{E R}$ is the response value predicted from the surrogate model. 


\subsection{Workplace optimization}

In modular construction, a multi-criteria workplace optimization strategy is required to consider not only single-task workplaces but also multiple-tasks workplaces based on various values of the WDPs. In this respect, the proposed framework integrates three versions of a genetic algorithm (GA):

i. A basic GA for single-objective optimization (i.e., one task workplace) [41].

ii. Non-dominated sorting GA, also called as NSGA-II [42], which is a modified version of GA for multi-objective optimization (i.e., two tasks workplace).

iii. Many-objective NSGA-II called as NSGA-III [[43]-[45]] to optimize workplace design for three or more tasks.

The optimization objective of this study is to minimize REBA or RULA risk scores of any operational task, and the decision variables are the significant WDPs. Since the WDPs involve categorical and continuous values, a mixed-variable optimization problem is formulated in which categorical WDPs take a discrete value +1 or -1 , and continuous WDPs take any value from +1 to -1. Accordingly, the developed surrogate models are used as fitness functions in the GA in order to explore:

i. Single optimal solution in the case of a single-task workplace.

ii. Set of Pareto optimal solutions for multi/many-tasks workplaces. As a result of the Pareto optimal solutions, the pseudo-weight vector method [46] is used to establish a tradeoffbased workplace design.

GA is an evolutionary algorithm that is commonly used in several domains, including 
construction, to reach optimal solutions for design engineering problems. GA adopts the concept of natural selection, using bio-inspired operators such as selection, crossover, and mutation. These operators help to generate a collection of solution candidates (individuals), which shape one single population that evolves towards the improved solution based on a fitness function evaluation. The primary role of the fitness function is to assign scores for individuals in order to select fittest ones for participation in the reproduction process (i.e., forming the next generation). However, the selection criterion of GA has some limitations when multi/many-objectives are optimized simultaneously. GA does not support the non-domination rank of individuals, which is a critical selection process to help in finding near the actual Pareto-optimal front with a good spread of solutions.

To overcome this limitation, NSGA-II and NSGA-III, which follow the general outlines of GA, use a modified selection process that enhances the computational performance and provides the following features: (i) individuals are selected frontwise using non-dominated sorting; and (ii) elitism selection method is adopted in which an already found Pareto-optimal solutions are included in the next generation in order to protect them from being deleted. Although NSGA-II is commonly used for many-objective optimization, NSGA-III is recommended to manipulate multiple dimensions in the objective space since it provides a balanced Pareto-optimal front with respect to each objective using a set of reference directions.

The primary process flow of workplace optimization is represented in Fig. 9. An initial population $\left(\mathbf{P}_{\mathbf{t}}\right)$ that includes a number of design alternatives is randomly generated by assigning different values for each of the WDPs based on their types and permissible design space. The REBA or RULA score of each design alternative (individual) in this population is calculated by 
the fitness function corresponding to each task in the workplace. Then, the next offspring population $\left(\mathbf{Q}_{\mathbf{t}}\right)$ is produced by three sequential steps, which are selection, crossover, and mutation.

In the selection, design alternatives that have the lowest risk scores are selected based on the tournament selection method, which helps to achieve faster convergence. These design alternatives are used to carry out the crossover by combining design alternatives into one or several new alternatives. The simulated binary crossover (SBX) [47], which is a single point crossover operator using binary notations for real values, is utilized. The crossover provides different design alternatives that inherit some characteristics from the selected individuals. However, GA can have difficulty to identify the optimal workplace design solution(s) since the design alternatives may tend to stagnate around local minima. To overcome this challenge, the mutation process is performed to ensure the diversity of the design solutions within the population. The mutation occurs by looping through all WDPs of the alternatives to select some of WDPs randomly to replace them with a new value.

Depending on the number of operational tasks in the workplace, a single or multi-objective optimization process is determined. When the number of tasks is one, the generated population $\left(\mathbf{Q}_{\mathbf{t}}\right)$ becomes the population of the next generation $(\mathrm{Gen}+1)$, and the reproduction process is repeated for a certain number of iterations in order to achieve an optimal solution for the singletask workplace. Otherwise, multi/many-tasks optimization is commenced in order to reach a set of Pareto optimal solutions. First, parents $\left(\mathbf{P}_{\mathbf{t}}\right)$ and the offspring population $\left(\mathbf{Q}_{\mathbf{t}}\right)$ are combined to form an intermediate population $\left(\mathbf{R}_{\mathbf{t}}\right)$, which is then ranked to identify the non-dominated sorting fronts.

As a result of this selection method, there will be a situation where a front needs to be split because not all solutions will be selected. In the case of optimizing a two-tasks workplace, 
solutions are selected based on crowding distance [42]; otherwise, the reference direction selection method [45] is used. Accordingly, the parent population $\left(\mathbf{P}_{\mathbf{t}+1}\right)$ is formulated, and the process continues until it reaches the number of generations $(\mathbf{G})$ defined by the user in order to identify optimal Pareto solutions.

Lastly, based on the risk score corresponding to each task, a tradeoff process is implemented in order to select a single preferred design solution from the obtained set of Pareto solutions. The pseudo-weight vector method is applied in order to calculate weights for each solution, which are the relative distance of the risk score from its maximum value in each fitness function. These weights are compared with the user-preferred weights, which considers more weight on higher risk tasks in order to prioritize its design requirements for final design selection. The solution which has a pseudo-weight closer to the user-preferred weight is selected [46]. The Python code of the workplace design optimization following the framework developed at Michigan State University [48]. 


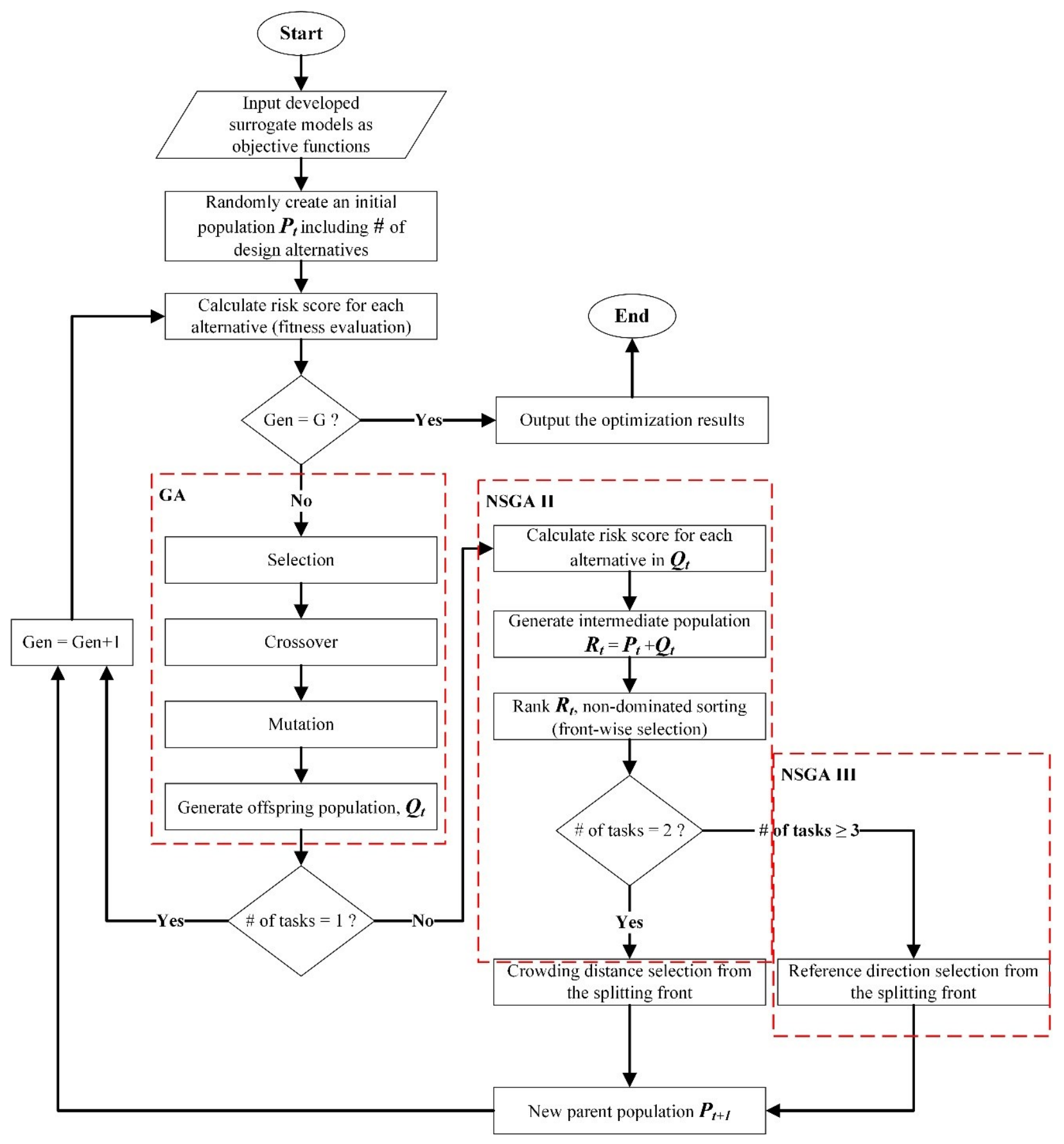

Fig. 9. process flow of workplace optimization 


\section{Chapter 4: Case Study}

The proposed framework is implemented to a production line that produces commercial and residential building components such as walls and floors with light gauge steels (LGS) in Edmonton, Canada. As illustrated in Fig. 10, the factory has mainly three workstations, which are assembly station to prepare the LGS, framing station to produce wall and floor frames, and sheathing station to attach the drywall sheets into the frames. According to the lean principle, the sheathing station is a bottleneck on the production line since it has a time-consuming and laborintensive sub-station, called as a drywall preparation station, including the following tasks:

i. The marking task (MT) to mark drywall sheets according to dimensions in shop drawings.

ii. The cutting task (CT) to cut drywall sheets to the required sizes and layouts.

iii. The sanding task (ST) to smooth edges of cut pieces.

Furthermore, as shown in Fig. 11., there is no specific workplace assigned to accomplish these tasks even though these tasks are repeatedly required to supply pre-cut pieces to the sheathing station. Instead, a drywall material bundle on a base trolley is used as a workplace. Due to this work environment, workers suffer frequent exposure to ergonomic risks, which may lead to increase the risk of work-related musculoskeletal disorders (WMSDs) that not only reduces the productivity of the production line but also increases social expenses for workers' recovery. To overcome these problems, this research study focuses on designing the optimal workplace for the drywall preparation station. 


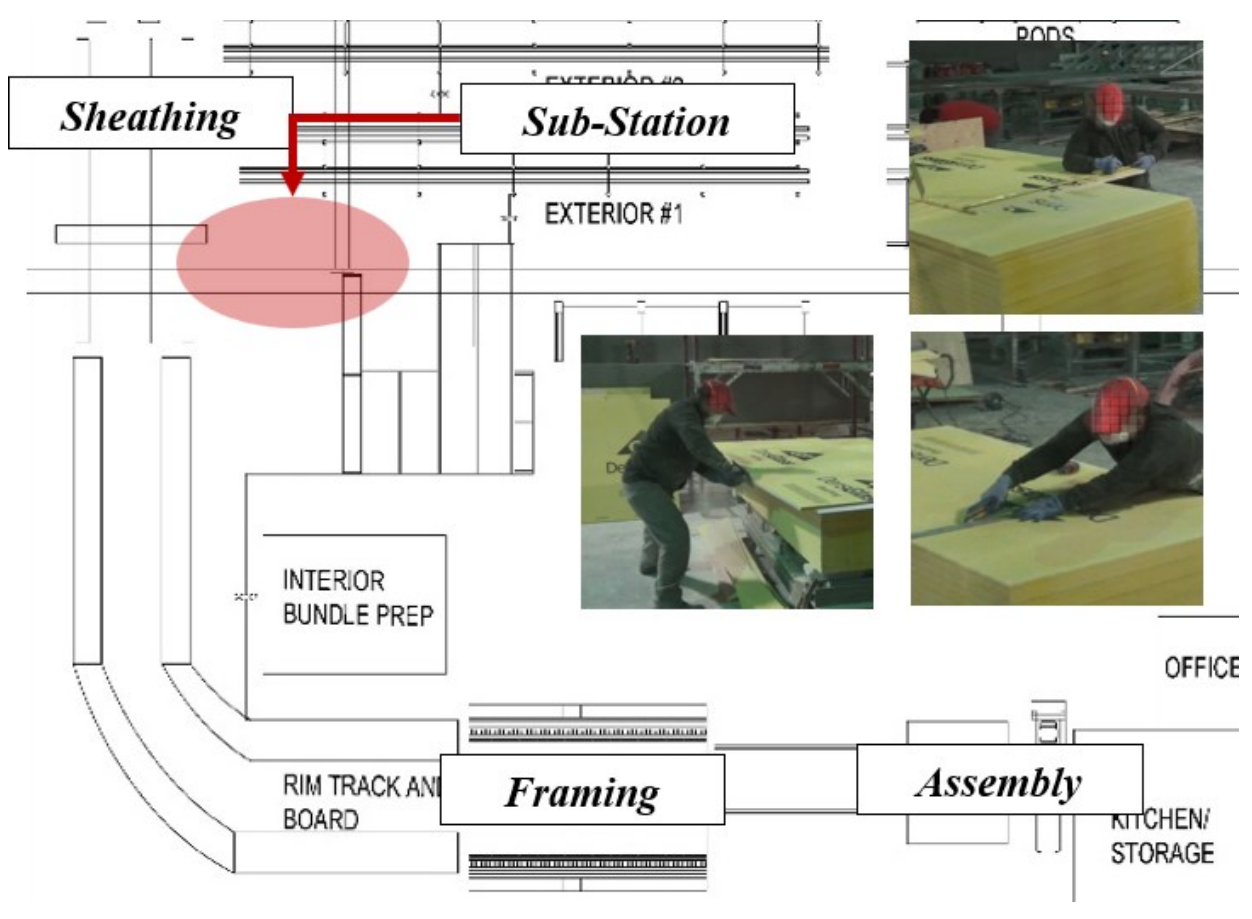

Fig. 10. Factory layout and target workplace

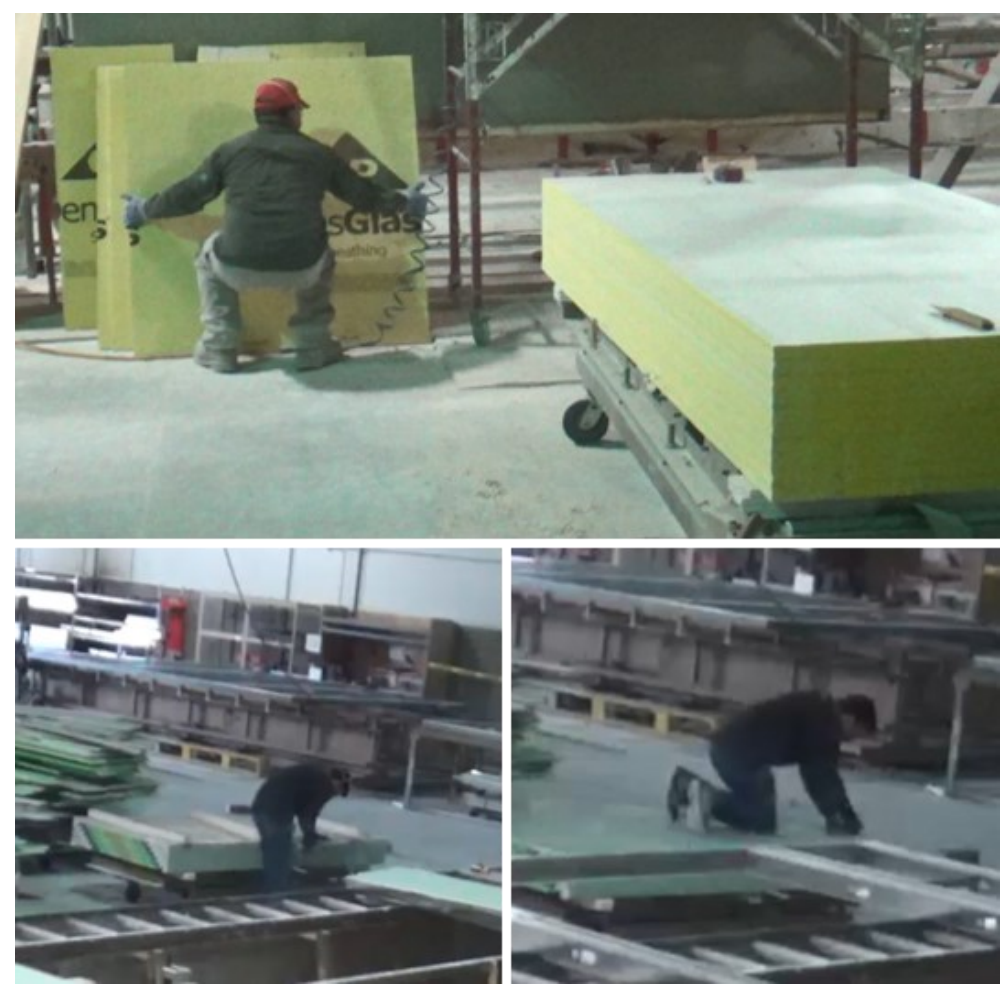

Fig. 11. Existing drywall preparation station 
To start, data collection sheets are utilized for the working pattern analysis in order to gather information about the operational tasks. An example of a CT data collection sheet is represented in Fig. 12. Based on the observation of several videos of the targeted workplace and site visit, the following working scenarios are accordingly identified:

i. Various body characteristics of workers are identified in the same workplace during different shifts.

ii. Workers tend to adopt bending and kneeling postures frequently to fit the changeable work surface height.

iii. The workpiece (WP) positions are randomly changed depending on workers.

iv. The worker stands without keeping a convenient distance from the workplace, which creates pressure points on the body.

v. Two work methods (front and side) with different body postures in MT and CT are alternately used.

vi. Workers in CT use two different cutting tools (utility knife itself or utility knife with a measuring tape).

vii. The side work methods in MT and CT lead to various bending postures since the worker needs to adjust his body to reach the cutting positions.

viii. The worker in ST pulls the WP outside the workplace to strip the cut part and sand the edge of the final cut piece by one- or two-hands.

Based on these scenarios, the WDPs of each task, which may lead to exposing workers to ergonomic risk factors, are identified to examine their effects on REBA and RULA scores. The 
values of the WDPs, including work surface height, WP position, and worker standing distance, are determined based on the ergonomic design standards and codes given in OSH Answers Fact Sheets by CCOHS [49] and ISO 14738 [31]. According to the human height data [50], average heights for Southeast Asian $(1640 \mathrm{~mm})$ and North American $(1770 \mathrm{~mm})$ are considered as minmax values for worker's height based on considering nationality of actual workers in the industrial partner plant. The WDPs related to the operating conditions are determined based on the results of the site visit and video observations. For example, in the depth of the removed piece, the minimum value is determined based on the shop drawings, and the maximum value is the half size of the drywall sheet. The dimension of the drywall is determined by $2438.4 \mathrm{~mm} \times 1219.2 \mathrm{~mm}$, which are mainly used by the collaborative partner. As a result, this information is represented in Fig. 13.

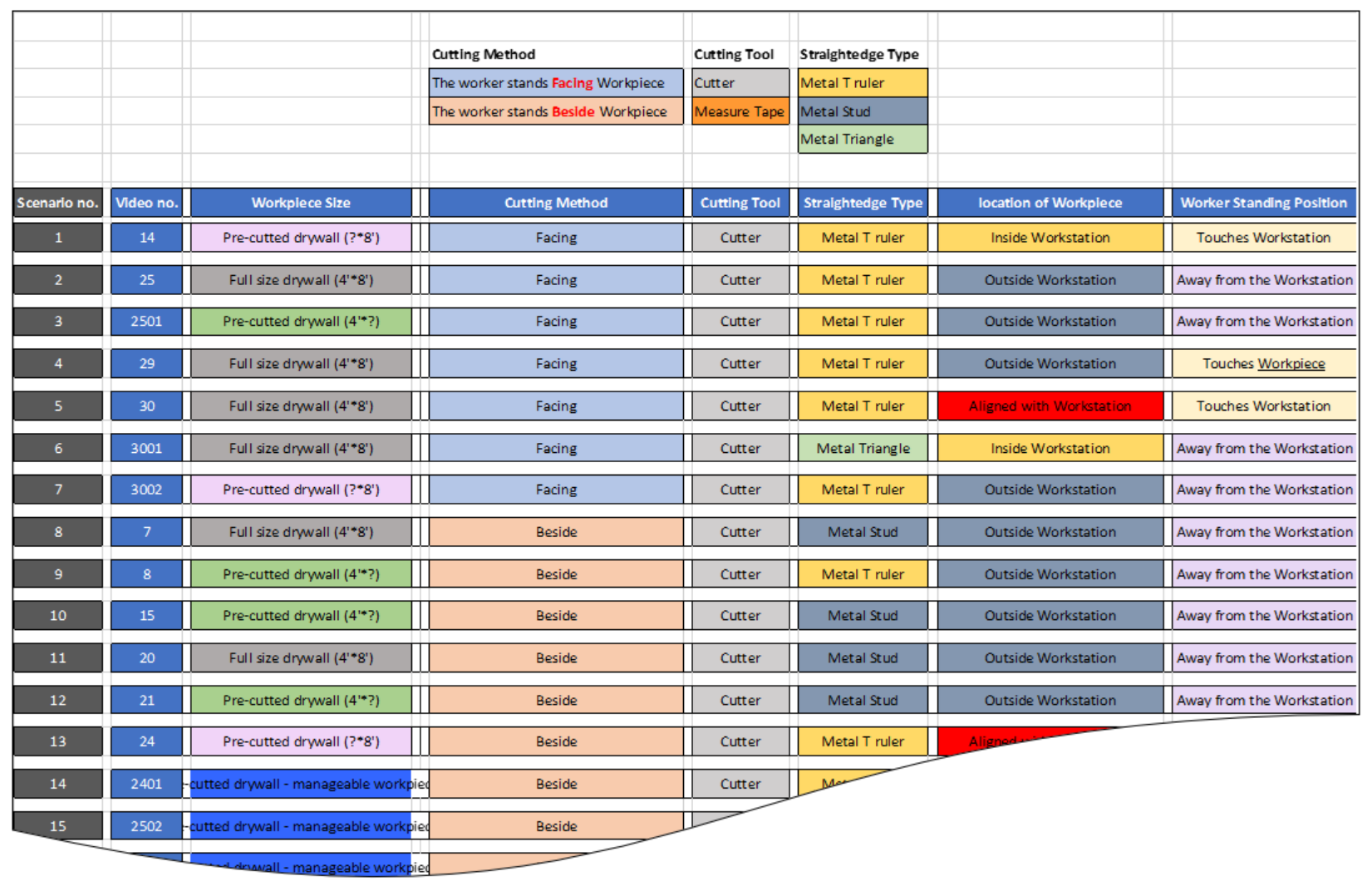

Fig. 12. An example of a CT data collection sheet 

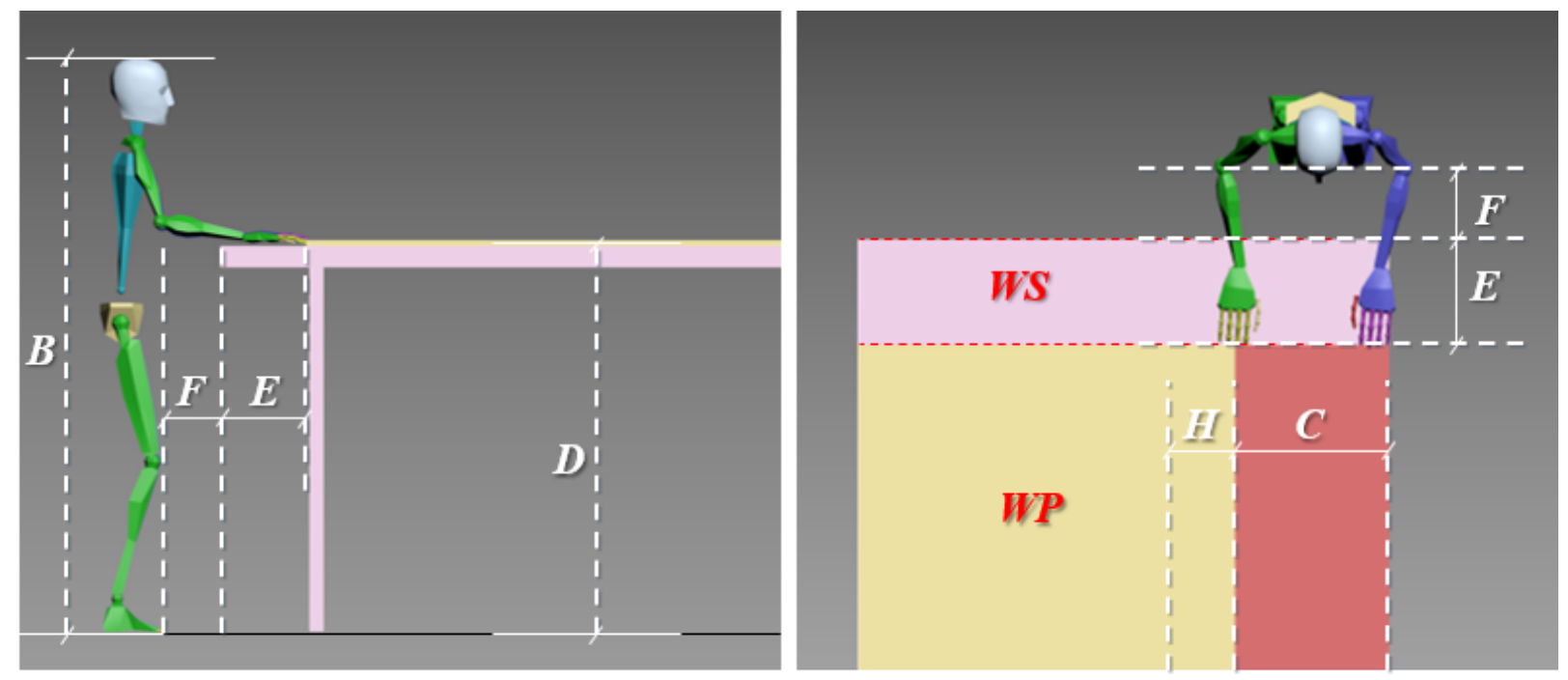

\begin{tabular}{|c|c|c|c|c|}
\hline \multirow{2}{*}{ WDPs } & \multirow{2}{*}{ Task } & \multicolumn{3}{|c|}{ Levels } \\
\hline & & Low $(-1)$ & Center (0) & High (1) \\
\hline \multirow{3}{*}{$\begin{array}{l}\text { A: Work method } \\
\text { (Categorical) }\end{array}$} & MT & Front mariking & - & Side marking \\
\hline & $\mathrm{CT}$ & Front ${ }_{\text {cutfing }}$ & - & Side cutting \\
\hline & $\mathrm{ST}$ & One-hand & - & Two-hand \\
\hline B: Worker height & All tasks & $1640 \mathrm{~mm}$ & $1705 \mathrm{~mm}$ & $1770 \mathrm{~mm}$ \\
\hline C: Depth of removed piece & All tasks & $152.4 \mathrm{~mm}$ & $381 \mathrm{~mm}$ & $609.6 \mathrm{~mm}$ \\
\hline D: Work surface height & All tasks & $900 \mathrm{~mm}$ & $1080 \mathrm{~mm}$ & $1260 \mathrm{~mm}$ \\
\hline E: WP position & $\mathrm{MT} \& \mathrm{CT}$ & $0 \mathrm{~mm}$ & $162.5 \mathrm{~mm}$ & $325 \mathrm{~mm}$ \\
\hline F: Worker standing distance & All tasks & $0 \mathrm{~mm}$ & $100 \mathrm{~mm}$ & $200 \mathrm{~mm}$ \\
\hline G: Cutting tool (Categorical) & $\mathrm{CT}$ & utility knife & - & $\begin{array}{l}\text { utility knife \& } \\
\text { measuring tape }\end{array}$ \\
\hline $\mathrm{H}$ : WP extra pull distance & ST & $50 \mathrm{~mm}$ & $150 \mathrm{~mm}$ & $250 \mathrm{~mm}$ \\
\hline
\end{tabular}

Fig. 13. The WDPs and their values for the three tasks 
According to the procedure of the proposed methodology, the values of the WDPs are transformed into three levels $(-1,0$, and +1$)$ for continuous numerical values and two levels $(-1$ and +1 ) for categorical values in order to generate the potential design alternatives by initial DSD. As a result, fourteen design alternatives for MT and ST, and eighteen alternatives for CT are generated since six, and seven WDPs are identified, respectively.

Moreover, a time study of the workers' motions in accordance with the standard operating procedures (SOPs) is conducted to identify: $(i)$ the prime body postures adopted by the worker for the different tasks; (ii) corresponding keyframes of each prime body posture. As an example, part of the time study results is represented in Fig. 14, Fig. 15, and Fig. 16. Considering different work methods of each task, these results are later used as an input to the proposed interactive workerworkplace simulation in order to develop 3D visualization of worker's motions at the preliminary workplace models. Different work methods of the tasks and corresponding 3D visualizations are illustrated in Fig. 17, Fig. 18, and Fig. 19.

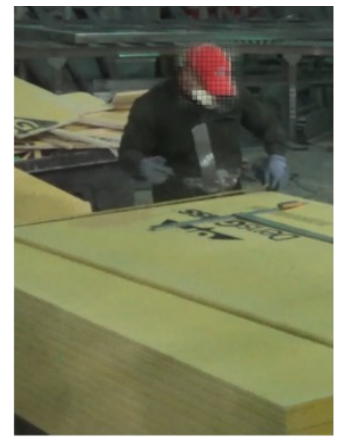

Pose 03 - Middle Sec.22(V)

Frame 45

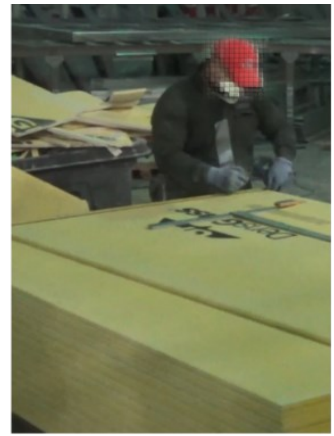

Pose 04 - End Sec.22(V)

Frame 60

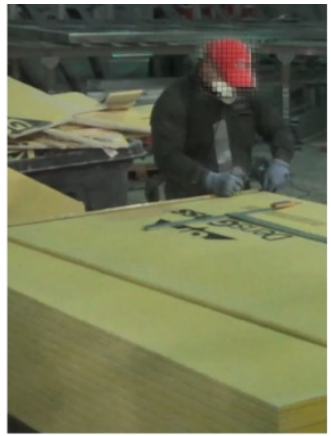

Pose 05 - Middle Sec.23 Frame 75

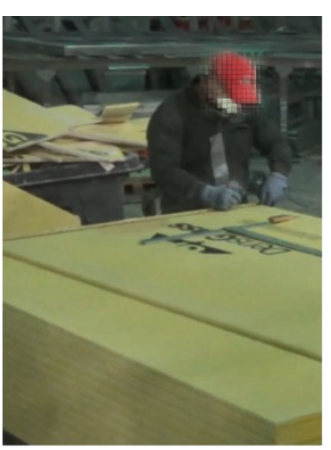

Pose 06 - End Sec.23 Frame 90

Scenario 01: 29 Marking Scenario - Standing Facing workstation - 02

Fig. 14. Time study of the marking task 


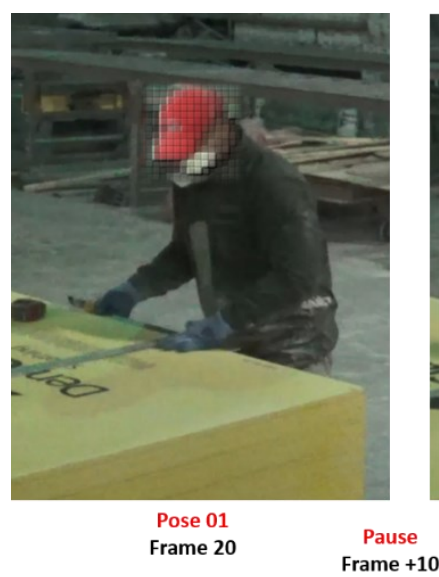

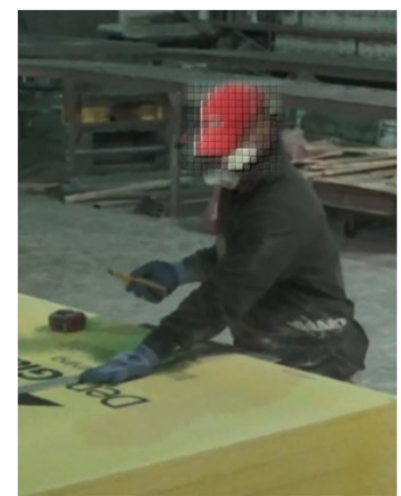

Pose 02

Frame +15

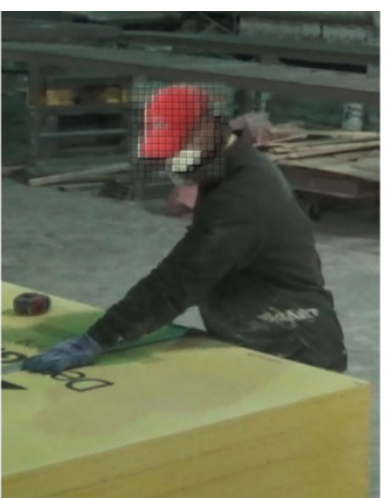

Pose 03

Frame +15

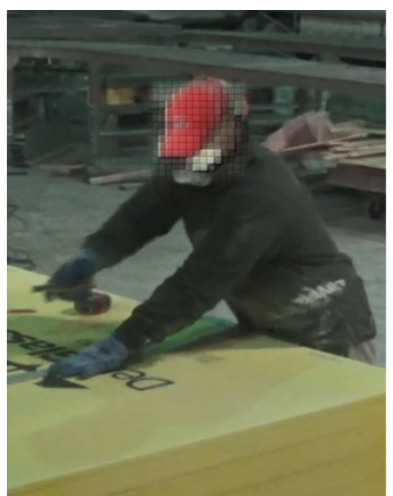

Pose 04

Frame +15

Scenario 01: Video 30CLPer Cutting Scenario - Facing Workpiece, with Cutter

Animation Second $01 \& 02$

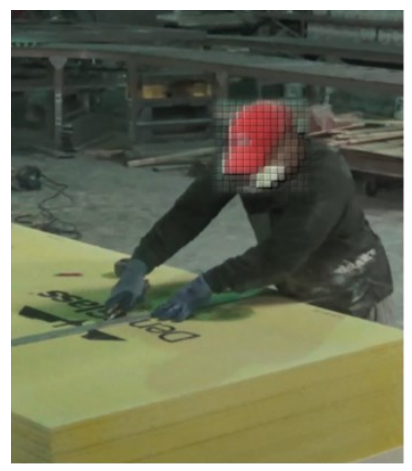

Pose 05

Frame +15

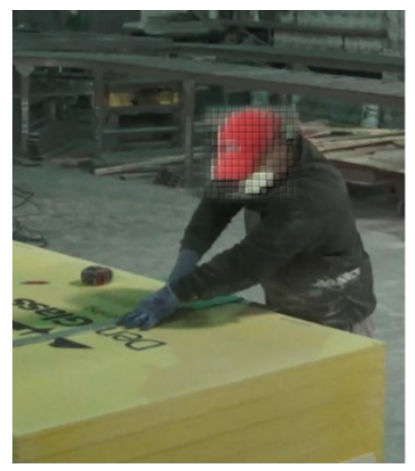

Pose 06

Frame +30

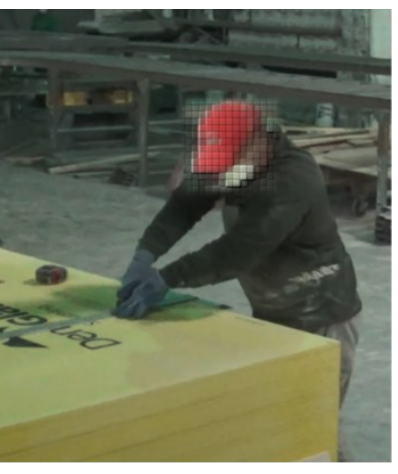

Pose 07

Frame +15

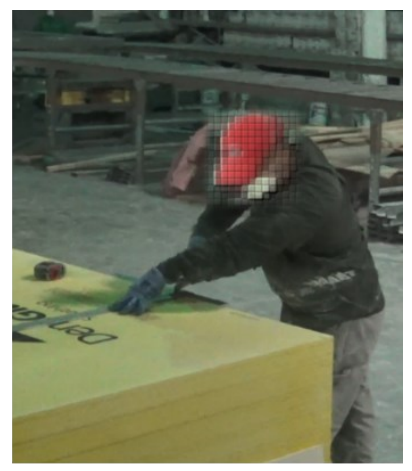

Pose 08

Frame +30

Animation Second 03

Animation Second 04

Animation Second 05

Fig. 15. Time study of the cutting task

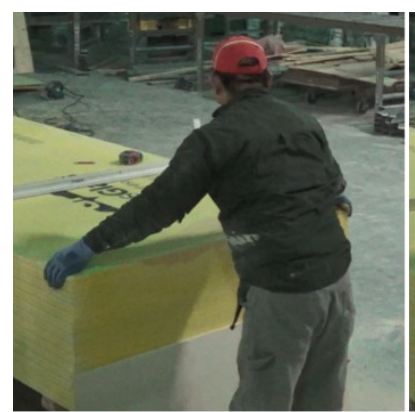

Pose 01

Frame 15

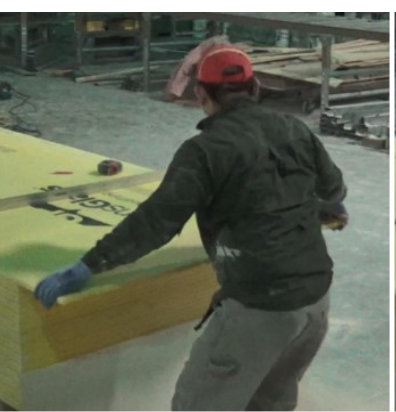

Pose 02

Frame 45

Scenario 01: Video FSPara30 - Pulling WP

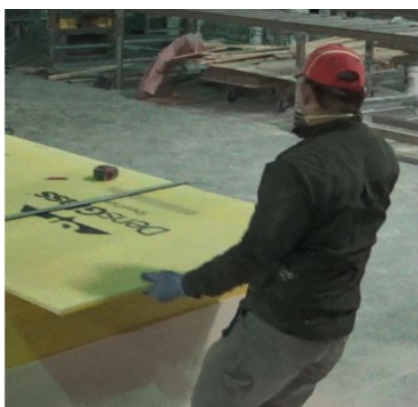

Pose 03

Frame 90

Animation 03 Seconds

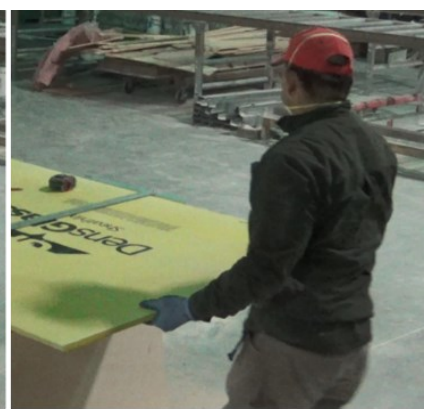

Pose 04

Frame 105

Fig. 16. Time study of the sanding task 


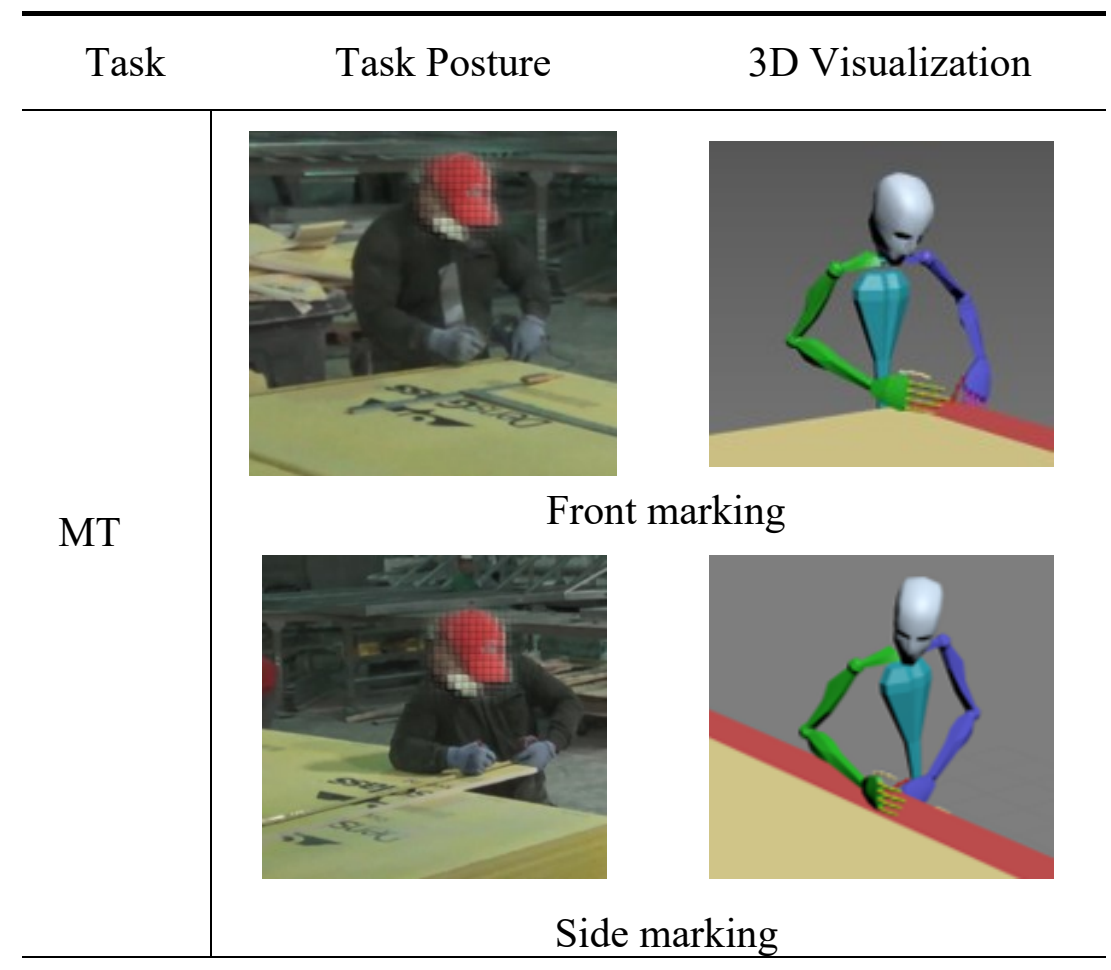

Fig. 17. Work methods and 3D Visualization of the marking task

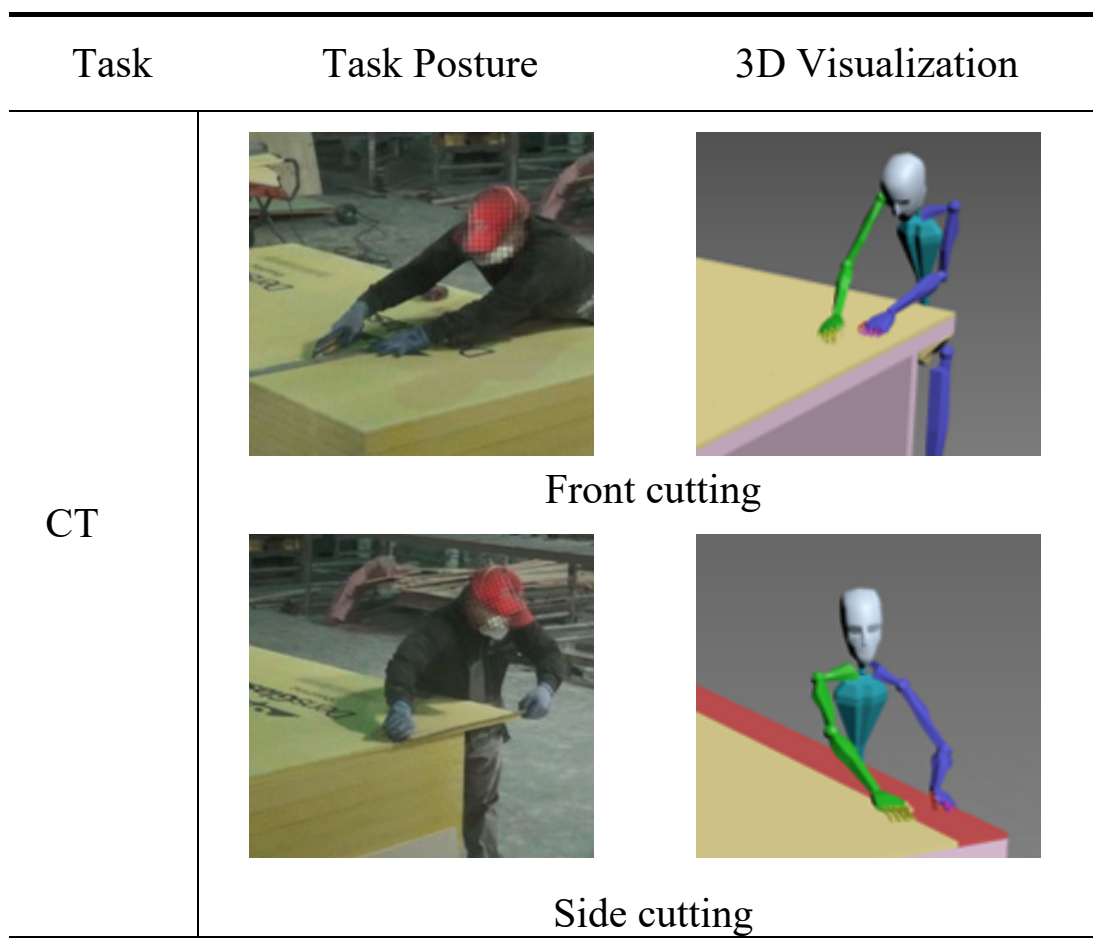

Fig. 18. Work methods and 3D Visualization of the cutting task 


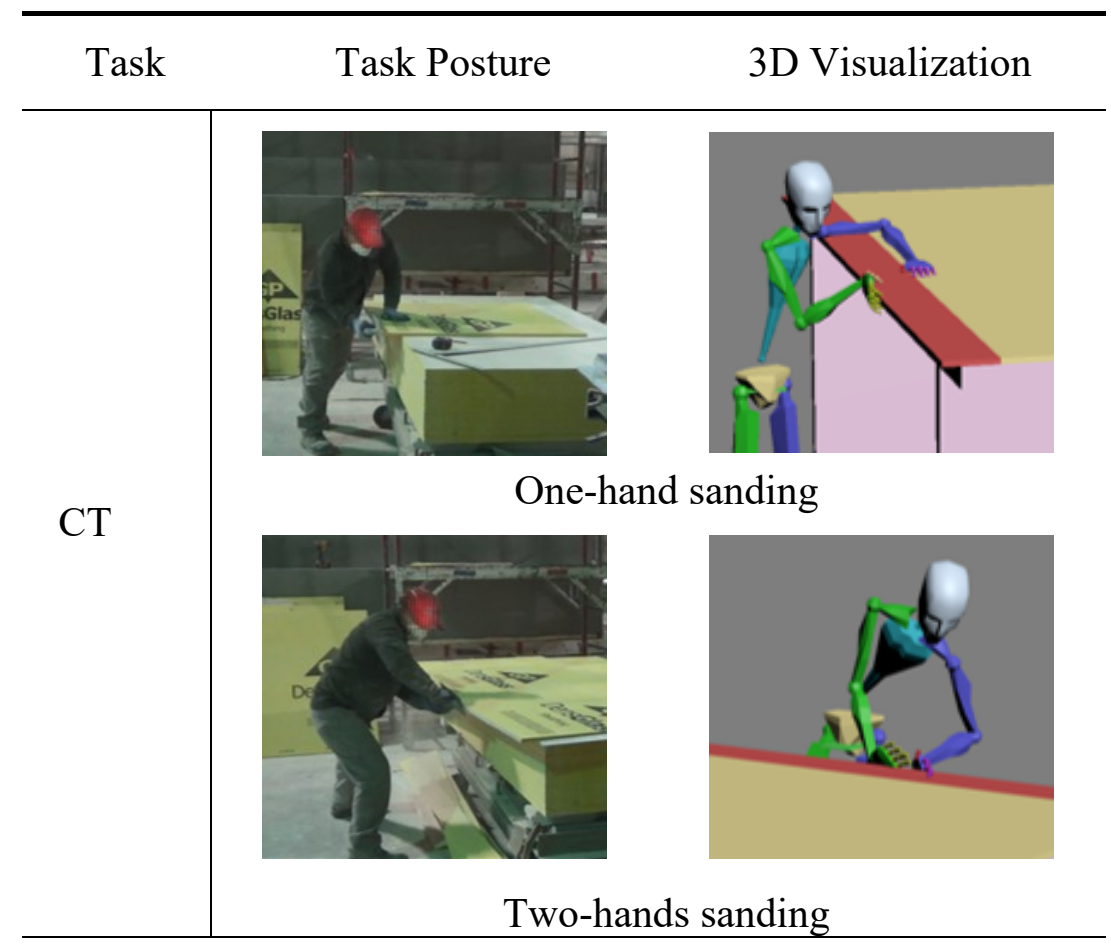

Fig. 19. Work methods and 3D Visualization of the sanding task

Based on the values of the WDPs at each of the design alternatives, the proposed interactive worker-workplace simulation models are developed to not only compute workers' body joint angles but also assess REBA and RULA risk scores. At this junction, it should be noted that REBA and RULA require mainly three types of information, which are the body joint angles acquired from the interactive worker-workplace simulation models, force scores estimated based on the weight of the WP $(31.9 \mathrm{Kg})$, and the number of task repetitions determined from the video and site observation. For example, to develop the interactive worker-workplace simulation for MT, as shown in Fig. 20, design alternative 13 is selected to build a preliminary workplace model in a 3D environment. Then, the 3D visualization of the worker's motions at the 3D preliminary workplace model is developed. Using the system [3], the RULA and REBA scores are computed based on the body joint angles. 
To simulate worker's motions at alternative 6, as shown in Fig. 20, the values of WDPs in the preliminary model are animated by changing the values of WDPs according to the values in alternative 6. All the changes in WDPs' values are animated within 100 frames defined by the researcher except for the WP position required the force. In addition, 3D visualization of the WP position is built from 100 frames to 190 frames since the WP position is moved from $0 \mathrm{~mm}$ to 325 $\mathrm{mm}$. It should be noted that the initial 3D visualization of the WP position to move the WP from $0 \mathrm{~mm}$ to $162.5 \mathrm{~mm}$ is built from 0 to 45 frames ( 1.5 seconds) estimated based on the time study. To produce the worker's motions corresponding to the 3D visualization of the WDPs, full-body IK is activated by linking the biped skeleton to the animated workplace models. The 3D visualization of the worker's motions is used to compute the REBA and RULA scores for alternative 6 , which are 8.59 and 6.77 , respectively. These processes are repeated to compute the REBA and RULA scores of all design alternatives illustrated in Table 1, Table 2, and Table 3 for MT, CT, and ST, respectively.

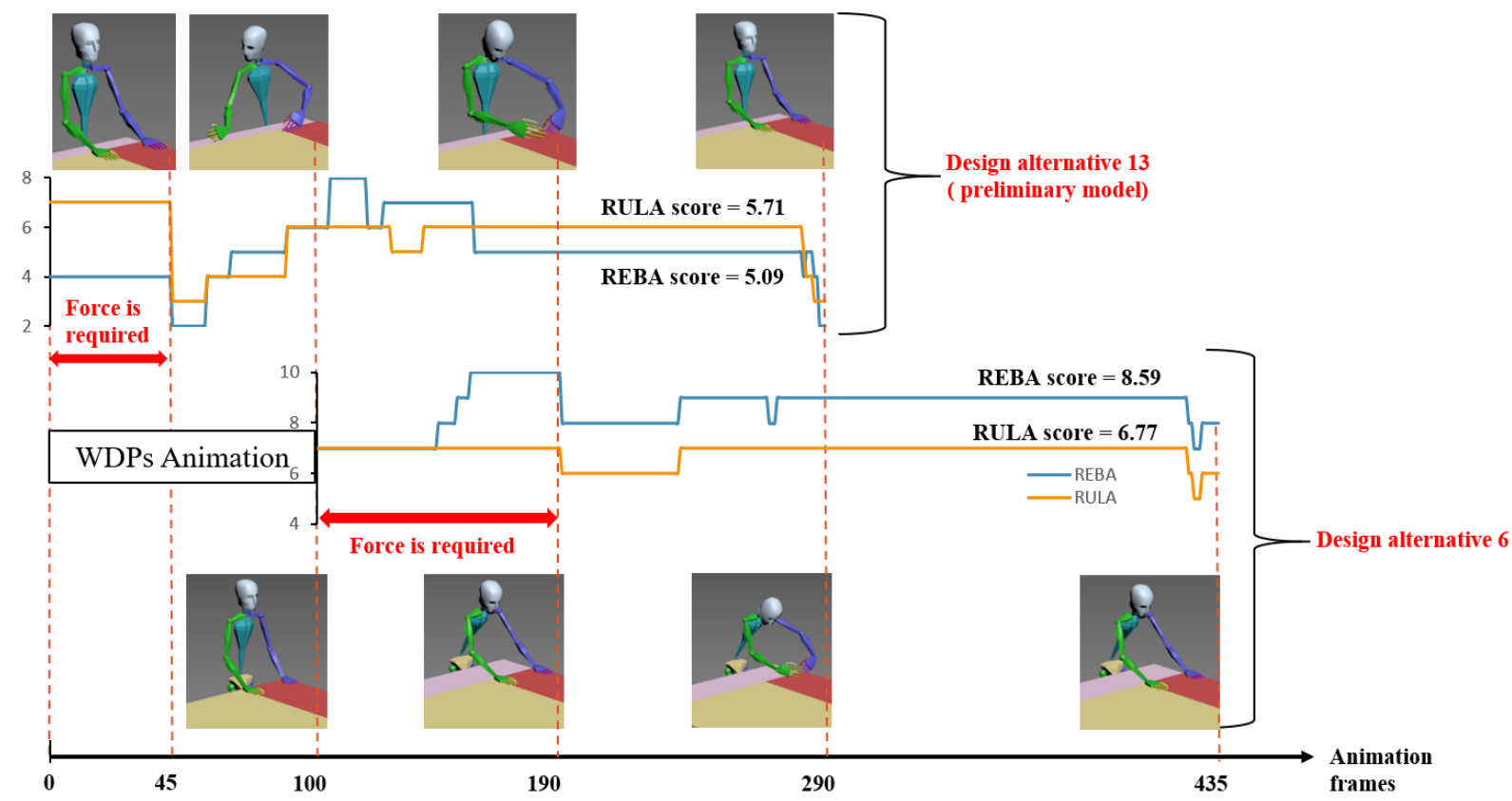

Fig. 20. Interactive simulation model for alternative 6 - MT 
Table 1. Overall REBA/RULA scores of all alternatives for the marking task

Design

alternatives

A $\quad$ B $\quad$ C $\quad$ D $\quad$ E $\quad F \quad$ Overall REBA Overall RULA

Score Score

\begin{tabular}{|c|c|c|c|c|c|c|c|c|}
\hline 1 & -1 & +1 & +1 & +1 & +1 & +1 & 6.22 & 6.03 \\
\hline 2 & +1 & -1 & -1 & -1 & -1 & -1 & 7.18 & 5.40 \\
\hline 3 & +1 & 0 & +1 & -1 & -1 & +1 & 7.95 & 6.15 \\
\hline 4 & -1 & 0 & -1 & +1 & +1 & -1 & 5.84 & 6.28 \\
\hline 5 & +1 & +1 & 0 & +1 & -1 & -1 & 6.24 & 5.97 \\
\hline 6 & -1 & -1 & 0 & -1 & +1 & +1 & 8.59 & 6.77 \\
\hline 7 & +1 & -1 & +1 & 0 & +1 & -1 & 7.42 & 5.80 \\
\hline 8 & -1 & +1 & -1 & 0 & -1 & +1 & 4.26 & 4.17 \\
\hline 9 & +1 & -1 & -1 & +1 & 0 & +1 & 6.53 & 5.86 \\
\hline 10 & -1 & +1 & +1 & -1 & 0 & -1 & 7.10 & 5.78 \\
\hline 11 & +1 & +1 & -1 & -1 & +1 & 0 & 8.87 & 6.42 \\
\hline 12 & -1 & -1 & +1 & +1 & -1 & 0 & 4.65 & 4.12 \\
\hline 13 & -1 & $\mathbf{0}$ & 0 & $\mathbf{0}$ & 0 & $\mathbf{0}$ & 5.09 & 5.71 \\
\hline 14 & +1 & 0 & 0 & 0 & 0 & 0 & 7.11 & 6.09 \\
\hline
\end{tabular}


Table 2. Overall REBA/RULA scores of all alternatives for the cutting task

\begin{tabular}{|c|c|c|c|c|c|c|c|c|c|}
\hline $\begin{array}{c}\text { Design } \\
\text { alternatives }\end{array}$ & $\mathrm{A}$ & B & $\mathrm{C}$ & $\mathrm{D}$ & $\mathrm{E}$ & $\mathrm{F}$ & $\mathrm{G}$ & $\begin{array}{c}\text { Overall REBA } \\
\text { Score }\end{array}$ & $\begin{array}{c}\text { Overall RULA } \\
\text { Score }\end{array}$ \\
\hline 1 & -1 & +1 & +1 & +1 & +1 & +1 & +1 & 7.66 & 5.93 \\
\hline 2 & +1 & -1 & -1 & -1 & -1 & -1 & -1 & 8.24 & 5.57 \\
\hline 3 & +1 & 0 & +1 & -1 & +1 & -1 & -1 & 10.50 & 6.43 \\
\hline 4 & -1 & 0 & -1 & +1 & -1 & +1 & +1 & 6.15 & 4.65 \\
\hline 5 & +1 & -1 & 0 & -1 & +1 & +1 & +1 & 10.94 & 6.83 \\
\hline 6 & -1 & +1 & 0 & +1 & -1 & -1 & -1 & 5.70 & 4.13 \\
\hline 7 & +1 & +1 & +1 & 0 & -1 & +1 & -1 & 9.40 & 6.19 \\
\hline 8 & -1 & -1 & -1 & 0 & +1 & -1 & +1 & 6.97 & 5.62 \\
\hline 9 & +1 & -1 & -1 & +1 & 0 & +1 & -1 & 7.33 & 6.02 \\
\hline 10 & -1 & +1 & +1 & -1 & 0 & -1 & +1 & 8.92 & 6.28 \\
\hline 11 & +1 & +1 & -1 & -1 & -1 & 0 & +1 & 8.46 & 5.89 \\
\hline 12 & -1 & -1 & +1 & +1 & +1 & 0 & -1 & 6.13 & 5.33 \\
\hline 13 & +1 & +1 & -1 & +1 & +1 & -1 & -1 & 7.29 & 6.03 \\
\hline 14 & -1 & -1 & +1 & -1 & -1 & +1 & +1 & 10.19 & 6.35 \\
\hline 15 & +1 & -1 & +1 & +1 & -1 & -1 & +1 & 7.14 & 5.19 \\
\hline 16 & -1 & +1 & -1 & -1 & +1 & +1 & -1 & 10.35 & 6.34 \\
\hline 17 & -1 & 0 & 0 & 0 & 0 & 0 & -1 & 7.04 & 5.24 \\
\hline 18 & +1 & 0 & 0 & 0 & 0 & 0 & +1 & 8.66 & 6.28 \\
\hline
\end{tabular}


Table 3. Overall REBA/RULA scores of all alternatives for the sanding task

Design

alternatives

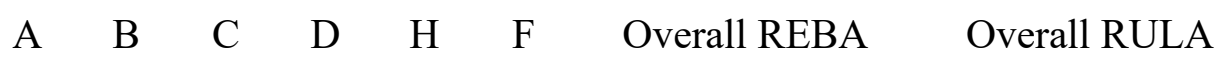

Score Score

\begin{tabular}{l|llllllll}
\hline 1 & -1 & +1 & +1 & +1 & +1 & +1 & 8.06 & 6.74 \\
2 & +1 & -1 & -1 & -1 & -1 & -1 & 8.67 & 6.28 \\
3 & +1 & 0 & +1 & -1 & -1 & +1 & 10.12 & 6.74 \\
4 & -1 & 0 & -1 & +1 & +1 & -1 & 7.98 & 6.23 \\
5 & +1 & +1 & 0 & +1 & -1 & -1 & 7.86 & 6.51 \\
6 & -1 & -1 & 0 & -1 & +1 & +1 & 9.06 & 6.26 \\
7 & +1 & -1 & +1 & 0 & +1 & -1 & 8.64 & 6.69 \\
8 & -1 & +1 & -1 & 0 & -1 & +1 & 8.78 & 6.60 \\
9 & +1 & -1 & -1 & +1 & 0 & +1 & 8.05 & 6.13 \\
10 & -1 & +1 & +1 & -1 & 0 & -1 & 9.62 & 6.67 \\
11 & +1 & +1 & -1 & -1 & +1 & 0 & 9.14 & 6.59 \\
12 & -1 & -1 & +1 & +1 & -1 & 0 & 8.57 & 6.72 \\
13 & -1 & 0 & 0 & 0 & 0 & 0 & 8.38 & 6.38 \\
14 & +1 & 0 & 0 & 0 & 0 & 0 & 8.44 & 6.52 \\
\hline
\end{tabular}

Once REBA and RULA scores of all design alternatives are computed, the statistical analysis of the DSD is implemented to identify significant WDPs, which influence REBA and RULA scores significantly, and use them to develop the surrogate models using the forward selection stepwise regression method [[30], [32]] for each operational task. For example, as represented in 
Fig. 21 and Fig. 22, in the case of using REBA for MT, four main effects of WDPs are statistically significant, which are work surface height (D), WP position (E), work method (A), and depth of removed piece (C) since the p-values are less than 0.05 . The $\mathrm{D}^{2}$ and $\mathrm{C}^{2}$ are also significant, which indicates that the relationship between these design parameters and REBA scores is not linear. In RULA, the most substantial effect is E, whereas worker height (B) has the smallest significant effect. Although worker standing distance $(\mathrm{F})$ is not a significant parameter in the statistical analysis, it has an interaction effect with $\mathrm{B}$, which means that the effect of $\mathrm{F}$ on the RULA score is determined by B. The results of the statistical analysis of MT is represented in Table 4 and Table 5. Also, the significant WDPs of the three tasks are summarized in Table 6.

Although the p-values of the WDPs in the models are less than 0.05 and $\mathrm{R}^{2}$ in the models are greater than $91.00 \%$, the proposed models may be overfitted and/or overspecified in terms of the number of WDPs. To address these problems, as represented in Table 7. this research has evaluated the models by $\mathrm{R}^{2}$ (adj) and $\mathrm{R}^{2}$ (pred), which range from $87.00 \%$ to $97.71 \%$ and $80.39 \%$ and $93.53 \%$, respectively. The predicted $\mathrm{R}^{2}$ values are in reasonable agreement with the adjusted $\mathrm{R}^{2}$ values, which indicates that the proposed surrogate models can predict REBA and RULA scores well for new design alternatives. However, comparing to other models, the RULA surrogate model for the ST has the lowest values in the three types of $\mathrm{R}^{2}$ since it involves only WDPs associated with force. In other words, these force-related WDPs suppress the effects of other WDPs on RULA scores, leading to reduce the accuracy of the prediction, since maximum force scores are considered during the ST resulting almost maximum RULA risk scores for all design alternatives.

To further verify the prediction ability of the developed surrogate models, several design alternatives are simulated. As represented in Table 8, the prediction error between REBA / RULA 
risk scores in the simulation and the corresponding anticipated values from the models is less than $10 \%$, which is acceptable in order to use these models as fitness functions in the GA. Moreover, the visual interpretation of the residual analysis shows no serious outliers or major errors in the probability normal distribution trend. Fig. 23 shows an example of the residual analysis of ST.

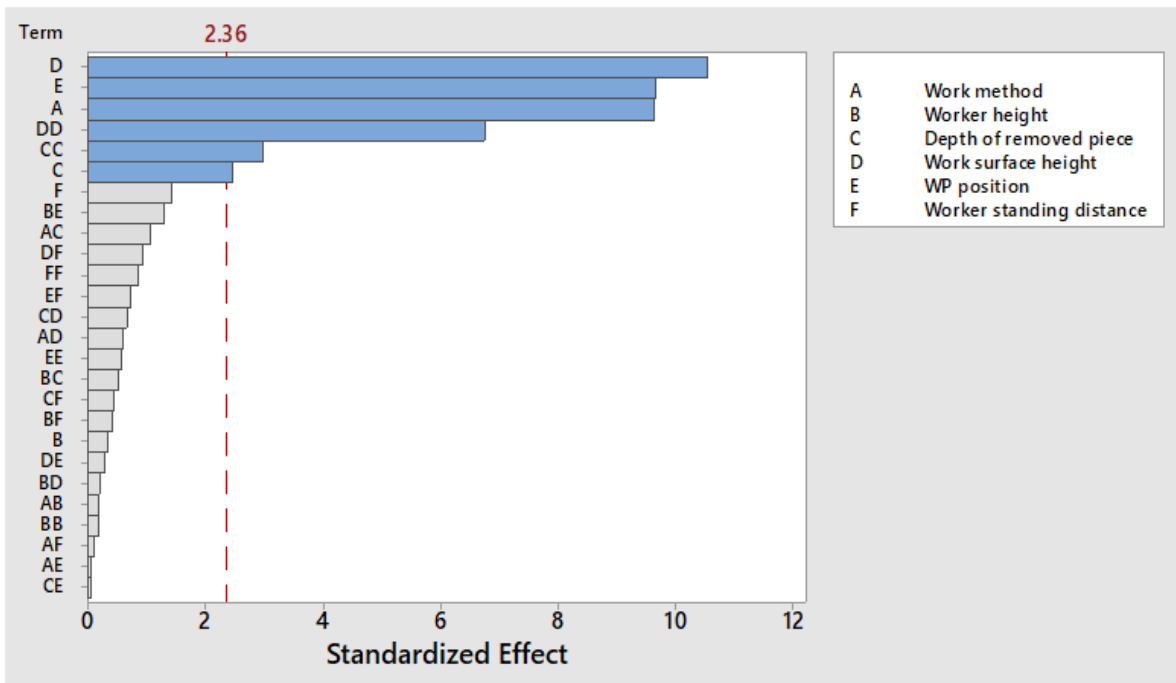

Fig. 21. Significant WDPs using REBA in MT

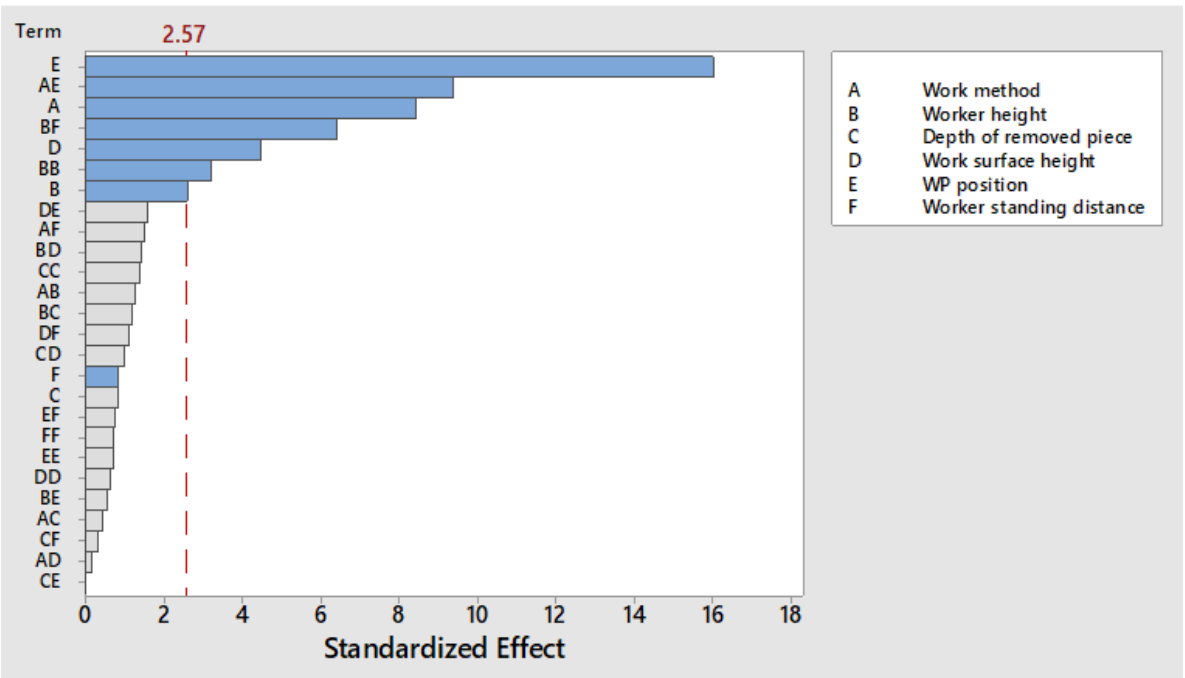

Fig. 22. Significant WDPs using RULA in MT 
Table 4. Statistical analysis of MT - REBA surrogate models

\begin{tabular}{lrrrrr}
\hline Analysis of Variance & & & & & \\
\hline Source & DF & Adj SS & Adj MS & F-Value & P-Value \\
\hline Model & 6 & 24.3028 & 4.05046 & 60.04 & 0.000 \\
Linear & 4 & 21.1550 & 5.28876 & 78.39 & 0.000 \\
$\quad$ Work method & 1 & 6.2811 & 6.28110 & 93.10 & 0.000 \\
$\quad$ Depth of removed piece & 1 & 0.4060 & 0.40595 & 6.02 & 0.044 \\
Work surface height & 1 & 7.4930 & 7.49296 & 111.06 & 0.000 \\
$\quad$ WP position & 1 & 6.3131 & 6.31313 & 93.57 & 0.000 \\
Square & 2 & 3.1477 & 1.57387 & 23.33 & 0.001 \\
$\quad$ Depth of removed piece*Depth of removed piece & 1 & 0.6037 & 0.60369 & 8.95 & 0.020 \\
$\quad$ Work surface height*Work surface height & 1 & 3.0787 & 3.07874 & 45.63 & 0.000 \\
Error & 7 & 0.4723 & 0.06747 & & \\
Total & 13 & 24.7750 & & & \\
\hline Coded Coefficients & & & & & \\
\hline Term & Coef & SE Coef & T-Value & P-Value & VIF \\
\hline Constant & 6.218 & 0.153 & 40.69 & 0.000 & \\
Work method & 0.7005 & 0.0726 & 9.65 & 0.000 & 1.09 \\
Depth of removed piece & 0.2046 & 0.0834 & 2.45 & 0.044 & 1.03 \\
Work surface height & -0.8790 & 0.0834 & -10.54 & 0.000 & 1.03 \\
WP position & 0.8069 & 0.0834 & 9.67 & 0.000 & 1.03 \\
Depth of removed piece*Depth of removed piece & -0.482 & 0.161 & -2.99 & 0.020 & 1.10 \\
Work surface height*Work surface height & 1.088 & 0.161 & 6.76 & 0.000 & 1.10 \\
\hline
\end{tabular}


Table 5. Statistical analysis of MT - RULA surrogate models

\begin{tabular}{|c|c|c|c|c|c|}
\hline \multicolumn{6}{|l|}{ Analysis of Variance } \\
\hline Source & DF & Adj SS & Adj MS & F-Value & P-Value \\
\hline Model & 8 & 7.37306 & 0.92163 & 66.62 & 0.000 \\
\hline Linear & 5 & 4.53852 & 0.90770 & 65.61 & 0.000 \\
\hline Work method & 1 & 0.98970 & 0.98970 & 71.54 & 0.000 \\
\hline Worker height & 1 & 0.09347 & 0.09347 & 6.76 & 0.048 \\
\hline Work surface height & 1 & 0.27837 & 0.27837 & 20.12 & 0.006 \\
\hline WP position & 1 & 3.55253 & 3.55253 & 256.78 & 0.000 \\
\hline Worker standing distance & 1 & 0.01012 & 0.01012 & 0.73 & 0.431 \\
\hline Square & 1 & 0.14401 & 0.14401 & 10.41 & 0.023 \\
\hline Worker height*Worker height & 1 & 0.14401 & 0.14401 & 10.41 & 0.023 \\
\hline 2-Way Interactions & 2 & 2.32258 & 1.16129 & 83.94 & 0.000 \\
\hline Work method*WP position & 1 & 1.22167 & 1.22167 & 88.30 & 0.000 \\
\hline Worker height* Worker standing distance & 1 & 0.57632 & 0.57632 & 41.66 & 0.001 \\
\hline Error & 5 & 0.06917 & 0.01383 & & \\
\hline Total & 13 & 7.44224 & & & \\
\hline \multicolumn{6}{|l|}{ Coded Coefficients } \\
\hline Term & Coef & SE Coef & T-Value & P-Value & VIF \\
\hline Constant & 5.8711 & 0.0622 & 94.43 & 0.000 & \\
\hline Work method & 0.2825 & 0.0334 & 8.46 & 0.000 & 1.13 \\
\hline Worker height & 0.0982 & 0.0378 & 2.60 & 0.048 & 1.03 \\
\hline Work surface height & -0.1695 & 0.0378 & -4.49 & 0.006 & 1.03 \\
\hline WP position & 0.6056 & 0.0378 & 16.02 & 0.000 & 1.03 \\
\hline Worker standing distance & 0.0323 & 0.0378 & 0.86 & 0.431 & 1.03 \\
\hline Worker height*Worker height & -0.2337 & 0.0725 & -3.23 & 0.023 & 1.08 \\
\hline Work method*WP position & -0.3791 & 0.0403 & -9.40 & 0.000 & 1.14 \\
\hline Worker height*Worker standing distance & -0.2762 & 0.0428 & -6.45 & 0.001 & 1.06 \\
\hline
\end{tabular}


Table 6. The significant WDPs of MT, CT, and ST

\begin{tabular}{ccccccc}
\hline & \multicolumn{5}{c}{ REBA } & \multicolumn{3}{c}{ RULA } \\
\cline { 2 - 7 } Task & Significant WDPs & $\begin{array}{c}\text { Most } \\
\text { effect }\end{array}$ & $\begin{array}{c}\text { Smallest } \\
\text { effect }\end{array}$ & Significant WDPs & $\begin{array}{c}\text { Most } \\
\text { effect }\end{array}$ & $\begin{array}{c}\text { Smallest } \\
\text { effect }\end{array}$ \\
\hline MT & D, E, A, D ${ }^{2}, \mathrm{C}^{2}, \mathrm{C}$ & $\mathrm{D}$ & $\mathrm{C}$ & $\mathrm{E}, \mathrm{AE}, \mathrm{A}, \mathrm{BF}, \mathrm{D}$, & $\mathrm{E}$ & $\mathrm{B}$ \\
& & & & $\mathrm{B} \mathrm{B}^{2}, \mathrm{~B}$ & & \\
$\mathrm{CT}$ & $\mathrm{D}, \mathrm{F}, \mathrm{A}, \mathrm{C}, \mathrm{E}, \mathrm{F}^{2}, \mathrm{CE}$ & $\mathrm{D}$ & $\mathrm{CE}$ & $\mathrm{D}, \mathrm{E}, \mathrm{A}, \mathrm{F}, \mathrm{AD}, \mathrm{C}$, & $\mathrm{D}$ & $\mathrm{AG}$ \\
& & & & G, DE, AG & & \\
ST & $\mathrm{D}, \mathrm{HF}, \mathrm{C}, \mathrm{D}^{2}, \mathrm{~F}, \mathrm{H}$ & $\mathrm{D}$ & $\mathrm{H}$ & $\mathrm{C}, \mathrm{B}, \mathrm{BC}, \mathrm{C}^{2}$ & $\mathrm{C}$ & $\mathrm{C}^{2}$ \\
\hline
\end{tabular}

Table 7. The developed surrogate models of MT, CT, and ST

\begin{tabular}{|c|c|c|c|c|c|c|}
\hline & $\begin{array}{c}\text { Tas } \\
\mathrm{k}\end{array}$ & Surrogate model & RMSE & $\mathrm{R}^{2}$ & $\mathrm{R}^{2}(\operatorname{adj})$ & $\mathrm{R}^{2}($ pred $)$ \\
\hline \multirow{3}{*}{$\begin{array}{l}\text { R } \\
\text { E } \\
\text { B } \\
\text { A }\end{array}$} & MT & $\begin{array}{l}\text { REBA Marking }=6.218+0.7005 \mathrm{~A}+0.2046 \mathrm{C}- \\
0.8790 \mathrm{D}+0.8069 \mathrm{E}-0.482 \mathrm{C}^{2}+1.088 \mathrm{D}^{2}\end{array}$ & 0.267 & $98.09 \%$ & $96.46 \%$ & $90.65 \%$ \\
\hline & CT & $\begin{array}{l}R E B A_{\text {Cutting }}=7.698+0.4988 \mathrm{~A}+.4385 \mathrm{C}- \\
1.3725 \mathrm{D}+.3976 \mathrm{E}+.5886 \mathrm{~F}+0.608 \mathrm{~F}^{2}- \\
0.249 \mathrm{CE}\end{array}$ & 0.351 & $97.21 \%$ & $95.26 \%$ & $90.92 \%$ \\
\hline & ST & $\begin{array}{l}\text { REBA Sanding }=8.3966+0.2397 \mathrm{C}-0.6078 \mathrm{D}- \\
0.1124 \mathrm{H}+0.1296 \mathrm{~F}+0.3844 \mathrm{D}^{2}-0.3306 \mathrm{HF}\end{array}$ & 0.097 & $98.77 \%$ & $97.71 \%$ & $93.53 \%$ \\
\hline \multirow[t]{3}{*}{$\begin{array}{l}\mathrm{R} \\
\mathrm{U} \\
\mathrm{L} \\
\mathrm{A}\end{array}$} & MT & $\begin{array}{l}\text { RULAMarking }= \\
5.8711+0.2825 \mathrm{~A}+0.0982 \mathrm{~B}- \\
0.1695 \mathrm{D}+0.6056 \mathrm{E}+0.0323 \mathrm{~F}-0.2337 \mathrm{~B}^{2}- \\
0.3791 \mathrm{AE}-0.2762 \mathrm{BF}\end{array}$ & 0.117 & $99.07 \%$ & $97.58 \%$ & $91.17 \%$ \\
\hline & CT & $\begin{array}{l}\text { RULACutting }=5.8081+0.3039 \mathrm{~A}+0.1440 \mathrm{C}- \\
0.4029 \mathrm{D}+0.3775 \mathrm{E}+0.2509 \mathrm{~F}+0.0837 \mathrm{G}+ \\
0.2080 \mathrm{AD}-0.0794 \mathrm{AG}+0.1018 \mathrm{DE}\end{array}$ & 0.113 & $98.70 \%$ & $97.24 \%$ & $92.97 \%$ \\
\hline & $\mathrm{ST}$ & $\begin{array}{l}R U L A_{\text {Sanding }}=6.4156+0.1022 \mathrm{~B}+0.1744 \mathrm{C}+ \\
0.1231 \mathrm{C}^{2}-0.0973 \mathrm{BC}\end{array}$ & 0.076 & $91.00 \%$ & $87.00 \%$ & $80.39 \%$ \\
\hline
\end{tabular}


Table 8. Verification results of the surrogate models for MT, CT, and ST

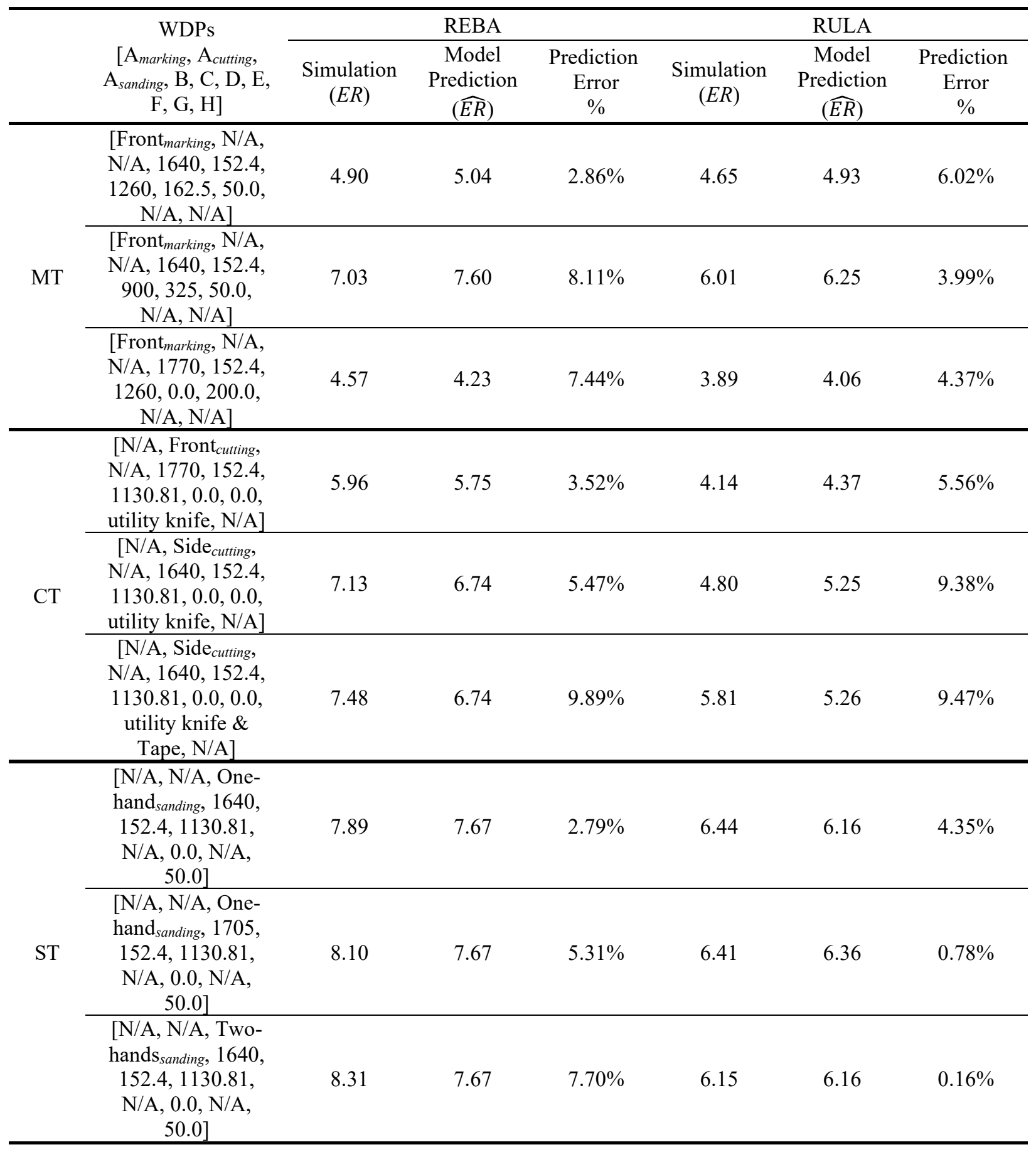



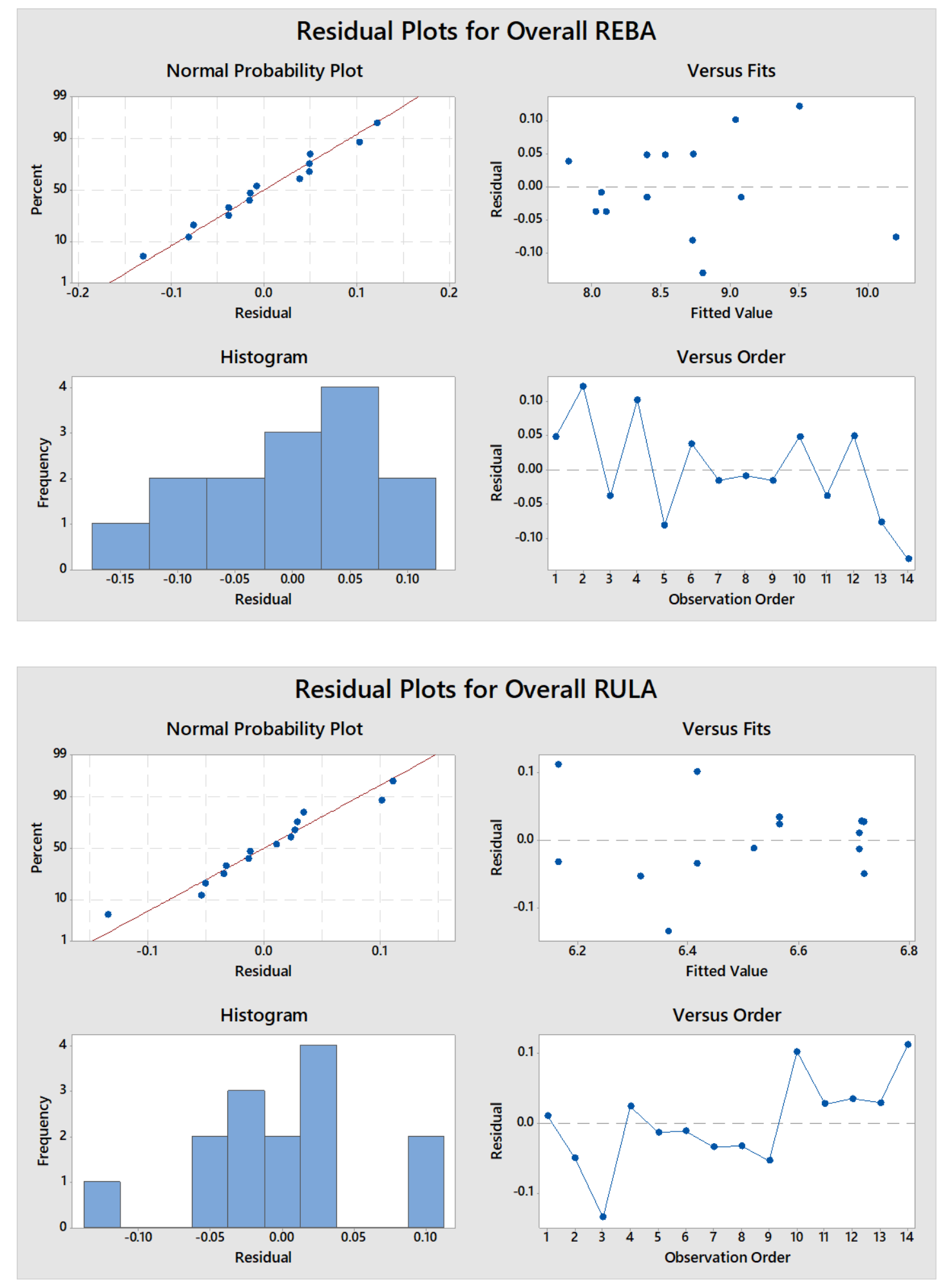

Fig. 23. An example of the of the residual analysis - ST 
Although this thesis focuses mainly on designing the optimal workplace to prevent occurring ergonomic risks for the drywall preparation, lean principles (e.g., balance of the production line) also recommend that some of the tasks may be moved to other workstations for better productivity and safety. In this respect, the design optimization is carried out to define optimal values of WDPs based on the combination of the tasks:

i. MT, CT, and ST for the separated single-task workplace.

ii. Two-tasks workplace for MT and CT. Pareto front solutions are shown in Fig. 24.

iii. Two-tasks workplace for CT and ST. Pareto front solutions are shown in Fig. 25.

iv. Three-tasks at one single workplace. Pareto front solutions are shown in Fig. 26

In addition, the user-preferred weights are assigned to the tasks based on consulting with the factory manager and workers. In this case, the ST has the highest weights since it is the most timeconsuming and difficult task among the three tasks. Table 9 represents the results of the design optimization based on the REBA risk scores, which are the main focus in this case study since it requires the entire body postures to complete the assigned tasks successfully instead of the upper body postures, which require RULA for ergonomic assessment.

As one of the examples, the WDPs for the three-tasks workplace are optimized by NSGAIII which runs for 200 times based on a few parameters which are population size (92), number of generations $(1,200)$, number of reference direction partitions (12), crossover (probability $=0.1$, eta $=20.0$ ), and mutation rate (probability $=1$, eta $=3.0$ ). The values of these parameters are determined by a large number of experiments. REBA scores of the Pareto optimal solutions range from 3.98 to 4.17 for MT, 4.67 to 4.96 for CT, and 7.57 to 7.75 for ST. 
Table 9. Optimal solutions and tradeoff weights of three tasks for workplace settings

\begin{tabular}{|c|c|c|c|c|c|c|c|}
\hline \multirow[b]{2}{*}{ Scenarios } & \multirow[b]{2}{*}{$\begin{array}{c}\text { Solut } \\
\text { ion }\end{array}$} & \multicolumn{2}{|c|}{$\left[\mathrm{W}_{\mathrm{MT}}, \mathrm{W}_{\mathrm{CT}}, \mathrm{W}_{\mathrm{ST}}\right]$} & \multirow[b]{2}{*}{$\begin{array}{c}\text { Optimal WDPs } \\
{\left[\mathrm{A}_{\text {marking, }} \mathrm{A}_{\text {cutting }}, \mathrm{C}, \mathrm{D},\right.} \\
\mathrm{E}, \mathrm{F}, \mathrm{H}]\end{array}$} & \multicolumn{3}{|c|}{ REBA scores } \\
\hline & & $\begin{array}{c}\text { User- } \\
\text { preferred } \\
\text { weight }\end{array}$ & $\begin{array}{l}\text { Pseudo } \\
\text { weight }\end{array}$ & & MT & $\mathrm{CT}$ & ST \\
\hline MT & 1 & N/A & N/A & $\begin{array}{c}{\left[\text { Front }_{\text {marking }}, \mathrm{N} / \mathrm{A}, 152.4,1150.9,0 .\right.} \\
0, \mathrm{~N} / \mathrm{A}, \mathrm{N} / \mathrm{A}]\end{array}$ & 3.84 & N/A & N/A \\
\hline $\mathrm{CT}$ & 2 & N/A & $\mathrm{N} / \mathrm{A}$ & $\begin{array}{c}{\left[\mathrm{N} / \mathrm{A}, \text { Front }_{\text {cutting }}, 152.4,1260,\right.} \\
0.0,52.523, \mathrm{~N} / \mathrm{A}]\end{array}$ & $\mathrm{N} / \mathrm{A}$ & 4.59 & N/A \\
\hline ST & 3 & N/A & N/A & $\begin{array}{c}{[\mathrm{N} / \mathrm{A}, \mathrm{N} / \mathrm{A}, 152.4,1223.64} \\
\mathrm{N} / \mathrm{A}, 0.0,50.0]\end{array}$ & $\mathrm{N} / \mathrm{A}$ & N/A & 7.56 \\
\hline \multirow{4}{*}{$\mathrm{MT}-\mathrm{CT}$} & 4 & {$[0.5,0.5]$} & $\begin{array}{l}{[0.492,0.50} \\
7]\end{array}$ & 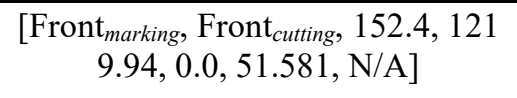 & 3.99 & 4.90 & N/A \\
\hline & 5 & {$[0.2,0.8]$} & $\begin{array}{c}{[0.198,0.80} \\
1]\end{array}$ & $\begin{array}{l}\text { [Front }_{\text {marking }}, \text { Front }_{\text {cutting }}, 152.4,124 \\
\quad 7.52,0.0,51.595, \mathrm{~N} / \mathrm{A}]\end{array}$ & 4.14 & 4.69 & N/A \\
\hline & 6 & {$[0.3,0.7]$} & $\begin{array}{c}{[0.309,0.69} \\
0]\end{array}$ & $\begin{array}{c}{\left[\text { Front }_{\text {marking }}, \text { Front }_{\text {cutting }}, 152.4,123\right.} \\
8.60,0.0,51.595, \mathrm{~N} / \mathrm{A}]\end{array}$ & 4.09 & 4.76 & N/A \\
\hline & 7 & {$[0.1,0.9]$} & $\begin{array}{c}{[0.106,0.89} \\
3]\end{array}$ & $\begin{array}{c}\text { [Frontmarking, Frontcutting, 152.4, } \\
1253.81,0.0,51.595, \mathrm{~N} / \mathrm{A}]\end{array}$ & 4.19 & 4.64 & N/A \\
\hline \multirow[t]{4}{*}{$\mathrm{CT}-\mathrm{ST}$} & 8 & {$[0.5,0.5]$} & $\begin{array}{c}{[0.501,0.49} \\
8]\end{array}$ & $\begin{array}{c}\text { [N/A, Front }{ }_{\text {cutting }}, 152.4 \\
1259.977,0.0,9.711,50.0]\end{array}$ & $\mathrm{N} / \mathrm{A}$ & 4.70 & 7.63 \\
\hline & 9 & {$[0.2,0.8]$} & $\begin{array}{l}{[0.206,0.79} \\
3]\end{array}$ & $\begin{array}{l}{\left[\mathrm{N} / \mathrm{A}, \text { Front }_{\text {cutting }}, 152.4,\right.} \\
1237.467,0.0,0.0,50.0]\end{array}$ & $\mathrm{N} / \mathrm{A}$ & 4.93 & 7.57 \\
\hline & 10 & {$[0.3,0.7]$} & $\begin{array}{c}{[0.311,0.68} \\
8]\end{array}$ & $\begin{array}{l}{\left[\mathrm{N} / \mathrm{A}, \text { Front }_{\text {cutting }}, 152.4\right.} \\
1248.025,0.0,0.0,50.0]\end{array}$ & $\mathrm{N} / \mathrm{A}$ & 4.85 & 7.58 \\
\hline & 11 & {$[0.1,0.9]$} & $\begin{array}{c}{[0.098,0.90} \\
1]\end{array}$ & $\begin{array}{l}\text { [N/A, Front } \text { cutting }, 152.4 \\
1228.738,0.0,0.0,50.0]\end{array}$ & $\mathrm{N} / \mathrm{A}$ & 4.99 & 7.56 \\
\hline \multirow{3}{*}{$\begin{array}{l}\text { MT-CT- } \\
\quad \text { ST }\end{array}$} & 12 & $\begin{array}{l}{[0.35,0.35} \\
0.3]\end{array}$ & $\begin{array}{c}{[0.337,0.32} \\
9,0.332]\end{array}$ & $\begin{array}{c}\text { [Front }_{\text {marking, }}, \text { Front }_{\text {cutting }}, 152.4, \\
1217.795,0.0,23.633,50.0]\end{array}$ & 3.98 & 4.96 & 7.67 \\
\hline & 13 & $\begin{array}{c}{[0.1,0.6,0 .} \\
3]\end{array}$ & $\begin{array}{l}{[0.102,0.65} \\
6,0.241]\end{array}$ & 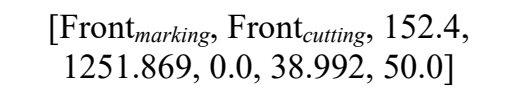 & 4.17 & 4.67 & 7.75 \\
\hline & 14 & $\begin{array}{l}{[0.1,0.1,0 \text {. }} \\
\quad 8]\end{array}$ & $\begin{array}{c}{[0.116,0.37} \\
8,0.504]\end{array}$ & $\begin{array}{c}\text { [Front }_{\text {marking }}, \text { Front }_{\text {cutting }}, 152.4, \\
1247.161,0.0,0.0,50.0]\end{array}$ & 4.14 & 4.85 & 7.57 \\
\hline
\end{tabular}




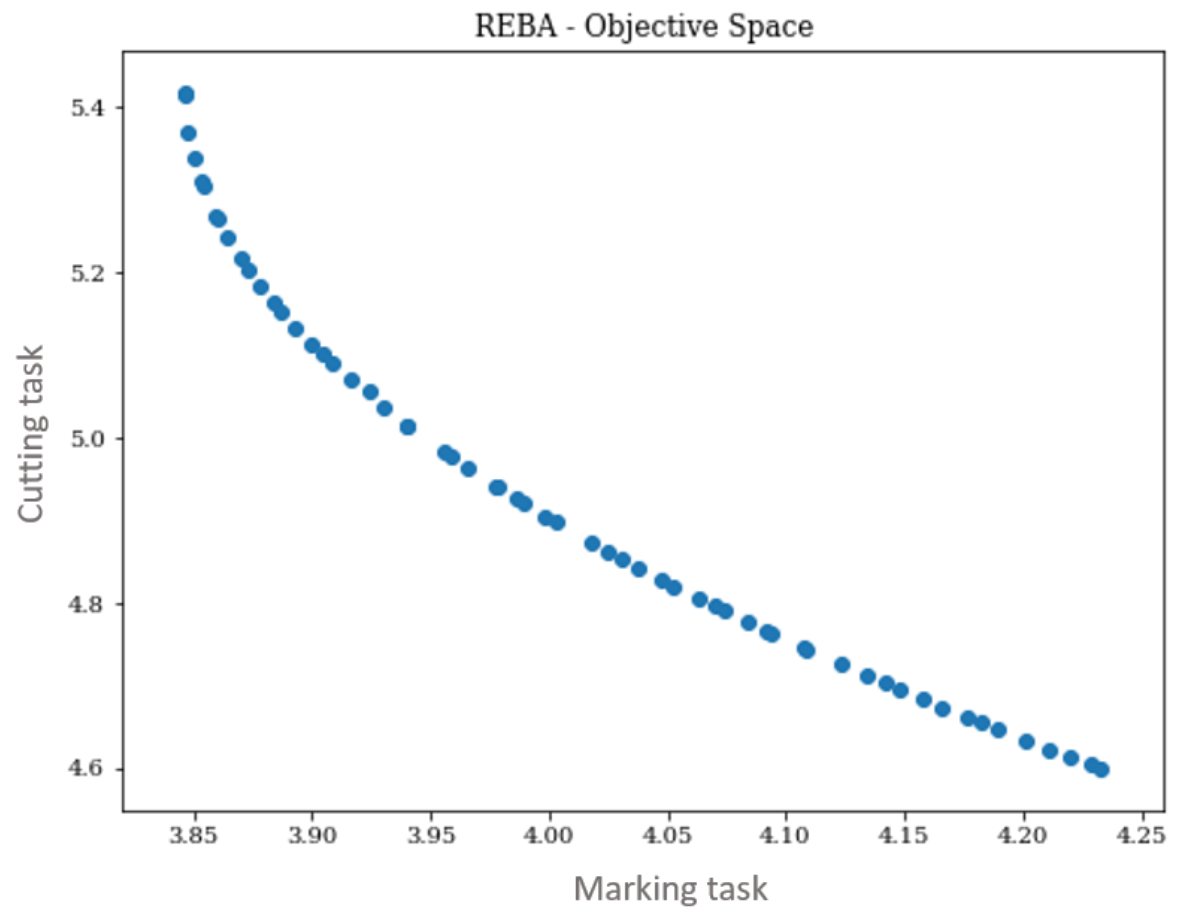

Fig. 24. Pareto optimal solutions for MT and CT

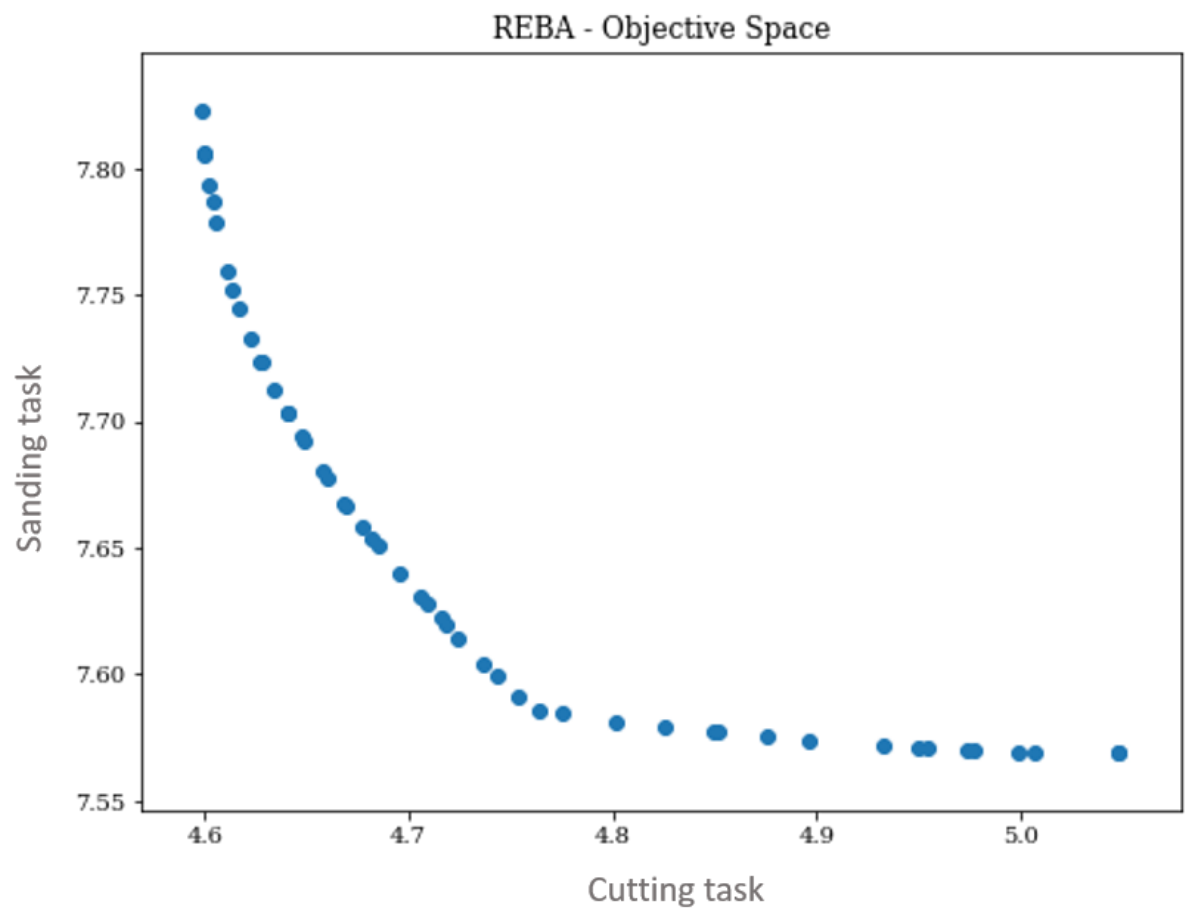

Fig. 25. Pareto optimal solutions for CT and ST 


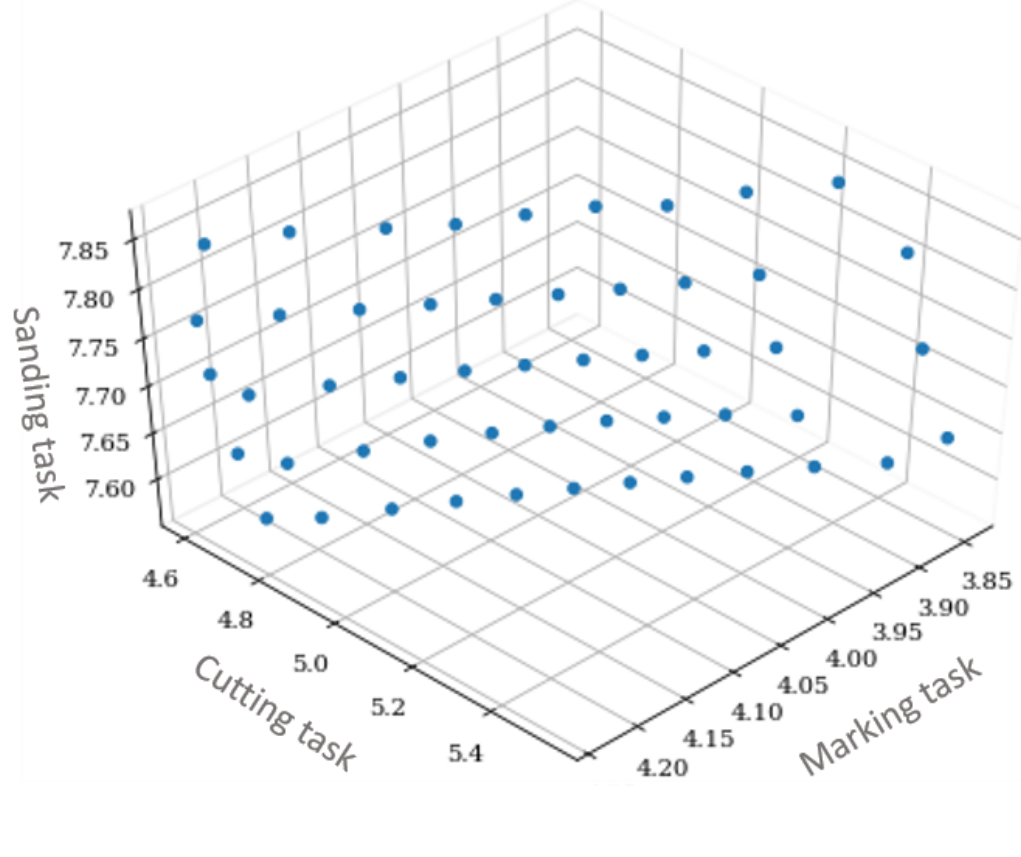

Fig. 26. Pareto optimal solutions for MT, CT, and ST

Since the collaborative partner prefers three-tasks workplace due to the congested production line, the solution 14 is selected as a workplace setting for the drywall preparation. In this respect, the proposed workplace should be designed by the following information:

i. Workers need to complete marking and cutting tasks at the front.

ii. The depth of the removed piece is $152.4 \mathrm{~mm}$, which is the maximum recommended value for all tasks. That is, the higher depth values are the main cause to position the workers on the side bending, increasing the risk scores.

iii. The work surface height is $1247.16 \mathrm{~mm}$.

iv. The best position of the WP for MT and CT is at the edge of the workstation.

v. The worker should stand where the front of his feet is in parallel to the edge of the table during the task operation, as illustrated in Fig. 13 (i.e., $\mathrm{F}=0 \mathrm{~mm}$ ). 
vi. The sanding task should be operated by pulling the WP to $50 \mathrm{~mm}$ extra pull distance from the $152.4 \mathrm{~mm}$ depth of the removed piece so that the worker can sand the cutting edges of the WP with minimum ergonomic risks.

To validate the expected performance of the selected alternative, the solution 14 is modeled for the three tasks using the interactive simulation. Fig. 27 represents REBA risk scores for the simulation and the corresponding anticipated values from the optimization model. The prediction errors are $1.66 \%, 4.15 \%$, and $2.45 \%$ for $\mathrm{MT}, \mathrm{CT}$, and ST, respectively, which indicate the reliability of the optimization model for the selected optimal solution.

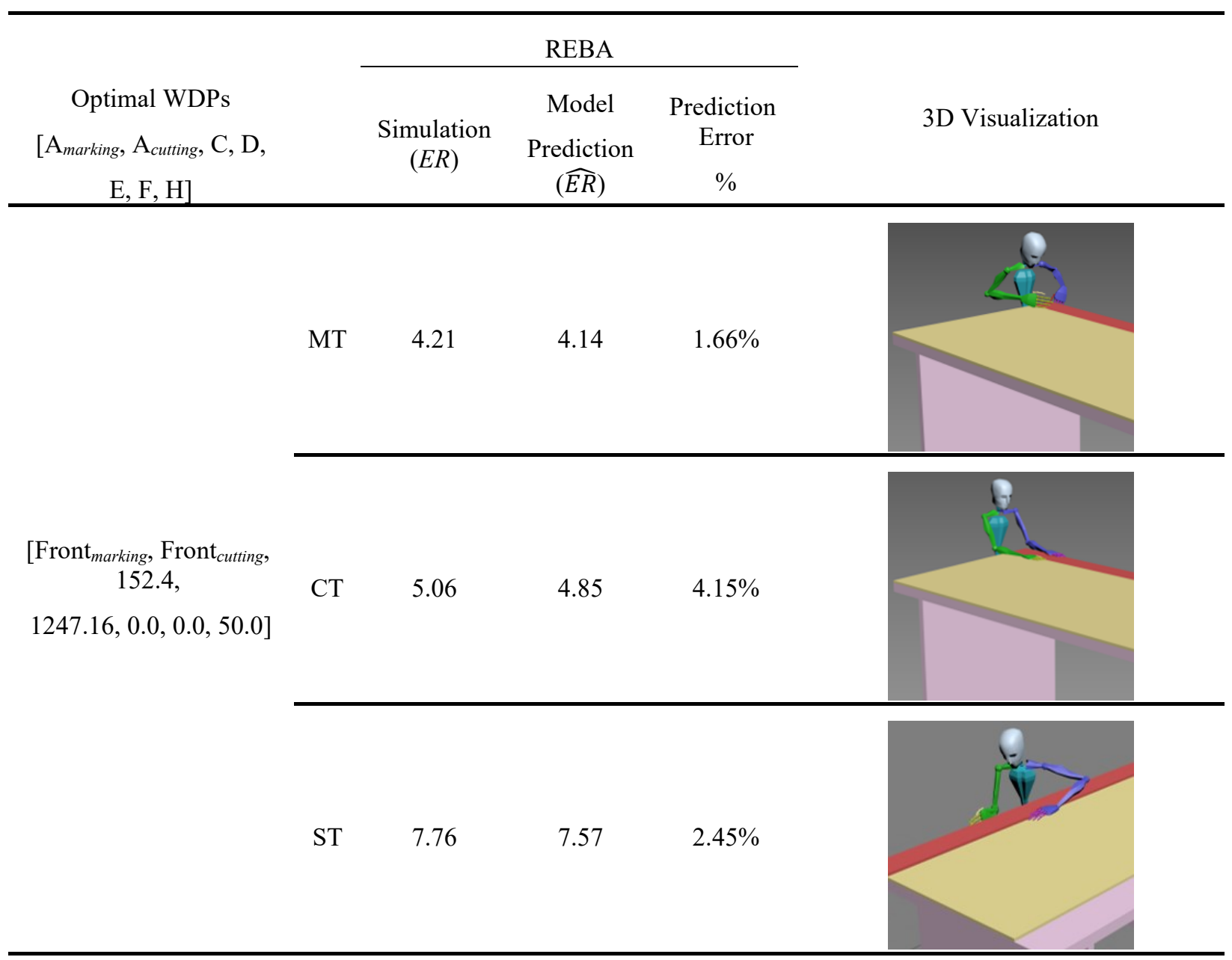

Fig. 27. Validation results of the solution 14 for MT, CT, and ST 
Based on current available space and tools in practice, REBA scores are predicted among the combination of tasks. However, without considering single or multiple tasks workplaces, the ST still has high-risk scores in all of the solutions since it is mandatory to move the heavy WP to outside of the proposed surface table for sanding completion. This result is obvious evidence that this task requires machinery support (e.g., vacuum lifter) to reduce the ergonomic risk scores. At this junction, it should be noted that this thesis does not consider the machinery in the workplace design due to the requirement of the industrial partner.

In addition, the proposed design approach provides a guide to developing a future action plan to not only mitigate the impact of ergonomic risk factors in the workplace but also correspond to return to work program in WCB [10] based on the result of analyzing significant WDPs and their effects. For instance, injured workers should not be assigned to perform the ST, which leads workers to adopt awkward postures while using force increasing ergonomic risks during the entire task duration. In other words, the MT is the most suitable for them since it is associated with minimal risk among the three tasks. 


\section{Chapter 5: Future Works}

The proposed framework is subject to some limitations and requires further development. The current design framework considers only ergonomic risk levels as a single metric for workplace design optimization based on identifying workplace design parameters (WDPs), leading to expose workers to ergonomic risk factors. However, other factors such as fatigue levels and biomechanical risk may influence the productivity and safety conditions of the production lines. This issue could be addressed by proposing effective methods to integrate other performance metrics based on identifying related WDPs.

Another limitation of the current proposed framework is that categorical WDPs use two levels $(-1$ and +1$)$ instead of three levels $(-1,0$, and +1$)$ used for numerical WDPs. However, the diverse nature of the tasks in modular production lines may require more than two level-based categorical WDPs in order to model and investigate all possible design alternatives accurately. In this respect, further efforts to incorporate multi-levels categorical WDPs during the design process are required to develop the flexibility and extensibility of the proposed design framework.

Currently, works are underway to evaluate physical prototypes of the proposed design in the case study based on lab experiments in order to assess the enhancement of workers' performance considering different weights on the workplace tasks.

Future research also includes the automation of the proposed method in order to provide a rapid optimization-based workplace design system in modular construction. Besides, coordination actions may be required to reflect the recommended depth of the removed piece in the shop drawings in order to reduce risk scores. Moreover, the cost reduction based on the improvement of safety in the production lines could be investigated by developing an evaluation model. 


\section{Chapter 6: Conclusion}

Modular construction is an attractive approach to achieve better productivity and low cost with high quality in the construction industry. Comparing to the manufacturing industry, which uses advanced technologies and machinery, the modular construction still adopts labor-intensive and hazardous manual tasks in production lines leading to expose workers frequently to ergonomic risks. To mitigate the ergonomic risks, optimal worker-friendly workplace design is critical to maximizing the benefits of modular construction. However, scientific and/or efficient methods are not fully introduced yet into the modular construction sector. Corresponding to this requirement, this thesis proposes a parameterized design optimization framework to develop worker-friendly workplaces with minimal ergonomic risks in the modular construction workplaces. The proposed framework consists of mainly four components: (i) workplace design initiation component to define workplace design parameters (WDPs) and create design alternatives; (ii) interactive skeletal simulation component to produce worker's body postures efficiently corresponding to the changes of the workplace parameters; (iii) statistical analysis component using definitive screening design method to develop the surrogate models to predict the risk scores in various workplace design alternatives; and (iv) multi-criteria optimization component that considers not only single-task workplaces but also multi/many-tasks workplaces to achieve optimal design solutions. A case study of designing a drywall preparation workplace in a real modular construction plant is presented. As a result, the proposed design framework offers the following benefits: (i) a costeffective and less time-consuming approach to assess multiple workplace design alternatives using the proposed interactive worker-workplace simulation model without the need to physically imitate the operational tasks at each design alternative; (ii) efficient and practical method that 
extends the applicability of the ergonomic design in modular construction based on a scientific approach to design optimal workplaces considering the minimal ergonomic risks; and (iii) a step towards mitigating enormous human and economic costs of ergonomic risk factors in the workplace by identifying root causes of ergonomic risks among various WDPs that helps to outline a practical action plan to ensure safety improvements. 


\section{References}

[1] N. Inyang, S. Han, M. Al-Hussein, M. El-Rich, A VR model of ergonomics and productivity assessment in panelized construction production line, Proceedings, Construction Research Congress 2012, West Lafayette, Indiana, USA, May 21-23, 2012, pp. 1084-1093, https://doi.org/10.1061/9780784412329.109.

[2] A. Golabchi, S. Han, A.R. Fayek, A fuzzy logic approach to posture-based ergonomic analysis for field observation and assessment of construction manual operations, Can. J. Civ. Eng. 43 (4) (2016) 294-303, https://doi.org/10.1139/cjce-2015-0143.

[3] X. Li, S. Han, M. Gül, M. Al-Hussein, Automated post-3D visualization ergonomic analysis system for rapid workplace design in modular construction, Autom. Constr. 98 (2019) 160174, https://doi.org/10.1016/j.autcon.2018.11.012.

[4] N. Inyang, M. Al-Hussein, M. El-Rich, S. Al-Jibouri, Ergonomic analysis and the need for its integration for planning and assessing construction tasks, J. Constr. Eng. Manage. 138 (2012) 1370-1376, https://doi.org/10.1061/(ASCE)CO.1943-7862.0000556.

[5] The Association of Workers' Compensation Boards of Canada (AWCBC): Statistics, http://awcbc.org/?page id=14\#injuries, (2017). <Accessed date: December 2019>

[6] The Center for Construction Research and Training: The construction chart book, 6th Ed., https://www.cpwr.com/publications/research-findings-articles/construction-chart-book, (2018). <Accessed date: December 2019>

[7] United States Department of Labor, Occupational Safety \& Health Administration: Prevention of work-related musculoskeletal disorders, internet report, 
https://www.osha.gov/pls/oshaweb/owadisp.show_document?p_id=4481\&p_table=UNIFIED _AGENDA, (2014). < Accessed date: December 2019>

[8] Canadian Centre for Occupational Health and Safety: Health and Safety Fact Sheets (OSH Answers), https://www.ccohs.ca/topics/hazards/ergonomic/wsmd/, (2019). <Accessed date: December 2019>

[9] A. Golabchi, S. Han, J. Seo, S. Han, S. Lee, M. Al-Hussein, An automated biomechanical simulation approach to ergonomic job analysis for workplace design, J. Constr. Eng. Manage. 141 (8) (2015), https://doi.org/10.1061/(ASCE)CO.1943-7862.0000998.

[10] Workers' Compensation Board, Alberta, For employers: Modified work, https://www.wcb.ab.ca/return-to-work/return-to-work-planning/for-employers.html ，(2019). <Accessed date: December 2019>

[11] The Institut de recherche Robert-Sauvé en santé et en sécurité du travail (IRSST): Guide and Tools for Modified Work, https://www.irsst.qc.ca/en/publicationstools/publication/i/100168/n/work-related-musculoskeletal-disorders-guide-and-tools-formodified-work-omrt-en, (2005). <Accessed date: December 2019>

[12] R.M. Williams, M. Westmorland, Perspectives on workplace disability management: a review of the literature, Work. 19 (1) (2002) 87-93, http://dx.doi.org/10.3233/WOR-203122.

[13] D. Wang, F. Dai, X. Ning, Risk assessment of work-related musculoskeletal disorders in construction: state-of-the-art review, J. Constr. Eng. Manage. 141 (6) (2015), https://doi.org/10.1061/(ASCE)CO.1943-7862.0000979.

[14] A. Golabchi, S. Han, S. AbouRizk, A simulation and visualization-based framework of labor efficiency and safety analysis for prevention through design and planning, Autom. Constr. 96 (2018) 310-323, https://doi.org/10.1016/j.autcon.2018.10.001. 
[15] A. Golabchi, X. Guo, M. Liu, S. Han, S. Lee, S. AbouRizk, An integrated ergonomics framework for evaluation and design of construction operations, Autom. Constr. 95 (2018) 7285, https://doi.org/10.1016/j.autcon.2018.08.003.

[16] X. Li, S. Han, M. Gül, M. Al-Hussein, M. El-Rich, 3D visualization-based ergonomic risk assessment and work modification framework and its validation for a lifting task, J. Constr. Eng. Manage. 144 (1) (2018) 04017093, https://doi.org/10.1061/(ASCE)CO.1943$\underline{7862.0001412 .}$

[17] S. Hignett, L. McAtamney, Rapid entire body assessment (REBA), Appl. Ergon. 31 (2) (2000) 201-205, https://doi.org/10.1016/S0003-6870(99)00039-3.

[18] L. McAtamney, E.N. Corlett, RULA: a survey method for the investigation of workrelated upper limb disorders, Appl. Ergon. 24 (2) (1993) 91-99, https://doi.org/10.1016/0003-6870(93)90080-S.

[19] S. Han, A. Bas, M. Al-Hussein, M. El-Rich, A. Telyas, Computer 3D model-based Physcial demand and ergonomic assessment of buildings mechanical system construction, Proceedings, the 28th International Conference of CIB W78, Sophia Antipolis, France, October 26-28, 2011, paper 153, http://itc.scix.net/paper/w78-2011-Paper-153.

[20] Autodesk Inc., 3ds Max, 3D modeling and rendering software for design visualization, games, and animation, https://www.autodesk.ca/en/products/3ds-max/overview, (2019). $<$ Accessed date: January 2019>

[21] M. Greig, W.P. Neumann, Six sigma: opportunities for ergonomics \& MSD prevention, Position paper, Centre of Research Expertise for the Prevention of Musculoskeletal Disorders. CRE-MSD 4184-2 (2018), https://uwaterloo.ca/centre-of-research-expertise-for-the- 
prevention-of-musculoskeletal-disorders/resources/position-papers/six-sigma-opportunitiesergonomics-msd-prevention.

[22] M. Tanco, E. Viles, L. Ilzarbe, M.J. Álvarez, Manufacturing industries need Design of Experiments (DoE), Proceedings, the World Congress on Engineering 2007 Vol II WCE 2007, London, U.K., July $2 \quad-\quad 4, \quad 2007$, pp. 1108-1112, http://www.iaeng.org/publication/WCE2007/WCE2007 pp1108-1112.pdf.

[23] F. Manlig, F. Koblasa, Design of simulation experiments using DOE, Applied Mechanics $\begin{array}{lllll}\text { and } & \text { Materials. } & 693 & \text { (2014) } & \text { 219-224, }\end{array}$ https://doi.org/10.4028/www.scientific.net/AMM.693.219.

[24] S. Cevheroğlu Çıra, A. Dağ, A. Karakuş, Application of Response Surface Methodology and Central Composite Inscribed Design for Modeling and Optimization of Marble Surface Quality, Advances in Materials Science \& Engineering. Article ID 2349476 (2016) 1-13, https://doi.org/10.1155/2016/2349476.

[25] D. del Rio Vilas, F. Longo, N.R. Monteil, A general framework for the manufacturing workstation design optimization: a combined ergonomic and operational approach, Simulation. 89 (3) (2013) 306-329, https://doi.org/10.1177/0037549712462862.

[26] A. Cimino, F. Longo, G. Mirabelli, A multimeasure-based methodology for the ergonomic effective design of manufacturing system workstations, Int. J. Ind. Ergonomics. 39 (2) (2009) 447-455, https://doi.org/10.1016/j.ergon.2008.12.004.

[27] I. Ben-Gal, J. Bukchin, The ergonomic design of workstations using virtual manufacturing and response surface methodology, IIE Transactions. 34 (4) (2002) 375-391, https://doi.org/10.1080/07408170208928877. 
[28] Siemens Industry Software Inc., Tecnomatix-Siemens, Siemens Digital Industries Software, https://www.plm.automation.siemens.com/global/en/products/tecnomatix/, (2019). $<$ Accessed date: January 2020>

[29] R. Yaesoubi, A Comparison of Factor Screening Methods for Simulation Models, Master's Thesis, Industrial Engineering, North Carolina State University, 2007, http://www.lib.ncsu.edu/resolver/1840.16/1448.

[30] K.M. Carley, N.Y. Kamneva, J. Reminga, Response Surface Methodology, Center for Computational Analysis of Social Organizational Systems (CASOS), Technical Report, Carnegie Mellon University, School of Computer Science, Pittsburgh, PA, 2004, http://www.casos.cs.cmu.edu/publications/papers/CMU-ISR-04-136.pdf.

[31] International organization for standardization, Safety of machinery: anthropometric requirements for the design of workstations at machinery, ISO 14738:2002 (2013), https://www.iso.org/standard/27556.html.

[32] B. Jones, C.J. Nachtsheim, A class of three-level designs for definitive screening in the presence of second-order effects, Journal of Quality Technology. 43 (1) (2011) 1-15, https://doi.org/10.1080/00224065.2011.11917841.

[33] B. Peeters, M. Roels, S. Van Aeken, G. Desmarets, Accelerating six sigma research with the definitive screening design (DSD) technique, Chemical Engineering. 126 (1) (2019) N.PAG, $\quad$ https://www.chemengonline.com/accelerating-six-sigma-research-definitivescreening-design-dsd-technique/.

[34] A. Erler, N. de Mas, P. Ramsey, G. Henderson, Efficient biological process characterization by definitive-screening designs: the formaldehyde treatment of a therapeutic 
protein as a case study, Biotechnol. Lett. 35 (2013) 323-329, https://doi.org/10.1007/s10529012-1089-y.

[35] Minitab, LLC, Minitab 18, Powerful statistical software everyone can use, State College, PA, http://www.minitab.com, (2018). <Accessed date: January 2019>

[36] M. Popovic, M. Bowers, Kinematics and Dynamics, Academic Press, Biomechatronics. (2019) 11-43, https://doi.org/10.1016/B978-0-12-812939-5.00002-1.

[37] Autodesk Inc., What Does Human IK Do?, What is inverse kinematics?, http://help.autodesk.com/view/HUMANIK/2016/ENU/?guid=_files_GUID_84DD119A_35 52_4D3F_9B4A_2072CB32E3CB htm, (2016). <Accessed date: January 2019>

[38] Autodesk Inc., Human IK, animation middleware, http:/help.autodesk.com/view/HUMANIK/2016/ENU/, (2016). <Accessed date: January 2019>

[39] Autodesk Inc., MotionBuilder, 3D character animation software, https://www.autodesk.com/products/motionbuilder/overview, (2019). <Accessed date: January 2019>

[40] J. Frost, Multiple regression analysis: Use adjusted R-squared and predicted R-squared to include the correct number of variables, Minitab Blog. 13 (6) (2013), https://blog.minitab.com/blog/adventures-in-statistics-2/multiple-regession-analysis-useadjusted-r-squared-and-predicted-r-squared-to-include-the-correct-number-of-variables.

[41] J. McCall, Genetic algorithms for modelling and optimisation, J. Comput. Appl. Math. 184 (1) (2005) 205-222, https://doi.org/10.1016/j.cam.2004.07.034. 
[42] K. Deb, A. Pratap, S. Agarwal, T. Meyarivan, A fast and elitist multiobjective genetic algorithm: NSGA-II, IEEE transactions on evolutionary computation. 6 (2) (2002) 182-197, http://dx.doi.org/10.1109/4235.996017.

[43] K. Deb, H. Jain, An evolutionary many-objective optimization algorithm using referencepoint-based nondominated sorting approach, part I: solving problems with box constraints, IEEE transactions on evolutionary computation. $18 \quad$ (4) (2014) 577-601, http://dx.doi.org/10.1109/TEVC.2013.2281535.

[44] H. Jain, K. Deb, An evolutionary many-objective optimization algorithm using referencepoint based nondominated sorting approach, part II: handling constraints and extending to an adaptive approach, IEEE Transactions on evolutionary computation. 18 (4) (2014) 602-622, http://dx.doi.org/10.1109/TEVC.2013.2281534.

[45] J. Blank, K. Deb, P.C. Roy, Investigating the normalization procedure of NSGA-III, Deb K. et al. (eds) Evolutionary Multi-Criterion Optimization. EMO 2019. Lecture Notes in Computer Science, vol 11411. Springer, Cham, https://doi.org/10.1007/978-3-030-12598119.

[46] K. Deb, Multi-Objective Optimization using Evolutionary Algorithms, (Vol. 16). John Wiley \& Sons, Inc., New York, NY, USA, 2001. ISBN 047187339X.

[47] K. Deb, K. Sindhya, T. Okabe, Self-adaptive simulated binary crossover for real-parameter optimization, Proceedings, the 9th Annual Conference on Genetic and Evolutionary Computation, GECCO '07, New York, NY, USA, 2007, pp. 11871194, http://doi.acm.org/10.1145/1276958.1277190.

[48] J. Blank, K. Deb, pymoo: Multi-objective Optimization in Python, https://pymoo.org/, (2019). <Accessed date: November 2019> 
[49] Canadian Centre for Occupational Health and Safety (CCOHS): OSH Answers Fact Sheets, Working in a Standing Position - Basic Information, https://www.ccohs.ca/oshanswers/ergonomics/standing/standing_basic.html, (2019). $<$ Accessed date: December 2019>

[50] M. Roser, C. Appel, H. Ritchie, Human Height, Published online at OurWorldInData.org, https:/ourworldindata.org/human-height, (2019). <Accessed date: April 2019> 


\section{Appendix}

Appendix 1: Statistical analysis of CT - REBA surrogate models

\begin{tabular}{|c|c|c|c|c|c|}
\hline \multicolumn{6}{|l|}{ Analysis of Variance } \\
\hline Source & $\mathrm{DF}$ & Adj SS & Adj MS & F-Value & P-Value \\
\hline Model & 7 & 43.0000 & 6.1429 & 49.78 & 0.000 \\
\hline Linear & 5 & 40.5017 & 8.1003 & 65.64 & 0.000 \\
\hline Work method & 1 & 4.1949 & 4.1949 & 33.99 & 0.000 \\
\hline Depth of removed piece & 1 & 2.6471 & 2.6471 & 21.45 & 0.001 \\
\hline Work surface height & 1 & 25.9315 & 25.9315 & 210.14 & 0.000 \\
\hline WP position & 1 & 2.1758 & 2.1758 & 17.63 & 0.002 \\
\hline Worker standing distance & 1 & 4.7702 & 4.7702 & 38.66 & 0.000 \\
\hline Square & 1 & 1.0258 & 1.0258 & 8.31 & 0.016 \\
\hline Worker standing distance*Worker standing distance & 1 & 1.0258 & 1.0258 & 8.31 & 0.016 \\
\hline 2-Way Interactions & 1 & 0.6644 & 0.6644 & 5.38 & 0.043 \\
\hline Depth of removed piece*WP position & 1 & 0.6644 & 0.6644 & 5.38 & 0.043 \\
\hline Error & 10 & 1.2340 & 0.1234 & & \\
\hline Total & 17 & 44.2340 & & & \\
\hline \multicolumn{6}{|l|}{ Coded Coefficients } \\
\hline Term & Coef & SE Coef & T-Value & P-Value & VIF \\
\hline Constant & 7.698 & 0.184 & 41.92 & 0.000 & \\
\hline Work method & 0.4988 & 0.0856 & 5.83 & 0.000 & 1.07 \\
\hline Depth of removed piece & 0.4385 & 0.0947 & 4.63 & 0.001 & 1.02 \\
\hline Work surface height & -1.3725 & 0.0947 & -14.50 & 0.000 & 1.02 \\
\hline WP position & 0.3976 & 0.0947 & 4.20 & 0.002 & 1.02 \\
\hline Worker standing distance & 0.5886 & 0.0947 & 6.22 & 0.000 & 1.02 \\
\hline Worker standing distance*Worker standing distance & 0.608 & 0.211 & 2.88 & 0.016 & 1.12 \\
\hline Depth of removed piece*WP position & -0.249 & 0.107 & -2.32 & 0.043 & 1.12 \\
\hline
\end{tabular}


Appendix 2: Statistical analysis of CT - RULA surrogate models

\begin{tabular}{|c|c|c|c|c|c|}
\hline \multicolumn{6}{|l|}{ Analysis of Variance } \\
\hline Source & DF & Adj SS & Adj MS & F-Value & P-Value \\
\hline Model & 9 & 7.7881 & 0.86535 & 67.61 & 0.000 \\
\hline Linear & 6 & 6.8174 & 1.13624 & 88.78 & 0.000 \\
\hline Work method & 1 & 1.5348 & 1.53479 & 119.92 & 0.000 \\
\hline Depth of removed piece & 1 & 0.2818 & 0.28185 & 22.02 & 0.002 \\
\hline Work surface height & 1 & 2.1880 & 2.18803 & 170.96 & 0.000 \\
\hline WP position & 1 & 1.9214 & 1.92144 & 150.13 & 0.000 \\
\hline Worker standing distance & 1 & 0.8557 & 0.85572 & 66.86 & 0.000 \\
\hline Cutting Tool & 1 & 0.1163 & 0.11631 & 9.09 & 0.017 \\
\hline 2-Way Interactions & 3 & 0.9707 & 0.32356 & 25.28 & 0.000 \\
\hline Work method*Work surface height & 1 & 0.5833 & 0.58329 & 45.57 & 0.000 \\
\hline Work method*Cutting Tool & 1 & 0.1014 & 0.10137 & 7.92 & 0.023 \\
\hline Work surface height*WP position & 1 & 0.1148 & 0.11482 & 8.97 & 0.017 \\
\hline Error & 8 & 0.1024 & 0.01280 & & \\
\hline Total & 17 & 7.8905 & & & \\
\hline \multicolumn{6}{|l|}{ Coded Coefficients } \\
\hline Term & Coef & SE Coef & T-Value & P-Value & VIF \\
\hline Constant & 5.8081 & 0.0271 & 214.13 & 0.000 & \\
\hline Work method & 0.3039 & 0.0278 & 10.95 & 0.000 & 1.08 \\
\hline Depth of removed piece & 0.1440 & 0.0307 & 4.69 & 0.002 & 1.03 \\
\hline Work surface height & -0.4029 & 0.0308 & -13.08 & 0.000 & 1.04 \\
\hline WP position & 0.3775 & 0.0308 & 12.25 & 0.000 & 1.04 \\
\hline Worker standing distance & 0.2509 & 0.0307 & 8.18 & 0.000 & 1.03 \\
\hline Cutting Tool & 0.0837 & 0.0278 & 3.01 & 0.017 & 1.08 \\
\hline Work method*Work surface height & 0.2080 & 0.0308 & 6.75 & 0.000 & 1.02 \\
\hline Work method*Cutting Tool & -0.0794 & 0.0282 & -2.81 & 0.023 & 1.11 \\
\hline Work surface height*WP position & 0.1018 & 0.0340 & 3.00 & 0.017 & 1.08 \\
\hline
\end{tabular}


Appendix 3: Statistical analysis of ST - REBA surrogate models

\begin{tabular}{|c|c|c|c|c|c|}
\hline \multicolumn{6}{|l|}{ Analysis of Variance } \\
\hline Source & DF & Adj SS & Adj MS & F-Value & P-Value \\
\hline Model & 6 & 5.35067 & 0.89178 & 93.30 & 0.000 \\
\hline Linear & 4 & 4.56256 & 1.14064 & 119.34 & 0.000 \\
\hline Depth of removed piece & 1 & 0.57458 & 0.57458 & 60.12 & 0.000 \\
\hline Work surface height & 1 & 3.69369 & 3.69369 & 386.46 & 0.000 \\
\hline WP extra pull distance & 1 & 0.12640 & 0.12640 & 13.22 & 0.008 \\
\hline Worker standing distance & 1 & 0.16788 & 0.16788 & 17.57 & 0.004 \\
\hline Square & 1 & 0.34831 & 0.34831 & 36.44 & 0.001 \\
\hline Work surface height*Work surface height & 1 & 0.34831 & 0.34831 & 36.44 & 0.001 \\
\hline 2-Way Interactions & 1 & 0.72122 & 0.72122 & 75.46 & 0.000 \\
\hline WP extra pull distance*Worker standing distance & 1 & 0.72122 & 0.72122 & 75.46 & 0.000 \\
\hline Error & 7 & 0.06691 & 0.00956 & & \\
\hline Total & 13 & 5.41758 & & & \\
\hline \multicolumn{6}{|l|}{ Coded Coefficients } \\
\hline Term & Coef & SE Coef & T-Value & P-Value & VIF \\
\hline Constant & 8.3966 & 0.0525 & 160.07 & 0.000 & \\
\hline Depth of removed piece & 0.2397 & 0.0309 & 7.75 & 0.000 & 1.00 \\
\hline Work surface height & -0.6078 & 0.0309 & -19.66 & 0.000 & 1.00 \\
\hline WP extra pull distance & -0.1124 & 0.0309 & -3.64 & 0.008 & 1.00 \\
\hline Worker standing distance & 0.1296 & 0.0309 & 4.19 & 0.004 & 1.00 \\
\hline Work surface height*Work surface height & 0.3844 & 0.0637 & 6.04 & 0.001 & 1.21 \\
\hline WP extra pull distance*Worker standing distance & -0.3306 & 0.0381 & -8.69 & 0.000 & 1.21 \\
\hline
\end{tabular}


Appendix 4: Statistical analysis of ST - RULA surrogate models

\begin{tabular}{lrrrrr}
\hline Analysis of Variance & & & & & \\
\hline Source & DF & Adj SS & Adj MS & F-Value & P-Value \\
\hline Model & 4 & 0.52752 & 0.131880 & 22.76 & 0.000 \\
Linear & 2 & 0.40853 & 0.204264 & 35.25 & 0.000 \\
$\quad$ Worker height & 1 & 0.10439 & 0.104389 & 18.01 & 0.002 \\
$\quad$ Depth of removed piece & 1 & 0.30414 & 0.304138 & 52.48 & 0.000 \\
Square & 1 & 0.04331 & 0.043309 & 7.47 & 0.023 \\
Depth of removed piece*Depth of removed piece & 1 & 0.04331 & 0.043309 & 7.47 & 0.023 \\
2-Way Interactions & 1 & 0.07568 & 0.075684 & 13.06 & 0.006 \\
$\quad$ Worker height*Depth of removed piece & 1 & 0.07568 & 0.075684 & 13.06 & 0.006 \\
Error & 9 & 0.05215 & 0.005795 & & \\
Total & 13 & 0.57967 & & & \\
\hline Coded Coefficients & & & & & \\
\hline Term & Coef & SE Coef & T-Value & P-Value & VIF \\
\hline Constant & 6.4156 & 0.0381 & 168.56 & 0.000 & \\
Worker height & 0.1022 & 0.0241 & 4.24 & 0.002 & 1.00 \\
Depth of removed piece & 0.1744 & 0.0241 & 7.24 & 0.000 & 1.00 \\
Depth of removed piece*Depth of removed piece & 0.1231 & 0.0450 & 2.73 & 0.023 & 1.00 \\
Worker height*Depth of removed piece & -0.0973 & 0.0269 & -3.61 & 0.006 & 1.00 \\
\hline
\end{tabular}


Appendix 5: Residual analysis of MT
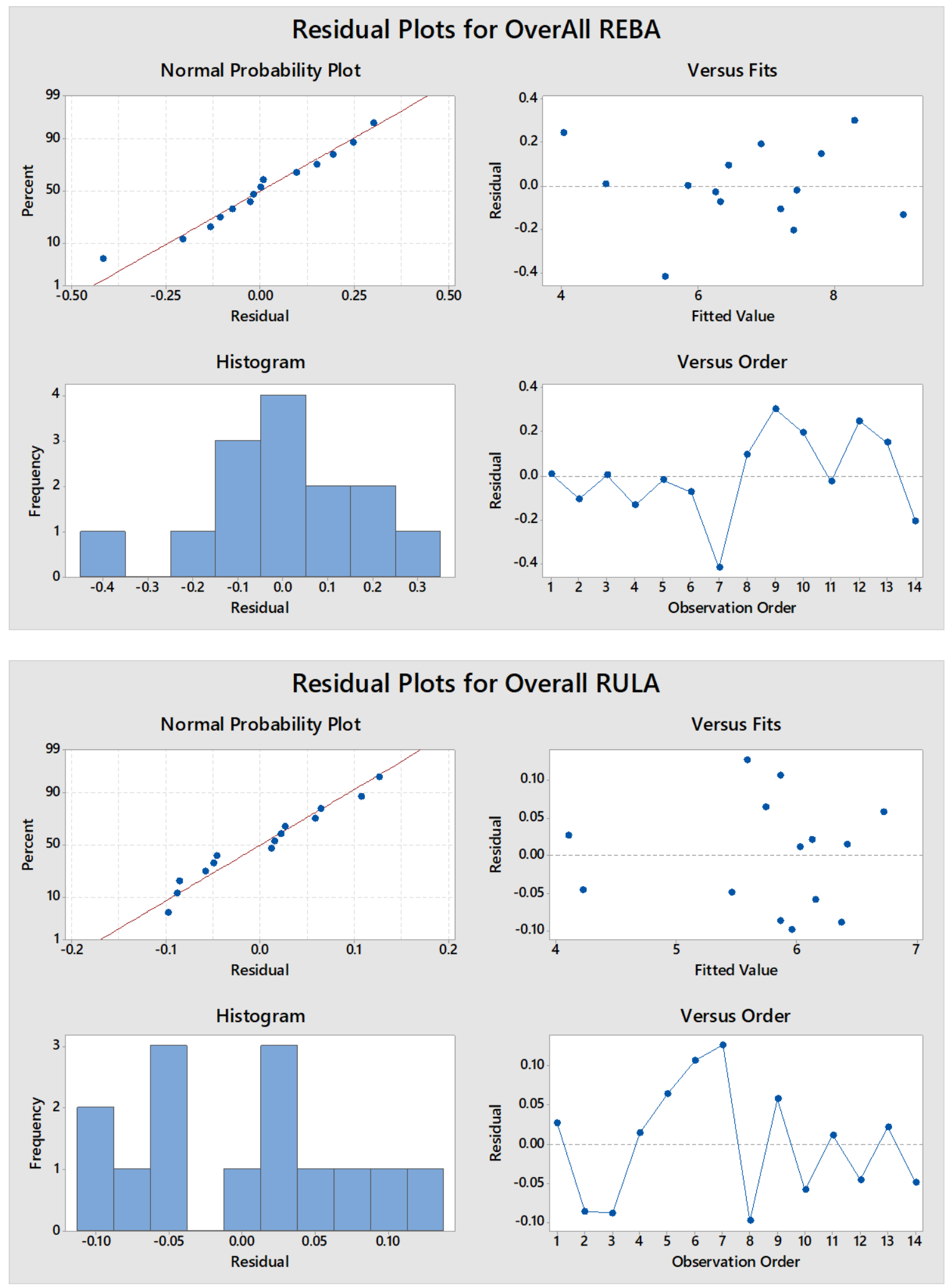
Appendix 6: Residual analysis of CT
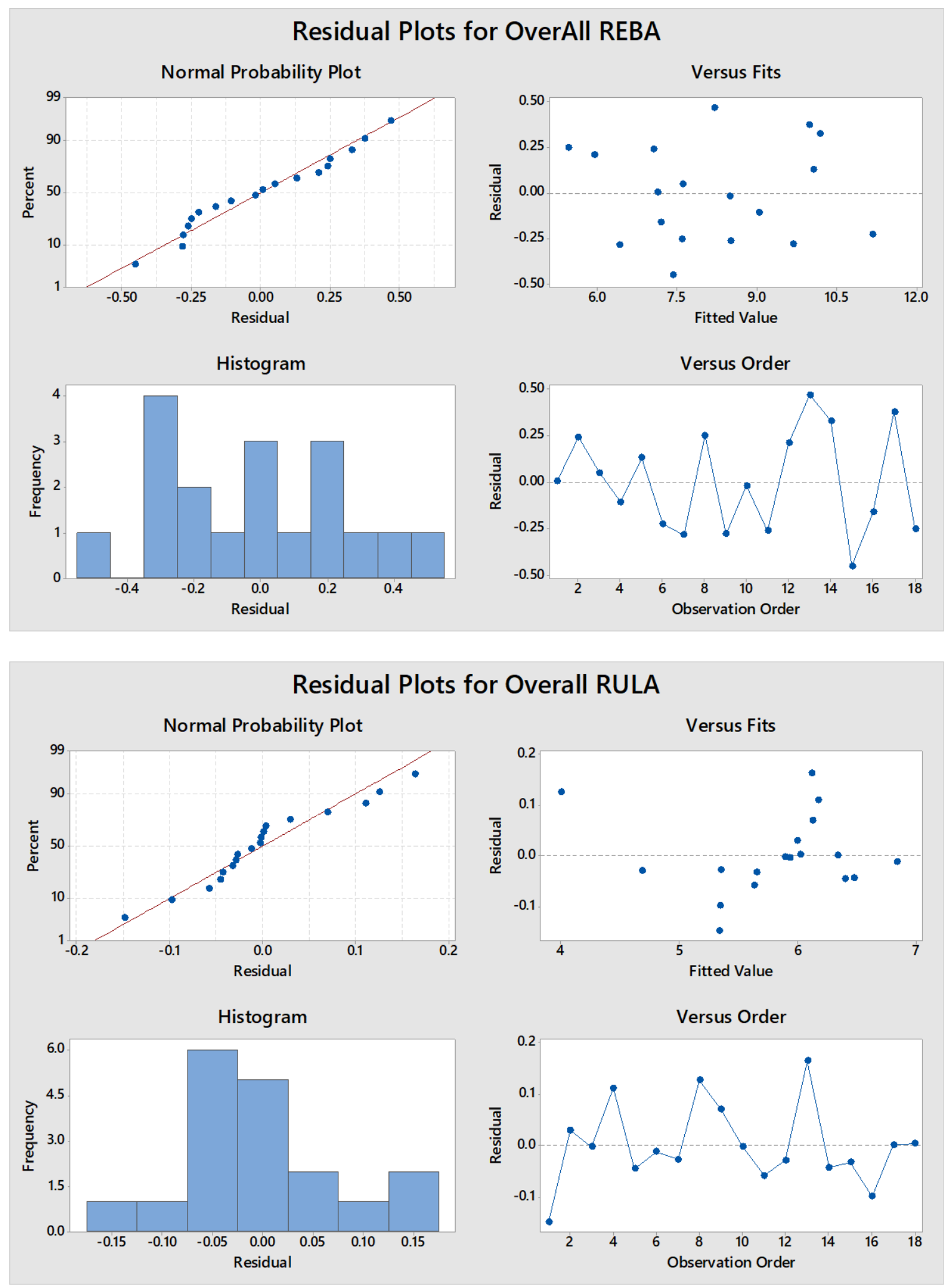
Appendix 7: Standardized effects of significant WDPs - CT
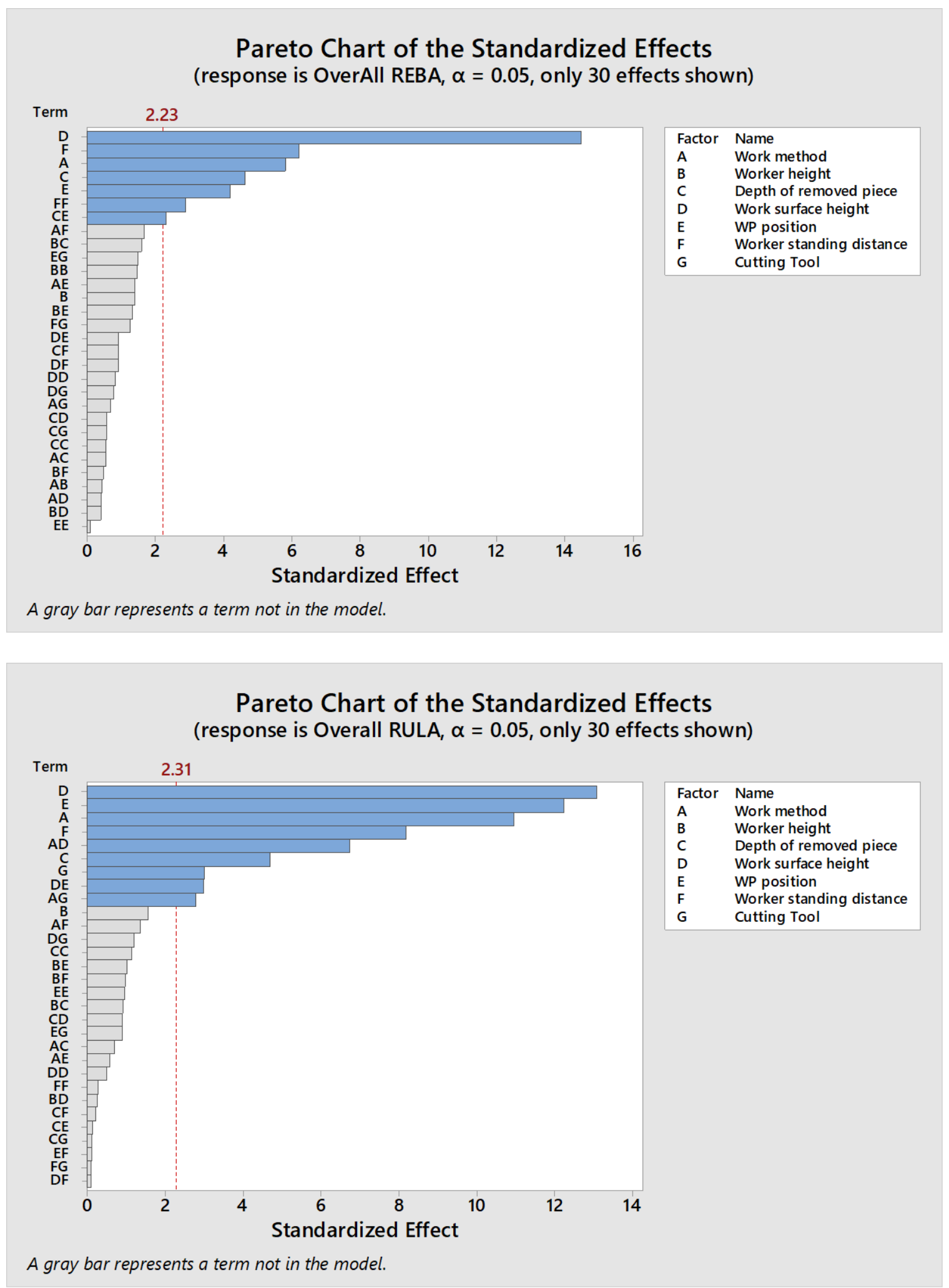
Appendix 8: Standardized effects of significant WDPs - ST
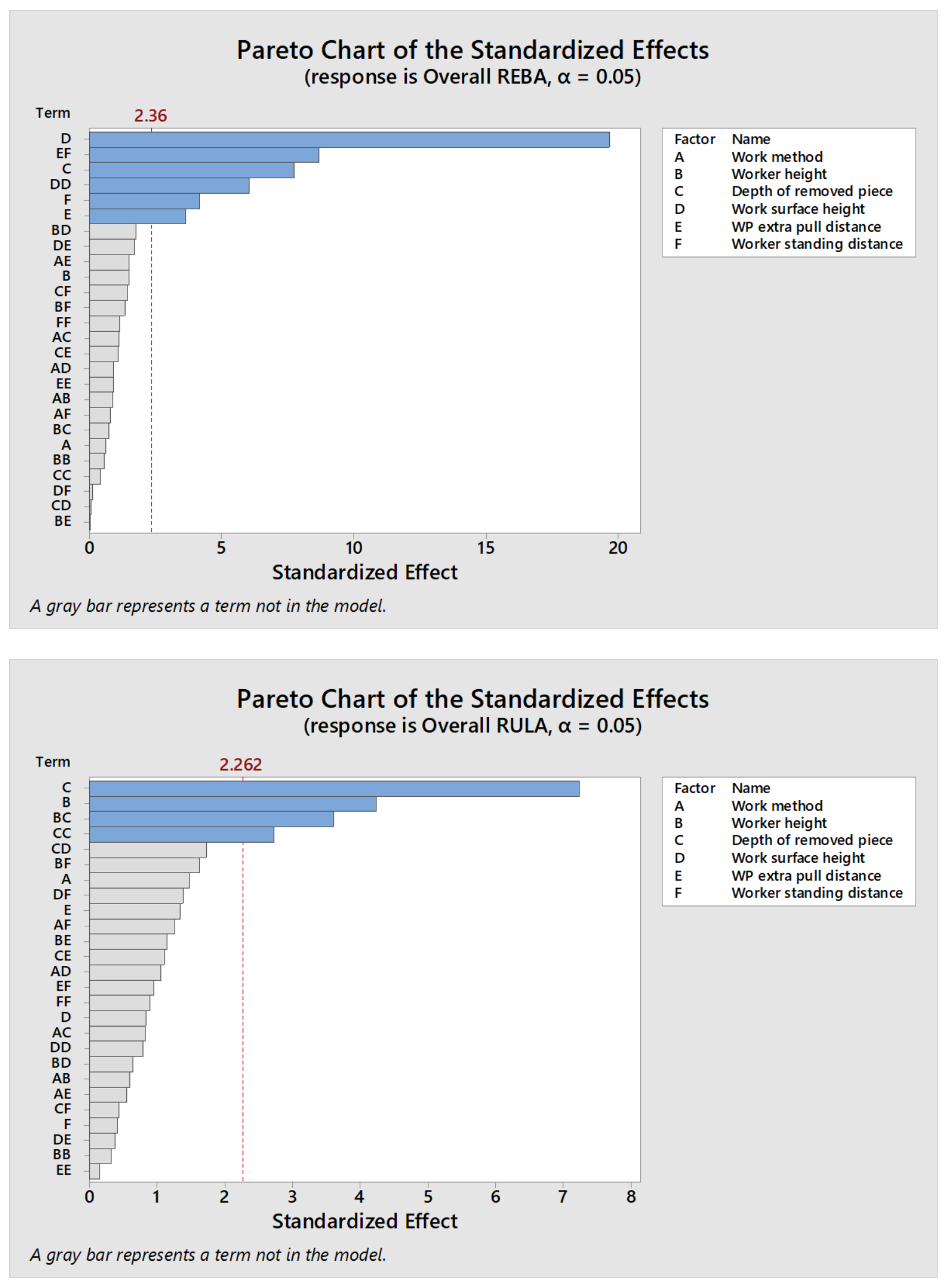